\author{
UNIVERSIDADE DE SÃO PAULO \\ ESCOLA DE ENGENHARIA DE SÃO CARLOS \\ DEPARTAMENTO DE ENGENHARIA DE ESTRUTURAS
}

Henrique Barbosa Soares

Formulação e implementação numérica para análise de estabilidade de perfis de parede fina via MEF posicional

São Carlos 

Henrique Barbosa Soares

\section{Formulação e implementação numérica para análise de estabilidade de perfis de parede fina via MEF posicional}

\section{VERSÃO CORRIGIDA}

(A versão original encontra-se na Escola de Engenharia de São Carlos)

Dissertação apresentada à Escola de Engenharia de São Carlos da Universidade de São Paulo, para obtenção do título de Mestre em Ciências - Programa de Pós-Graduação em Engenharia Civil (Engenharia de Estruturas).

Área de concentração: Estruturas

Orientador: Prof. Dr. Rodrigo Ribeiro Paccola

São Carlos 
AUTORIZO A REPRODUÇÃO TOTAL OU PARCIAL DESTE TRABALHO, POR QUALQUER MEIO CONVENCIONAL OU ELETRÔNICO, PARA FINS DE ESTUDO E PESQUISA, DESDE QUE CITADA A FONTE.

Ficha catalográfica elaborada pela Biblioteca Prof. Dr. Sérgio Rodrigues Fontes da EESC/USP com os dados inseridos pelo(a) autor(a).

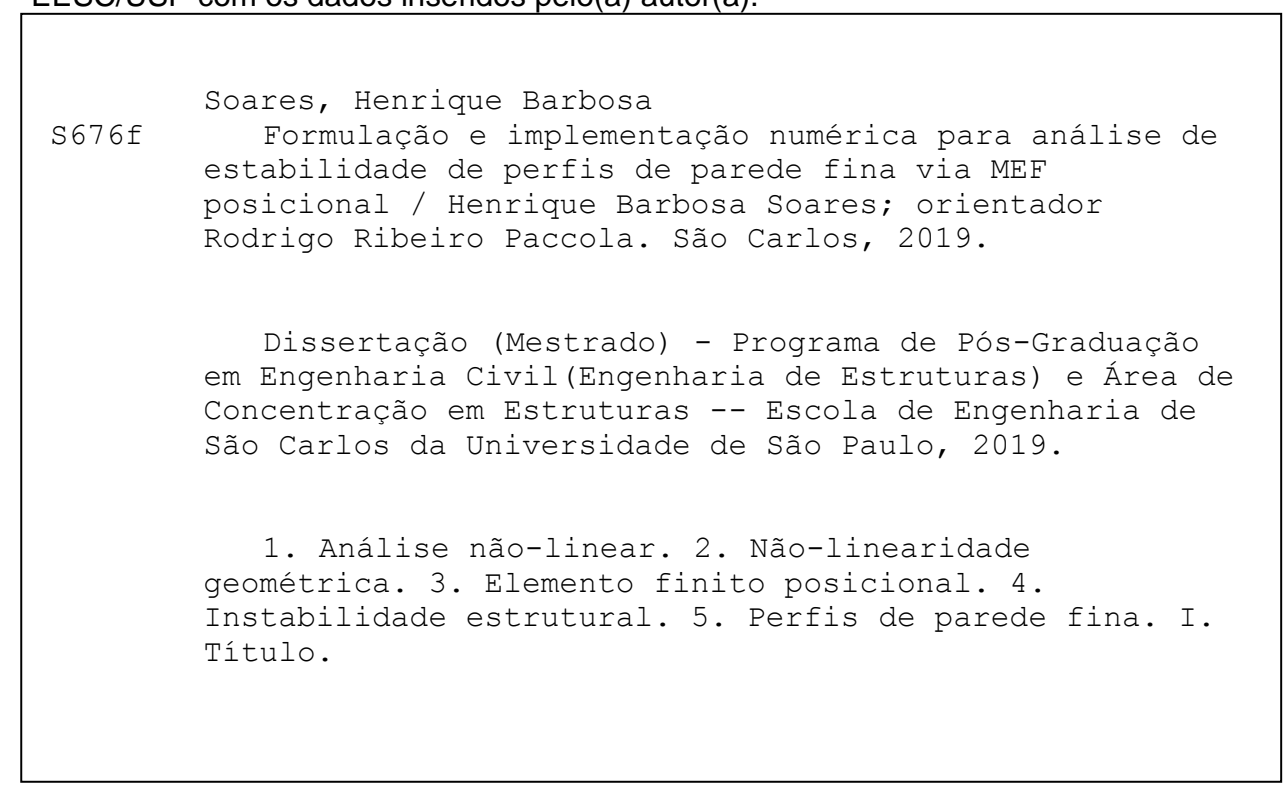

Eduardo Graziosi Silva - CRB - 8/8907 


\section{FOLHA DE JULGAMENTO}

Candidato: Engenheiro HENRIQUE BARBOSA SOARES.

Título da dissertação: "Desenvolvimento de formulação numérica e ferramenta computacional para análise de instabilidade de perfis de parede fina via formulação posicional do MEF ".

Data da defesa: 14/03/2019.

Comissão Julgadora:

Prof. Associado Rodrigo Ribeiro Paccola

(Orientador)

(Escola de Engenharia de São Carlos/EESC)

Prof. Dr. Alex Sander Clemente de Souza

(Universidade Federal de São Carlos/UFSCar)

Prof. Dr. Cilmar Donizefi Baságlia

ApNoVAso
Resultado:

Aprovaso
Aprovado

(Universidade Estadual de Campinas/UNICAMP)

Coordenador do Programa de Pós-Graduação em Engenharia Civil (Engenharia de Estruturas):

Prof. Titular Humberło Breves Coda

Presidente da Comissão de Pós-Graduação:

Prof. Titular Murilo Araujo Romero 



\section{AGRADECIMENTOS}

Agradeço aos meus pais, que sempre me apoiaram na decisão de seguir essa carreira.

Agradeço ao professor Rodrigo Ribeiro Paccola pela orientação e pela ajuda na elaboração da interface gráfica do programa, que foi fundamental para a conclusão deste trabalho.

Ao professor Humberto Breves Coda, agradeço pelas valiosas contribuições dadas no decorrer da realização deste trabalho e pela atenção dispensada ao longo deste período.

Agradeço a todos os amigos que fizeram parte da minha rotina, em especial a Caio, Bernardo e Péricles pelos momentos compartilhados durante esses dois anos de mestrado.

Por fim, agradeço à Coordenação de Aperfeiçoamento de Pessoal de Nível Superior - Brasil (CAPES) - Código de Financiamento 001 - pela bolsa de estudos concedida, imprescindível para a realização deste trabalho. 



\section{RESUMO}

SOARES, H. B. Formulação e implementação numérica para análise de estabilidade de perfis de parede fina via MEF posicional. 2019. 99p. Dissertação (Mestrado) - Escola de Engenharia de São Carlos, Universidade de São Paulo, São Carlos, 2019.

No presente trabalho, desenvolve-se um programa computacional para análise de instabilidade de perfis de parede fina por meio do método dos elementos finitos (MEF), com discretização em elementos de casca. Para tal finalidade, utiliza-se uma formulação não-linear geométrica do MEF, com descrição lagrangeana total do equilíbrio, tendo posições nodais e vetores generalizados como variáveis fundamentais da formulação, possibilitando a adoção de lei constitutiva tridimensional completa. Dada a adoção de vetores generalizados ao invés de giros, surge o problema de não unicidade desses vetores nas regiões de encontro entre elementos não coplanares. Para contornar esse problema, desenvolvem-se algumas estratégias de acoplamento que são eficientes e que não comprometem o condicionamento do sistema resultante. Em seguida, introduz-se no programa uma estratégia, baseada na análise linear de instabilidade, que consiste na obtenção de autovalores e autovetores correspondendo, respectivamente, a cargas críticas e modos de instabilidade associados. É realizada uma extensão dessa estratégia para a incorporação da análise não-linear de instabilidade, possibilitando a determinação de pontos críticos ao longo da trajetória de equilíbrio de um ponto da estrutura. Desenvolve-se, também, uma interface gráfica para o programa, para a qual se implementam algoritmos para geração de malha de elementos finitos triangulares e quadrilaterais e se possibilita a aplicação de condições de contorno de forma simples. Por fim, apresentam-se exemplos para validar o código computacional desenvolvido e para explorar as potencialidades do mesmo. A partir desses exemplos, conclui-se que a estratégia proposta e a ferramenta computacional desenvolvida funcionam adequadamente, oferecendo como principal vantagem respostas em geral livres de travamento volumétrico quando comparadas aos resultados provenientes da formulação convencional do MEF, encontrados na literatura.

Palavras-chave: Análise não-linear. Não-linearidade geométrica. Elemento finito posicional. Instabilidade estrutural. Perfis de parede fina. 



\begin{abstract}
SOARES, H. B. Formulation and numerical implementation for stability analysis of thin-walled members by positional MEF. 2019. 99p. Dissertação (Mestrado) - Escola de Engenharia de São Carlos, Universidade de São Paulo, São Carlos, 2019.
\end{abstract}

In the present work, a computational program is developed to perform instability analysis in thin-walled profiles employing the finite element method (FEM), using shell elements. For this purpose, a non-linear geometric formulation of FEM is adopted, with Total Lagrangean description of the equilibrium, having nodal positions and unconstrained vectors as fundamental variables of the formulation, instead of displacements and rotations, making possible the adoption of complete three-dimensional constitutive law. Given the adoption of generalized vectors instead of rotations, the problem arises of the vectors' non-uniqueness in the regions of connection between non-coplanar shell elements. To overcome this problem, some coupling strategies are developed that are efficient and do not result in ill conditioning of the resulting system of equilibrium equations. Then, a strategy based on buckling analysis is considered in the program, which consists of obtaining eigenvalues and eigenvectors related, respectively, to critical loads and instability modes. An extension of this strategy is developed to consider the nonlinear analysis of instability, making possible to determine critical points along the equilibrium path of a point in the structure. A graphical interface is also developed for the program, for which algorithms are implemented for triangular and quadrilateral finite elements mesh generations and easy boundary conditions assignments. Finally, some examples are presented to validate the developments and to explore the potentialities of the computational tool obtained in the work. From the results, it is possible to conclude that the program works properly, offering as main advantage volumetric responses, in general, free of locking when compared to results using the conventional FEM formulation, as found in the literature.

Keywords: Non-linear analysis. Geometric non-linearity. Positional finite element. Structural instability. Thin-walled members. 



\section{LISTA DE FIGURAS}

Figura 1 - Mudança de configuração de corpo tridimensional . . . . . . . . . . . . 24

Figura 2 - Volume infinitesimal nas configurações inicial e atual . . . . . . . . . 25

Figura 3 - Volume prismático nas configurações inicial e atual . . . . . . . . . . 26

Figura 4 - Mapeamento da superfície de referência do elemento finito de casca posicional 32

Figura 5 - Versor normal na configuração inicial e vetor generalizado na configuração

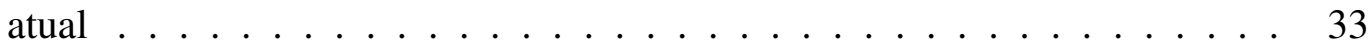

Figura 6 - Acoplamento via (a) bissetriz e via (b) elemento de barra simples de vetores generalizados não coincidentes de um mesmo nó . . . . . . . . . . . . . . 38

Figura 7 - Equivalência entre as energias de deformação de: (a) sólido que preenche o espaço de ligação e (b) elemento de barra simples . . . . . . . . . . . . 39

Figura 8 - Geometria da conexão utilizada neste trabalho . . . . . . . . . . . . 40

Figura 9 - Elemento de barra simples conectando dois vetores generalizados . . . . . . 41

Figura 10 - Situações de equilíbrio (a) estável, (b) instável e (c) indiferente . . . . . . . 46

Figura 11 - Instabilidade bifurcacional e trajetórias pós-críticas . . . . . . . . . . . . 48

Figura 12 - Instabilidade por ponto limite . . . . . . . . . . . . . . . . . . . 49

Figura 13 - Viga biapoiada sob força de compressão . . . . . . . . . . . . . . . 52

Figura 14 - Modos de instabilidade de viga biapoiada sob força de compressão . . . . . 52

Figura 15 - Janela principal do programa . . . . . . . . . . . . . . . 57

Figura 16 - Janela para inserção dos dados de geometria e material . . . . . . . . . . 58

Figura 17 - Definições da seção transversal do exemplo modelo . . . . . . . . . . . . . 59

Figura 18 - Janela para inserção das condições de contorno . . . . . . . . . . . . . . . . 60

Figura 19 - Janela para inserção de parâmetros . . . . . . . . . . . . . . . . . 61

Figura 20 - Janela para exibição dos autovalores computados . . . . . . . . . . . . . 61

Figura 21 - Tubo cilíndrico com diafragmas rígidos e discretização adotada . . . . . . . 64

Figura 22 - Gráfico força $\mathrm{x}$ deslocamento $\operatorname{dos} \operatorname{nos} A$ e $B \ldots \ldots$. . . . . . . . . . 64

Figura 23 - Configuração deformada final do cilindro . . . . . . . . . . . . . . . 65

Figura 24 - Perfil U com uma extremidade engastada e outra livre . . . . . . . . . . 66

Figura 25 - Configurações deformadas do perfil U (a) rotulado, (b) com elemento de barra simples e (c) com multiplicador de Lagrange . . . . . . . . . . . . 66

Figura 26 - Placa delgada simplesmente apoiada sob compressão . . . . . . . . . . . . 67

Figura 27 - Modos de instabilidade de placa simplesmente apoiada . . . . . . . . . . 68

Figura 28 - Modos de instabilidade de placa simplesmente apoiada em 3 bordos . . . . 69

Figura 29 - Modos de instabilidade de placa biapoiada . . . . . . . . . . . . . . 70

Figura 30 - Esquema estático e detalhe da seção transversal . . . . . . . . . . . . . . 71

Figura 31 - Discretização adotada e tipos de imperfeição impostas . . . . . . . . . . . . 71

Figura 32 - Modos de instabilidade de perfil U com imperfeição de flexão . . . . . . . . 72 
Figura 33 - Modos de instablidade referência de perfil U com imperfeição de flexão . 72

Figura 34 - Modos de instabilidade de perfil U com imperfeição local . . . . . . . . . 73

Figura 35 - Modos de instablidade de perfil U com imperfeição local . . . . . . . . . . 74

Figura 36 - Modos de instabilidade de perfil U com imperfeição de torção . . . . . . . . 74

Figura 37 - Modos de instablidade de perfil U com imperfeição de torção . . . . . . . . 75

Figura 38 - Definição do problema e algumas dimensões . . . . . . . . . . . . . 76

Figura 39 - Discretizações utilizadas . . . . . . . . . . . . . . . . 77

Figura 40 - Comparação do primeiro modo . . . . . . . . . . . . . . 77

Figura 41 - Outras cargas críticas e seus respectivos modos de instabilidade para as duas discretizações utilizadas e acoplamento via elemento de barra simples . . . 78

Figura 42 - Definição do problema e discretização adotada . . . . . . . . . . . . . 79

Figura 43 - Defeitos de Koiter aplicado na seção central $x=300$ : (a) local, (b) de flexão e (c) de torção . . . . . . . . . . . . . . . . . . . . . . 80

Figura 44 - Trajetórias de equilíbrio do ponto $A$ para imposições de defeitos em força . . 81

Figura 45 - Valor do multiplicador $\lambda$ em função do nível de carga para diferentes defeitos 82

Figura 46 - Deslocamento transversal global no meio do vão (ponto $B$ ) . . . . . . . . . 82

Figura 47 - Configuração deformada da estrutura no último passo de carregamento ampliada em 5 vezes . . . . . . . . . . . . . . . . 83

Figura 48 - Espaço auxiliar com elemento finito triangular cúbico padrão . . . . . . . . 98 


\section{LISTA DE TABELAS}

Tabela 1 - Cargas críticas (em kN) de placa simplesmente apoiada . . . . . . . . . 68

Tabela 2 - Cargas críticas (em kN) de placa simplesmente apoiada em 3 bordos . . . . 69

Tabela 3 - Cargas críticas (em kN) de placa biapoiada . . . . . . . . . . . . . 69

Tabela 4 - Autovalores para modo de imperfeição por flexão . . . . . . . . . . . 71

Tabela 5 - Autovalores para modo de imperfeição local . . . . . . . . . . . . 73

Tabela 6 - Autovalores para modo de imperfeição de torção . . . . . . . . . . . . . 74

Tabela 7 - Cargas críticas para análise não-linear de estabilidade . . . . . . . . 75

Tabela 8 - Primeira carga crítica de flambagem $($ em $k N) \ldots \ldots \ldots$. . . . . . 78

Tabela 9 - Cargas críticas para diferentes comprimentos e rigidez da conexão . . . . . 80

Tabela 10 - Cargas críticas para três situações de imperfeição e comprimento igual a $600 \quad 80$

Tabela 11 - Cargas críticas obtidas por Newton-Raphson . . . . . . . . . . . . . 81 



\section{SUMÁRIO}

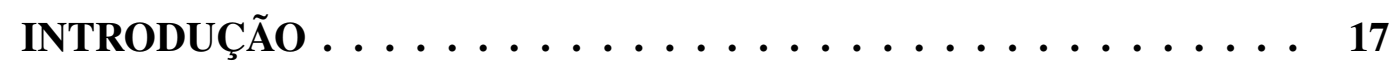

$1.1 \quad$ Objetivo geral $\ldots \ldots \ldots \ldots \ldots \ldots \ldots \ldots$

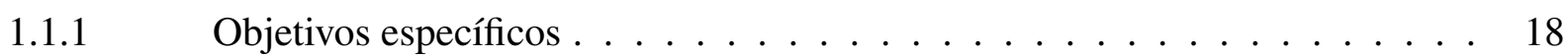

$1.2 \quad$ Justificativa $\ldots \ldots \ldots \ldots \ldots \ldots \ldots \ldots$

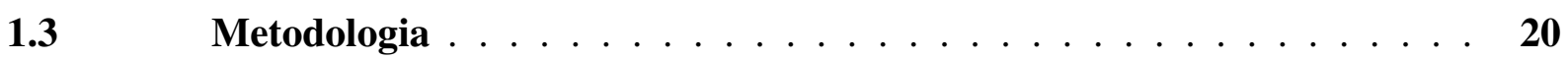

$1.4 \quad$ Estado da arte $\ldots \ldots \ldots \ldots \ldots \ldots \ldots$

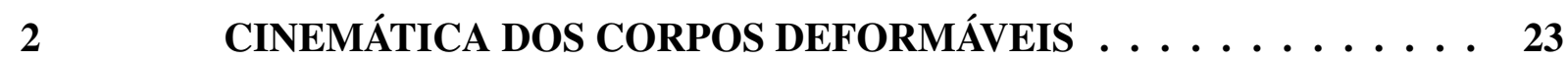

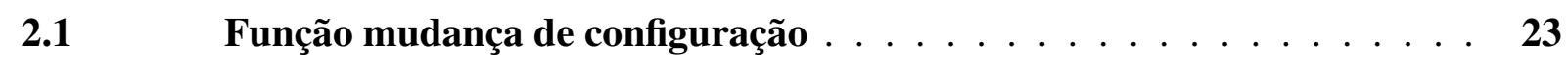

$2.2 \quad$ Medida de deformação de Green-Lagrange $\ldots \ldots \ldots \ldots$

2.3 Mudança de área e de volume na mudança de configuração . . . . . . 25

2.4 Equilíbrio local Lagrangeano $\ldots \ldots \ldots \ldots \ldots \ldots$

2.5 Princípio da estacionariedade da energia mecânica $\ldots \ldots \ldots \ldots$

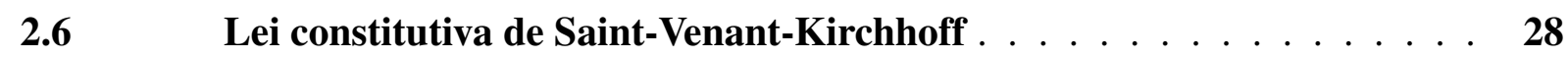

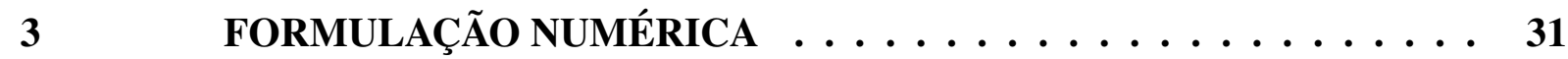

$3.1 \quad$ Elemento finito de casca posicional $\ldots \ldots \ldots \ldots \ldots \ldots$

3.2 Procedimento de solução do problema não-linear . . . . . . . . . . . 34

3.3 Integração numérica $\ldots \ldots \ldots \ldots \ldots \ldots$

$3.4 \quad$ Estratégia de acoplamento entre elementos não coplanares . . . . . . . . 37

3.4.1 Determinação da rigidez da ligação entre elementos não-coplanares . . . . . 38

3.4.2 Elemento finito de barra simples . . . . . . . . . . . . . . . 40

3.4.3 Multiplicadores de Lagrange $\ldots \ldots \ldots \ldots$. . . . . . . . . 42

4 ESTABILIDADE ESTRUTURAL $\ldots \ldots \ldots \ldots \ldots \ldots \ldots$

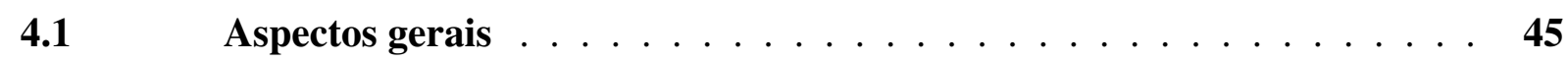

4.2 Teoremas de energia $\ldots \ldots \ldots \ldots \ldots \ldots \ldots$

$4.3 \quad$ Tipos de perda de estabilidade $\ldots \ldots \ldots \ldots \ldots \ldots$

$4.3 .1 \quad$ Instabilidade bifurcacional . . . . . . . . . . . . . . . . . . 48

4.3.2 Instabilidade por ponto limite $\ldots \ldots \ldots \ldots \ldots \ldots$

$4.4 \quad$ Análise linear de estabilidade $\ldots \ldots \ldots \ldots \ldots \ldots$

$4.5 \quad$ Análise não-linear de estabilidade $\ldots \ldots \ldots \ldots \ldots \ldots$

4.6 Resolução do problema de valor principal . . . . . . . . . . . . . 54

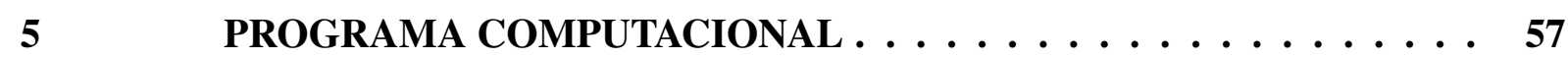

$5.1 \quad$ Etapa de pré-processamento de dados $\ldots \ldots \ldots \ldots \ldots \ldots$

$5.2 \quad$ Etapa de processamento $\ldots \ldots \ldots \ldots \ldots \ldots$ 
$5.3 \quad$ Etapa de pós-processamento de dados $\ldots \ldots \ldots \ldots \ldots$

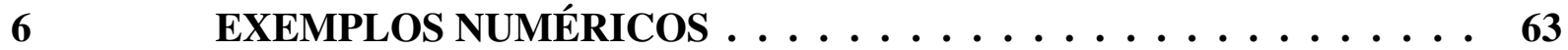

$6.1 \quad$ Exemplo 1: Tubo cilíndrico com diafragmas rígidos . . . . . . . . . 63

$6.2 \quad$ Exemplo 2: Perfil U sob ação de duas forças concentradas $\ldots \ldots \ldots$

$6.3 \quad$ Exemplo 3: Instabilidade em placas . . . . . . . . . . . . . . . . . . 67

$6.4 \quad$ Exemplo 4: Instabilidade em perfil $U \ldots \ldots \ldots$

6.5 Exemplo 5: Montante típico perfurado de rack de armazenamento $\ldots 76$

6.6 Exemplo 6: Avaliação da sensibilidade do acoplamento mesa-alma $\ldots 79$

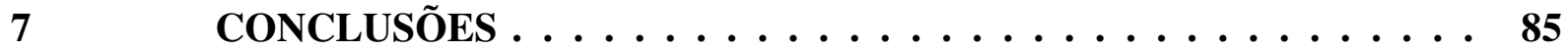

$7.1 \quad$ Sugestões de desenvolvimentos futuros $\ldots \ldots \ldots \ldots$

REFERÊNCIAS ........................ 89

APÊNDICE A GERAÇÃO DE MALHA ............. 93

APÊNDICE B GERAÇÃO DAS FUNÇÕES DE FORMA . . . . . . . 97 


\section{CAPÍTULO 1}

\section{INTRODUÇÃO}

Na prática tradicional de elaboração de projetos de engenharia, diversos critérios referentes às possibilidades de colapso estrutural são levados em consideração, além da verificação do comportamento adequado em serviço. As possíveis situações de colapso ou ruína estrutural compreendem falha do material por ruptura frágil, plastificação, fadiga, entre outros, e falha de uma peça ou do sistema estrutural por instabilidade, que consiste em perda repentina de rigidez da estrutura, levando ao aparecimento de grandes deslocamentos de forma abrupta.

Com relação à estabilidade de estruturas, uma análise simplificada muito utilizada, inclusive presente nas normas técnicas de projeto, é a flambagem elástica. Nessa análise, a carga crítica determinada é aquela que, ao atingida, qualquer mínima perturbação na estrutura pode ocasionar grandes deslocamentos de forma imediata. $\mathrm{O}$ ponto no qual essa carga é atingida é denominado ponto de bifurcação, pois a partir deste ponto a estrutura possui mais de uma trajetória de equilíbrio que pode ser seguida, podendo ser essa trajetória estável ou instável. A determinação das trajetórias de equilíbrio para essa situação só é possível com a realização de análises não-lineares (REIS; CAMOTIM, 2000).

O uso do termo "flambagem" é meio controverso no meio científico nacional devido à falta de consenso sobre o tipo de instabilidade a que ele se refere (BRAGA, 2015). Nos cursos de graduação, esse termo é utilizado para denominar a ocorrência de instabilidade por ponto de bifurcação, sendo limitada à hipótese de pequenos deslocamentos. Portanto, em situações gerais, o termo instabilidade é o mais correto a se utilizar.

Há também outras situações de perda de estabilidade em estruturas. Realizando-se carregamento incremental, em algumas estruturas observa-se que acima de um certo valor de força aplicada não há posição de equilíbrio nas proximidades deste ponto. Diz-se então que a estrutura atingiu um ponto limite. Nessa situação, a próxima posição de equilíbrio nas proximidades do ponto limite é obtida com uma carga inferior à carga crítica, caracterizando um caminho instável.

Em vista disso, surge a necessidade da utilização de métodos que levem em consideração a não-linearidade geométrica, mais especificamente de métodos que são capazes de percorrer 
toda a trajetória de equilíbrio de uma estrutura independentemente do nível de deslocamentos presente.

Dessa forma, justifica-se a realização do presente trabalho, buscando-se o desenvolvimento de formulação e ferramenta numérica para análise de instabilidade de estruturas, com destaque às estruturas compostas de perfis de parede fina. Estas estruturas, devido à sua esbeltez natural, estão mais suscetíveis à ocorrência desses fenômenos, tanto localmente (instabilidades localizadas na alma ou nas abas dos perfis) quanto globalmente (modos de flexão e torção).

A formulação utilizada baseia-se em uma abordagem via MEF posicional, seguindo os desenvolvimentos em andamento no grupo de pesquisa no qual a presente proposta se insere no SET/EESC/USP.

\subsection{Objetivo geral}

Este trabalho tem como objetivo geral desenvolver formulação para análise de instabilidade utilizando-se o MEF posicional para elementos finitos de casca e implementar um programa computacional baseado nesta formulação, incluindo elaboração de interface gráfica. Para isso é necessário o cumprimento de algumas atividades, descritas a seguir.

\subsubsection{Objetivos específicos}

Realizar levantamento bibliográfico acerca dos temas relevantes para o trabalho, objetivando a consolidação do conhecimento relacionado ao tema proposto.

Implementar programa computacional para processamento em linguagem Fortran. Abordase então a fundamentação necessária para a implementação do MEF posicional, com descrição lagrangeana total e utilização de elementos finitos de casca, com posições e vetores generalizados como parâmetros nodais em lugar dos tradicionais deslocamentos e giros.

Realizar buscas por bibliotecas computacionais disponíveis em linguagem Fortran que contenham rotinas para determinação de autovalores e autovetores otimizadas para operações com matrizes esparsas. Essas rotinas são utilizadas para a resolução do problema generalizado de autovalor oriundo da decomposição da matriz hessiana do problema em duas parcelas distintas, o que possibilita a determinação de cargas críticas e modos de instabilidade.

Desenvolver interface gráfica em ambiente Delphi e linguagem Object Pascal. Para isso, elabora-se rotinas para geração automática de malha e rotina responsável pela comunicação com o programa desenvolvido em Fortran, para o qual são passados os dados que foram fornecidos pelo usuário por meio da interface gráfica e do qual os resultados finais são extraídos.

Incorporar à versão do programa em Fortran a formulação para análise não-linear de instabilidade, aproveitando-se da mesma estratégia utilizada para a análise linear de instabilidade. 
Com isso, possibilita-se a determinação de pontos críticos ao longo da trajetória de equilíbrio de uma estrutura.

\subsection{Justificativa}

A consideração e verificação da ocorrência de instabilidades em sistemas estruturais constituídos por estruturas de parede fina, em geral perfis metálicos, é uma prática necessária no desenvolvimento desse tipo de projeto. Isso sé dá pelo fato de os perfis metálicos serem, em geral, peças esbeltas, estando mais suscetíveis à ocorrência desse fenômeno. Normalmente, essas verificações são baseadas em análises de instabilidade provenientes de métodos empíricos, formulados a partir de resultados experimentais. Essa análise, no entanto, tem aplicação restrita aos tipos de experimentos realizados e uma extrapolação para casos gerais é melhor realizada com a utilização de métodos numéricos que se fundamentem em teorias mais gerais, sendo os parâmetros do problema calibrados a partir dos resultados experimentais.

Neste sentido, diversas pesquisas vêm sendo desenvolvidas buscando-se a obtenção de ferramentas e técnicas numéricas para representação mais precisa do comportamento de tais estruturas, objetivando-se capturar a ocorrência de fenômenos de instabilidade aos quais estes sistemas estruturais estão sujeitos. Entre esses trabalhos, destacam-se a Teoria Generalizada de Vigas (GBT), o Método das Faixas Finitas (FSM) e a teoria assintótica de Koiter (KASP), dentre outros.

É neste contexto que se insere o presente trabalho, ou seja, desenvolvimento de formulação e ferramenta numérica para análise de instabilidade de estruturas de parede fina, utilizando para tanto o MEF posicional, abordagem não-linear geométrica com formulação Lagrangeana Total e elemento finito de casca. A principal vantagem dessa formulação reside no fato de ser possível a utilização de lei constitutiva completa tridimensional, dada a generalidade da cinemática adotada. Com isso, os resultados obtidos são mais completos quando comparados aos que são fornecidos por meio das formulações citadas e à abordagem tradicional do MEF em deslocamentos, a qual utiliza-se de leis constitutivas simplificadas.

Recentemente, Kzam (2016) apresentou uma formulação também baseada no MEF posicional para análise da instabilidade estrutural global e local, buscando pontos críticos ao longo de trajetórias de equilíbrio para elementos finitos de barra simples, casca e barra geral, sendo um trabalho desenvolvido no mesmo grupo de pesquisa em que o presente projeto se insere no SET/EESC/USP. No presente trabalho realizou-se uma nova implementação computacional, especificamente para elementos finitos de casca, na qual objetivou-se a otimização do custo computacional. Como novos desenvolvimentos realizados, ressaltam-se a avaliação de estratégias para o acoplamento entre as paredes que compõem o perfil, a análise de autovalores ao longo da trajetória de equilíbrio e a avaliação de estratégia para a definição da trajetória de equilíbrio a ser percorrida a partir de um ponto de bifurcação. 


\subsection{Metodologia}

Neste trabalho, realizam-se novas implementações computacionais, em linguagem Fortran, para elemento finito de casca posicional. A ideia utilizada aqui é baseada no trabalho de Kzam (2016), que obteve bons resultados para o referido elemento finito.

Baseado nos trabalhos de Coda e Paccola (2007) e Coda e Paccola (2008), implementamse os elementos finitos de casca de 6 e 7 parâmetros nodais. Verifica-se a adequação desses elementos para problemas de instabilidade, analisando-se aspectos referentes à ocorrência de travamentos em razão das diferentes cinemáticas apresentadas.

Quanto ao acoplamento entre as paredes do perfil, utiliza-se a estratégia proposta inicialmente por Silva (2014), que consiste na inserção de um elemento de barra conectando os vetores generalizados não coincidentes de um mesmo nó, sendo a rigidez desse elemento elevada o suficiente para a simulação de uma ligação rígida. Baseado nessa estratégia, desenvolve-se aqui uma metodologia para a determinação de uma rigidez para esse elemento que leve em consideração o material presente na região do acoplamento. Com isso, simula-se mais precisamente um acoplamento real e evita-se problemas de mau condicionamento decorrentes de valores elevados de rigidez.

Para a resolução do problema de autovalor resultante da análise de instabilidade utilizouse a biblioteca computacional ARPACK. Para que seu uso fosse possível, foi necessária a elaboração de uma rotina para a realização do processo iterativo e para manipulação das matrizes envolvidas no problema. O detalhamento desse processo está apresentado no Capítulo 4.

A interface gráfica foi desenvolvida em ambiente Delphi. Para isso, implementou-se algoritmos para geração de malha de elementos finitos e para aplicação de condições de contorno por meio da interface.

Por fim, realizam-se exemplos de validação do programa implementado e exemplos de aplicação buscando explorar as potencialidades da formulação desenvolvida.

\subsection{Estado da arte}

O início do estudo da instabilidade estrutural, que culminou para o que se conhece hoje, ocorreu em meados do século XVIII com o trabalho de Euler (1744). Euler possuía um grande interesse por forma geométrica de curvas elásticas e sua principal contribuição nessa área foi a determinação da carga crítica de instabilidade para colunas esbeltas (TIMOSHENKO, 1953; TIMOSHENKO; GERE, 1961).

A partir da teoria geral da flexão proposta por Navier, apresentada na literatura clássica de Resistência dos Materiais ou Mecânica dos Sólidos, pôde-se determinar analiticamente a carga crítica de instabilidade para colunas. No entanto, notou-se que as formulações não 
eram representativas quando se consideravam colunas robustas em uma direção. Timoshenko (1921) solucionou este problema propondo a consideração de distorções e de rotação da seção à cinemática do problema.

Neste período, a descrição analítica de caracterização dos pontos críticos e a determinação das ações críticas continuou sendo estudada por diversos pesquisadores, tendo como contribuição os trabalhos de Bryan (1888), Lyapunov (1982), Southwell (1913), dentre outros.

Devido a resultados inesperados em alguns experimentos envolvendo cascas cilíndricas e esféricas, houve uma necessidade de se estudar o que acontece com esse tipo de estrutura. Koiter (1967 apud ELISHAKOFF, 2000) descreveu o comportamento dessas estruturas prevendo a existência de imperfeições, que afetavam significativamente o nível de carga crítica, além de analisar o equilíbrio pós-crítico, originando a chamada teoria assintótica de Koiter. Com relação ao estudo do equilíbrio pós-crítico, citam-se também as contribuições de Kármán e Tsien (1941), Thompson (1963), Budiansky e Hutchinson (1964), Sewell (1969), entre outros.

Com o desenvolvimento do método dos elementos finitos, na metade do século XX, este se tornou uma importante ferramenta para análise de instabilidade de estruturas. Até então, a maioria dos trabalhos relacionados a esse tema eram realizados com base em formulações analíticas. No entanto, outros métodos específicos para esse tipo de análise foram desenvolvidos, como a Teoria Generalizada de Vigas (GBT), desenvolvida originalmente por Schardt (1966), e o método das faixas finitas (FSM), utilizado para análises de instabilidade inicialmente por Schafer (1997). O método foi posteriormente aprimorado com a incrementação de hipóteses da GBT, originando no Método das Faixas Finitas Confinado (cFSM) (ÁDÁNY; SCHAFER, 2004).

Um grupo de pesquisa do Departamento de Engenharia Civil da Universidade Técnica de Lisboa desenvolveu um programa intitulado GBTUL (Generalized Beam Theory at University of Lisbon), atualmente na versão 2.06, que determina as cargas críticas e modos de instabilidade de perfis metálicos utilizando a Teoria Generalizada de Vigas (GBT). O desenvolvimento desse programa foi iniciado por Silvestre (2005) na realização de seu doutorado. Dentre as contribuições para a formulação do GBT, ressalta-se a consideração de seções abertas ramificadas (DINIS; CAMOTIM; SILVESTRE, 2006), a consideração de seções de parede fina sob flexão não uniforme (BEBIANO; SILVESTRE; CAMOTIM, 2007), a análise de "primeira ordem" de membros com seção transversal arbitrária (GONÇALVES; DINIS; CAMOTIM, 2009), o estudo da influência do ponto de aplicação da carga no comportamento de perfis formados a frio (BASAGLIA; CAMOTIM; CODA, 2014), a análise considerando ligações semirrígidas em pórticos planos (MESACASA JR, 2016), dentre outros .

Quanto ao FSM e ao cFSM, Schafer e Peköz (1998) implementaram esse método em um programa computacional, posteriormente intitulado CUFSM, atualmente na versão 4.05. Esse programa possui funcionalidades semelhantes ao GBTUL descrito anteriormente.

Com relação especificamente ao MEF tradicional, a metodologia utilizada para a realiza- 
ção de análises de instabilidade é bem difundida e está presente na grande maioria dos softwares comerciais. Mais recentemente, destaca-se o desenvolvimento do MEF posicional, que culminou na realização de diversos trabalhos, tendo as principais contribuições descritas a seguir, incluindo a mais recente aplicação em análises de instabilidade.

O Método dos Elementos Finitos baseado em posições foi idealizado por Coda (2003), sendo a ideia central por trás do desenvolvimento do método idealizada por Bonet et al. (2000). A descrição posicional do método tornou-se relevante no meio acadêmico e ganhou notoriedade devido à sua facilidade de implementação computacional para problemas geometricamente nãolineares. Por exemplo, Greco (2004) utilizou o método para desenvolvimento da formulação para estruturas reticuladas com consideração de impacto, utilizando formulações estática e dinâmica.

Marques (2006) ampliou a formulação para a consideração de não-linearidade em sólidos bidimensionais. Para análise dinâmica, ele utilizou como integrador temporal o algoritmo de Newmark, que se mostrou eficiente para todos os problemas dinâmicos testados, inclusive os que consideram impacto.

Maciel (2008) introduziu a formulação de pórticos planos e sólidos tridimensionais. Para pórticos planos ele adotou a cinemática de Reissner-Timoshenko por meio da introdução de vetores generalizados na formulação e para sólidos tridimensionais ele fez uso de elemento finito tetraédrico com aproximação cúbica.

A partir de então, diversos trabalhos foram realizados para aprimoramento da formulação e inclusão de melhorias. Entre eles está o trabalho de Kzam (2016), que iniciou o estudo do fenômeno da instabilidade estrutural via MEF posicional, tema objeto de estudo do presente trabalho. Em sua tese foi realizada a análise de instabilidade para três tipos de elementos: barra simples, casca e barra geral. Para análise com elemento de barra simples, o método ArcLength foi utilizado para a determinação da trajetória fundamental e de trajetórias bifurcadas. A utilização do elemento de barra geral foi o principal foco do trabalho, no qual enriquecimentos cinemáticos para a seção transversal foram propostos de forma a permitir mobilidades referentes a comportamentos de instabilidade local para esse tipo de elemento. A implementação da análise de instabilidade em elementos de casca serviu como referência para a verificação do comportamento esperado nas análises com o elemento de barra geral.

A partir dos trabalhos supracitados, nota-se que o estudo de instabilidade via MEF posicional é recente e promissor, abrindo a possibilidade de melhorias no estudo do comportamento pós-crítico de estruturas, incluindo não linearidade física e dinâmica. Portanto, o presente trabalho se insere como continuação deste estudo, além de desenvolver um programa computacional que servirá como alternativa aos já existentes e constituindo base para desenvolvimentos futuros no grupo de pesquisa. 


\section{CAPÍTULO 2}

\section{CINEMÁTICA DOS CORPOS DEFORMÁVEIS}

Na descrição do comportamento de um determinado corpo deformável existem diversos fatores que devem ser levados em consideração. A depender da escala desejada para o estudo (microscópica ou macroscópica), alguns fatores preponderam sobre outros. Na descrição macroscópica do comportamento de um sólido, por exemplo, os efeitos devido à microscopia do material presente podem ser substituídos pelos seus efeitos macroscópicos por meio da utilização de uma lei constitutiva material adequada e adotando-se a hipótese do meio contínuo.

Há também interesse em se realizar análises de estruturas que podem estar sujeitas a grandes deslocamentos. Nessa situação, tem-se a necessidade de introdução da não-linearidade geométrica ao problema, tornando possível a análise de estabilidade dessas estruturas. Para este fim, no presente trabalho utiliza-se a descrição lagrangeana total do equilíbrio.

Nas próximas seções deste capítulo será descrita a cinemática utilizada neste trabalho, compreendendo as definições das grandezas, descrição lagrangeana do equilíbrio, aplicação de princípios energéticos e lei constitutiva material. A abordagem e o conteúdo apresentado neste capítulo foi extraído de Coda (2018).

\subsection{Função mudança de configuração}

Um corpo sólido deformável quando sujeito a ações externas tem sua forma alterada. A função que relaciona a posição do sólido deformado com a configuração inicial recebe o nome de função mudança de configuração $\vec{f}$. Estando o domínio de $\vec{f}$ na configuração inicial, a descrição é dita lagrangeana.

A configuração inicial pode ser escrita em relação à configuração atual por meio da função inversa de $\vec{f}$, denotada por $\vec{g}$. A descrição do equilíbrio baseada na configuração atual é dita euleriana. Os desenvolvimentos seguintes neste trabalho serão realizados com a descrição lagrangeana.

Na Figura 1 representa-se esquematicamente a mudança de configuração de um sólido no espaço tridimensional. No sistema de referência $X_{1} X_{2} X_{3}$ define-se a configuração inicial do 
sólido $\left(\Omega_{0}\right)$. A atuação da função $\vec{f}$ modifica a configuração do corpo para a forma apresentada no sistema de referência $x_{1} x_{2} x_{3}$, correspondendo à configuração atual $\left(\Omega_{1}\right)$.

Figura 1 - Mudança de configuração de corpo tridimensional

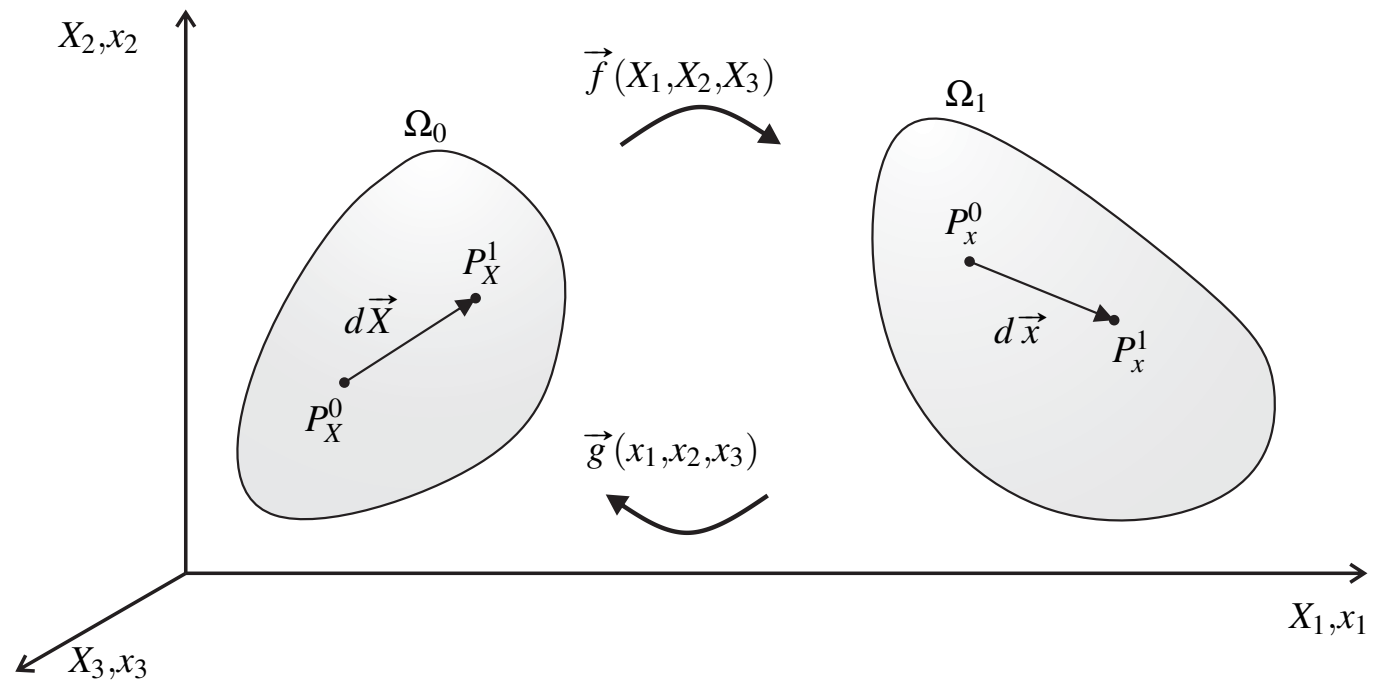

Fonte: Elaborado pelo autor

Escolhendo-se dois pontos infinitesimalmente próximos situados no interior de um sólido, define-se a posição relativa entre eles por meio dos vetores $d \vec{X}$, na configuração inicial, e $d \vec{x}$, na configuração atual, conforme indicado na Figura 1. Esses vetores podem ser relacionados entre si por meio da seguinte expressão:

$$
d \vec{x}=\mathbf{A} \cdot d \vec{X}
$$

sendo $\mathbf{A}=\nabla \vec{f}=\frac{\partial \vec{f}}{\partial \vec{X}}$

\subsection{Medida de deformação de Green-Lagrange}

Para a descrição de uma formulação não-linear geometricamente exata, é necessária a utilização de uma medida de deformação objetiva, ou seja, que registra deformação nula quando ocorrem apenas deslocamentos de corpo rígido, seja de translação ou de rotação.

A medida de deformação quadrática, ou de Green, é uma medida simples e que atende ao critério de objetividade (OGDEN, 1984). Além disso, é uma medida dita lagrangeana, pois a deformação é medida com relação à configuração inicial do corpo. Sua expressão é dada por:

$$
\mathbb{E}=\frac{1}{2}(\mathbf{C}-\mathbf{I})
$$

em que $\mathbf{C}$ é o tensor de alongamento de Cauchy-Green, definido como:

$$
\mathbf{C}=\mathbf{A}^{T} \mathbf{A}
$$




\subsection{Mudança de área e de volume na mudança de configuração}

Tomando-se na configuração inicial de um corpo um paralelepípedo de dimensões infinitesimais com faces paralelas aos planos coordenados, conforme Figura 2, seu volume inicial fica fornecido como:

$$
d V_{0}=\left(d \vec{X}^{1} \wedge d \vec{X}^{2}\right) \cdot d \vec{X}^{3}
$$

A atuação de ações externas sobre o corpo mudará a configuração do paralelepípedo, sendo seu volume final fornecido como:

$$
d V=\left(d \vec{x}^{1} \wedge d \vec{x}^{2}\right) \cdot d \vec{x}^{3}
$$

Figura 2 - Volume infinitesimal nas configurações inicial e atual

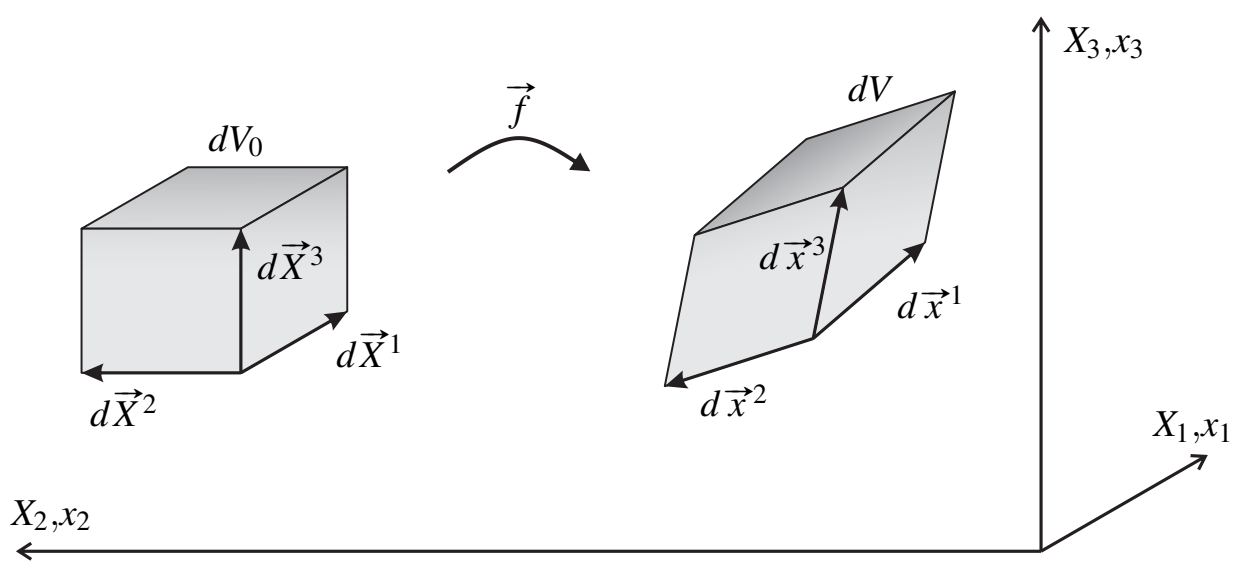

Fonte: Elaborado pelo autor

A partir das Equações (2.4) e (2.5) é possível demonstrar que a relação entre os volumes inicial e final, definida como o jacobiano da transformação, pode ser dada por meio do determinante do tensor gradiente da função mudança de configuração, ou seja:

$$
J=\frac{d V}{d V_{0}}=\operatorname{det}(\mathbf{A})
$$

A relação entre áreas pode ser obtida considerando um sólido prismático de área de base $d \mathbb{A}_{0}$ na configuração inicial e $d \mathbb{A}$ na configuração final, conforme Figura 3. Denotando por $\vec{u}$ o vetor que liga os centros das faces opostas do prisma na configuração inicial e por $\vec{v}$ o vetor correspondente na configuração atual, pode-se determinar o volume dos prismas pelas seguintes relações:

$$
d V_{0}=\vec{u}^{T} \cdot \vec{N} d \mathbb{A}_{0}
$$




$$
d V=\vec{v}^{T} \cdot \vec{n} d \mathbb{A}
$$

sendo $\vec{N}$ e $\vec{n}$ versores perpendiculares à área da base nas configurações inicial e atual, respectivamente.

Figura 3 - Volume prismático nas configurações inicial e atual

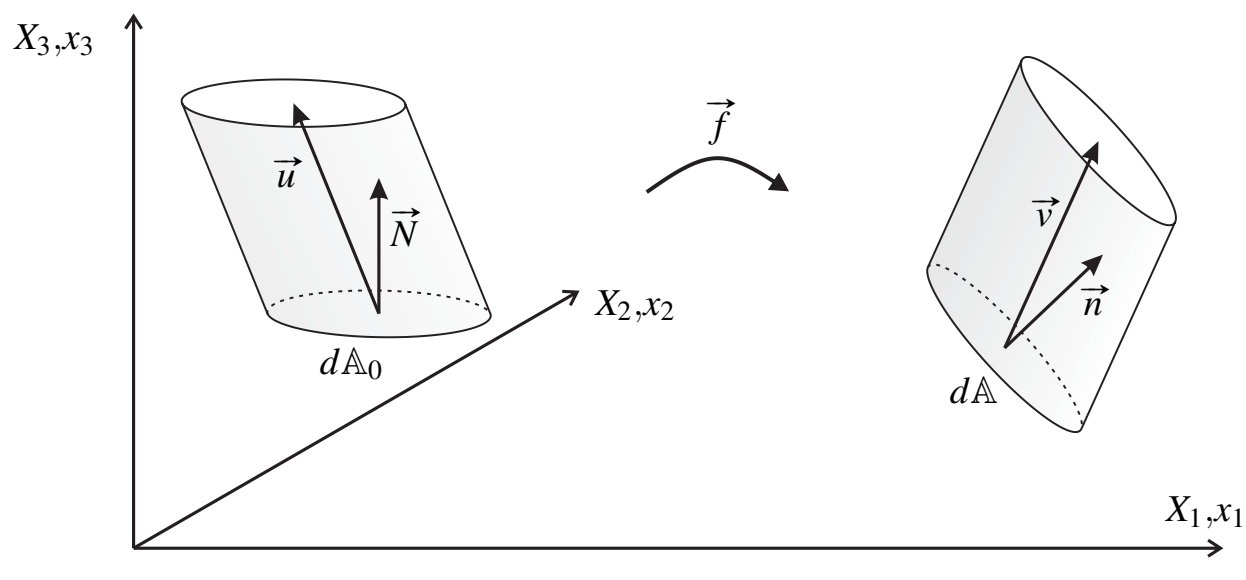

Fonte: Elaborado pelo autor

Substituindo-se as Equações (2.6) e (2.7) na Equação (2.8) e sabendo que $\vec{v}=\mathbf{A} \cdot \vec{u}$, obtém-se:

$$
d V=\vec{u}^{T} \cdot \mathbf{A}^{T} \cdot \vec{n} d \mathbb{A}=J \vec{u}^{T} \cdot \vec{N} d \mathbb{A}_{0}
$$

Dada a arbitrariedade do vetor $\vec{u}^{T}$, a expressão (2.9) pode ser simplificada, obtendo-se a chamada Fórmula de Nanson:

$$
\vec{n} \cdot d \mathbb{A}=J\left(\mathbf{A}^{T}\right)^{-1} \cdot \vec{N} d \mathbb{A}_{0} \quad \text { ou } \quad \vec{n} \cdot d \mathbb{A}=J \mathbf{B} \cdot \vec{N} d \mathbb{A}_{0}
$$

sendo $\mathbf{B}=\mathbf{A}^{-T}$.

\subsection{Equilíbrio local Lagrangeano}

Inicialmente apresenta-se as equações de equilíbrio eulerianas e a partir delas obtém-se as equações de equilíbrio lagrangeanas utilizando-se as relações de mudança de área e volume apresentadas anteriormente.

Considerando-se um elemento infinitesimal de um sólido que sofreu mudança de configuração, o equilíbrio na configuração atual fornece:

$$
\operatorname{div}\left(\boldsymbol{\sigma}^{T}\right)+\vec{b}=\rho \ddot{\vec{x}} \quad \text { ou } \quad \sigma_{j i, j}+b_{i}=\rho \ddot{x}_{i}
$$

sendo $\boldsymbol{\sigma}$ a tensão de Cauchy, $\vec{b}$ a força de volume e $\rho$ a massa específica do material. 
Integrando-se a Equação (2.11) no volume do sólido e utilizando-se o Teorema da Divergência obtém-se:

$$
\int_{\mathbb{A}} \boldsymbol{\sigma}^{T} \cdot \vec{n} d \mathbb{A}+\int_{V} \vec{b} d V=\int_{V} \rho \ddot{\vec{x}} d V \quad \therefore \quad \int_{\mathbb{A}} \vec{p} d \mathbb{A}+\int_{V} \vec{b} d V=\int_{V} \rho \ddot{\vec{x}} d V
$$

sendo $\vec{p}=\boldsymbol{\sigma}^{T} \cdot \vec{n}$ a força de superfície atuante no sólido.

Para escrever as equações de equilíbrio lagrangeanas, basta substituir as relações de mudança de volume (2.6) e de área (2.10) na Equação (2.12), obtendo-se:

$$
\int_{\mathbb{A}_{0}} \mathbf{P}^{T} \cdot \vec{N} d \mathbb{A}_{0}+\int_{V_{0}} \vec{b}_{0} d V_{0}=\int_{V_{0}} \rho_{0} \ddot{\vec{x}} d V_{0}
$$

sendo $\mathbf{P}^{T}=J \boldsymbol{\sigma}^{T} \cdot \mathbf{B}$ o transposto do primeiro tensor de tensões de Piola-Kirchhoff (não-simétrico), $\vec{b}_{0}$ a força de volume na configuração inicial e $\rho_{0}$ a massa específica inicial, considerando-se a conservação de massa.

Aplicando-se o Teorema da Divergência na Equação (2.13) e considerando a arbitrariedade do volume, obtém-se:

$$
\operatorname{div}\left(\mathbf{P}^{T}\right)+\vec{b}_{0}=\rho_{0} \ddot{\vec{x}} \quad \text { ou } \quad P_{j i, j}+b_{i}^{0}=\rho_{0} \ddot{x}_{i}
$$

que consiste na versão lagrangeana da equação de equilíbrio local.

\subsection{Princípio da estacionariedade da energia mecânica}

A energia total $\Pi$ de um sistema conservativo é dada pela soma das energias de deformação $\mathbb{U}$, potencial $\mathbb{P}$ e cinética $\mathbb{K}$, ou seja:

$$
\Pi=\mathbb{U}+\mathbb{P}+\mathbb{K}
$$

O princípio da estacionariedade afirma que, na situação de equilíbrio, a primeira variação do funcional de energia deve ser nulo:

$$
\delta \Pi=\delta \mathbb{U}+\delta \mathbb{P}+\delta \mathbb{K}=0
$$

Os parâmetros nodais escolhidos para o cálculo das variações serão as posições, já visando a posterior apresentação da formulação posicional do MEF.

Inicialmente, pondera-se a Equação (2.14) com uma função teste e integra-se no volume do corpo analisado com o objetivo de se chegar à forma fraca do problema:

$$
\delta \Pi=\int_{V_{0}}\left(\rho_{0} \ddot{\vec{x}}-\operatorname{div}\left(\mathbf{P}^{T}\right)-\vec{b}_{0}\right) \cdot \delta \vec{x} d V_{0}=0
$$


Integrando por partes a segunda parcela de (2.17) e utilizando o Teorema da Divergência, resulta:

$$
\delta \Pi=\int_{V_{0}} \rho_{0} \ddot{\vec{x}} \cdot \delta \vec{x} d V_{0}-\int_{\mathbb{A}_{0}} \mathbf{P}^{T} \cdot \vec{N} \cdot \delta \vec{x} d \mathbb{A}_{0}+\int_{V_{0}} \mathbf{P}^{T}: \nabla(\delta \vec{x}) d V_{0}-\int_{V_{0}} \vec{b}_{0} \cdot \delta \vec{x} d V_{0}=0
$$

mas $\nabla(\delta \vec{x})=\delta \nabla \vec{x}=\delta \nabla \vec{f}=\delta \mathbf{A}$ é a variação do gradiente da função mudança de configuração e $\mathbf{P}^{T} \cdot \vec{N}$ pode ser entendido como a força de superfície na configuração inicial.

Portanto, a Equação (2.18) fica reescrita como

$$
\delta \Pi=\int_{V_{0}} \rho_{0} \ddot{\vec{x}} \cdot \delta \vec{x} d V_{0}-\int_{\mathbb{A}_{0}} \vec{p}_{0} \cdot \delta \vec{x} d \mathbb{A}_{0}+\int_{V_{0}} \mathbf{P}^{T}: \delta \mathbf{A} d V_{0}-\int_{V_{0}} \vec{b}_{0} \cdot \delta \vec{x} d V_{0}=0
$$

Como a terceira integral da Equação (2.18) se refere à energia de deformação, conclui-se que A é conjugado energético de $\mathbf{P}^{T}$. Imaginando-se deliberadamente que $\mathbf{P}^{T}=\mathbf{A} \cdot \mathbf{S}$, sendo $\mathbf{S}$ denominado como segundo tensor de tensões de Piola-Kirchhoff, pode-se mostrar que $\mathbf{S}$ é simétrico e que seu conjugado energético é a deformação de Green $\mathbb{E}$. Portanto, obtém-se a expressão final da primeira variação da energia total:

$$
\delta \Pi=\int_{V_{0}} \rho_{0} \ddot{\vec{x}} \cdot \delta \vec{x} d V_{0}-\int_{\mathbb{A}_{0}} \vec{p}_{0} \cdot \delta \vec{x} d \mathbb{A}_{0}-\int_{V_{0}} \vec{b}_{0} \cdot \delta \vec{x} d V_{0}+\int_{V_{0}} \mathbf{S}: \delta \mathbb{E} d V_{0}=0
$$

a partir da qual identifica-se as parcelas da Equação (2.16):

$$
\begin{aligned}
& \delta \mathbb{U}=\int_{V_{0}} \mathbf{S}: \delta \mathbb{E} d V_{0} \\
& \delta \mathbb{P}=-\int_{\mathbb{A}_{0}} \vec{p}_{0} \cdot \delta \vec{x} d \mathbb{A}_{0}-\int_{V_{0}} \vec{b}_{0} \cdot \delta \vec{x} d V_{0} \\
& \delta \mathbb{K}=\int_{V_{0}} \rho_{0} \ddot{\vec{x}} \cdot \delta \vec{x} d V_{0}
\end{aligned}
$$

\subsection{Lei constitutiva de Saint-Venant-Kirchhoff}

Neste trabalho é adotada a lei constitutiva de Saint-Venant-Kirchhoff (SVK), lei esta que relaciona de forma linear a tensão de Piola-Kirchhoff de segunda espécie $\mathbf{S}$ com a deformação de Green $\mathbb{E}$. A expressão da energia específica de deformação para esta lei é

$$
u_{e}(\mathbb{E})=\frac{1}{2} \mathbb{E}: \mathfrak{C}: \mathbb{E}
$$

sendo $\mathfrak{C}$ o tensor constitutivo elástico. 
A derivada primeira de $u_{e}$ em relação à $\mathbb{E}$ fornece o segundo tensor de tensões de Piola-Kirchhoff:

$$
\mathbf{S}=\frac{\partial}{\partial \mathbb{E}}\left(\frac{1}{2} \mathbb{E}: \mathfrak{C}: \mathbb{E}\right)=\frac{1}{2}(\mathfrak{I}: \mathfrak{C}: \mathbb{E}+\mathbb{E}: \mathfrak{C}: \mathfrak{I})=\mathfrak{C}: \mathbb{E}
$$

sendo $\mathfrak{I}$ o tensor identidade de quarta ordem.

A segunda derivada de $u_{e}$ em relação a $\mathbb{E}$ fornece o tensor constitutivo elástico e, pelo teorema de Clairaut-Schwartz, observa-se uma das simetrias desse tensor:

$$
\frac{\partial^{2} u_{e}}{\partial \mathbb{E} \otimes \partial \mathbb{E}}=\frac{\partial \mathbf{S}}{\partial \mathbb{E}}=\mathfrak{C}: \mathfrak{I}=\mathfrak{C}
$$

A lei constitutiva SVK possui o tensor constitutivo semelhante ao da lei de Hooke, pois também é uma relação linear entre tensão e deformação correspondente. Portanto, o tensor constitutivo elástico para o caso geral considerando material isotrópico é dado por:

$$
\mathfrak{C}=2 G \mathfrak{I}+\lambda \mathbf{I} \otimes \mathbf{I}
$$

sendo $G$ é o módulo de elasticidade transversal e $\lambda=v E /[(1+v)(1-2 v)]$ a constante de Lamé, na qual $v$ é o coeficiente de Poisson e $E$ é o módulo de elasticidade longitudinal.

Considerando-se que a lei constitutiva a ser utilizada é tridimensional e não possui simplificações, a tensão $\mathbf{S}$ pode ser escrita em função de $\mathbb{E}$ e das propriedades do material como

$$
\mathbf{S}=2 G \mathbb{E}+\lambda \operatorname{tr}(\mathbb{E}) \mathbf{I}
$$

na qual $\operatorname{tr}(\cdot)$ denota o traço de um tensor. 



\section{CAPÍTULO 3}

\section{FORMULAÇÃO NUMÉRICA}

As equações de equilíbrio obtidas por meio da análise não-linear possuem soluções analíticas para um conjunto específico de problemas, dependendo principalmente da geometria do sólido e de suas condições de contorno. Portanto, o uso de métodos aproximativos para a resolução desses problemas se torna indispensável.

O MEF é um dos métodos aproximativos mais utilizados atualmente. De forma geral, o método consiste em subdividir o meio contínuo em diversos subdomínios, denominados elementos finitos. O comportamento das grandezas de importância é então descrito para cada elemento finito e a composição deles levará à descrição do comportamento do sólido como um todo. Além da aproximação das grandezas envolvidas, a depender da configuração inicial do sólido os elementos finitos podem não representar a geometria do problema de forma exata, introduzindo uma aproximação extra ao problema.

Dito isto, implementa-se no programa computacional a possibilidade de discretização da estrutura em malha estruturada de elementos triangulares ou quadrilaterais, com qualquer grau de aproximação polinomial, conforme apresentado no Apêndice A. As funções de forma associadas a esses elementos finitos foram determinadas conforme descrito no Apêndice B.

Ao longo deste capítulo serão descritas as cinemáticas dos elementos finitos utilizados, bem como algumas estratégias para contornar um problema encontrado no acoplamento de elementos de casca não-coplanares utilizados para a discretização das paredes dos perfis.

\subsection{Elemento finito de casca posicional}

A formulação não-linear geométrica do elemento finito de casca posicional foi desenvolvida por Coda e Paccola (2007), inicialmente com 6 graus de liberdade por nó, sendo 3 referentes às posições e 3 referentes às componentes do vetor generalizado. Dada a ocorrência do fenômeno de travamento volumétrico, Coda e Paccola (2008) incluíram um sétimo parâmetro, que considera taxa de variação linear da espessura da casca. As duas formulações foram utilizadas neste trabalho para fins de comparação. 
Na Figura 4 ilustra-se o mapeamento da superfície de referência do elemento finito de casca posicional.

Figura 4 - Mapeamento da superfície de referência do elemento finito de casca posicional

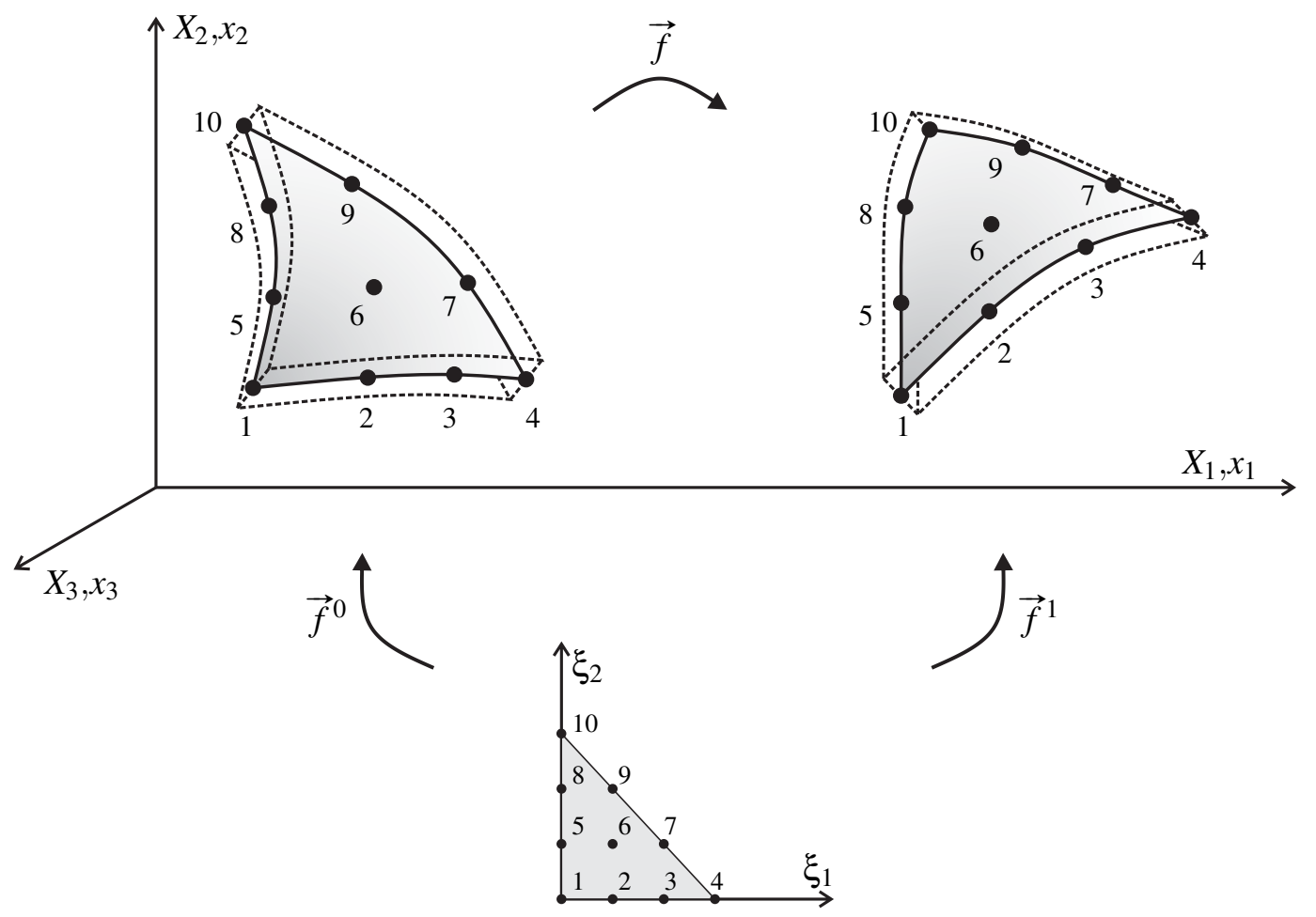

Fonte: Elaborado pelo autor

Da Figura 4, observa-se que a função mudança de configuração pode ser escrita como $\vec{f}=\vec{f}^{1} \circ\left(\vec{f}^{0}\right)^{-1}$ e, portanto, tem-se que $\mathbf{A}=\mathbf{A}^{1} \cdot\left(\mathbf{A}^{0}\right)^{-1}$, sendo $\mathbf{A}^{0}$ e $\mathbf{A}^{1}$ os gradientes das funções $\vec{f}^{0}$ e $\vec{f}^{1}$, respectivamente.

O mapeamento de qualquer ponto da superfície de referência na configuração inicial é dado pela interpolação entre os valores de posição nodal conhecidos:

$$
f_{i}^{m 0}=\phi_{\ell}\left(\xi_{1}, \xi_{2}\right) X_{i \ell}
$$

sendo $\phi_{\ell}$ as funções de forma definidas no espaço auxiliar $\xi_{1} \xi_{2}$ e $X_{i \ell}$ a posição nodal de cada nó $\ell$ do elemento na configuração inicial, na direção $i$.

De forma análoga, o mapeamento da superfície de referência na configuração atual é dado por:

$$
f_{i}^{m 1}=\phi_{\ell}\left(\xi_{1}, \xi_{2}\right) x_{i \ell}
$$

sendo $x_{i \ell}$ as posições nodais de cada nó $\ell$ do elemento na configuração atual, na direção $i$.

Mapeiam-se também os demais pontos do interior da casca a partir da superfície de referência por meio do vetor generalizado, considerando-o, por simplicidade, inicialmente 
unitário e ortogonal à superfície de referência, conforme Figura 5. Considerando que a superfície de referência é a superfície média do elemento, o mapeamento completo das posições iniciais e atuais fica dado por:

$$
\begin{aligned}
& f_{i}^{0}=\phi_{\ell}\left(\xi_{1}, \xi_{2}\right) X_{i \ell}+\frac{h_{0}}{2} \xi_{3} \phi_{k}\left(\xi_{1}, \xi_{2}\right) N_{i k}^{0} \\
& f_{i}^{1}=\phi_{\ell}\left(\xi_{1}, \xi_{2}\right) x_{i \ell}+\frac{h_{0}}{2} \xi_{3} \phi_{k}\left(\xi_{1}, \xi_{2}\right) \bar{G}_{i k}
\end{aligned}
$$

sendo $h_{0}$ a espessura da casca, $N_{i k}^{0}$ o versor normal de cada nó $k$ na configuração inicial, $\bar{G}_{i k}$ o vetor generalizado de cada nó $k$ na configuração atual (ver Figura 5) e $\xi_{3}$ a coordenada do espaço auxiliar referente a um eixo ortogonal aos eixos $\xi_{1}$ e $\xi_{2}$ e que assume valores no intervalo $[-1,+1]$.

Figura 5 - Versor normal na configuração inicial e vetor generalizado na configuração atual

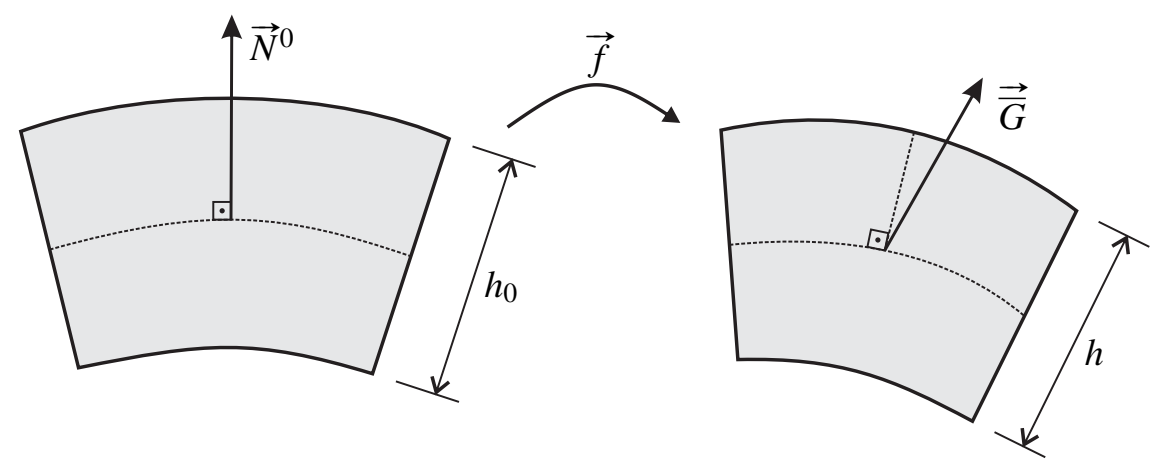

Fonte: Elaborado pelo autor

A cinemática descrita para o elemento de casca apresentado impõe que as componentes do vetor generalizado sejam variáveis do problema. Dessa forma, na configuração atual o vetor não necessariamente permanecerá unitário e ortogonal à superfície de referência, permitindo assim uma maior mobilidade da estrutura.

O gradiente da função de mapeamento da configuração inicial com relação às coordenadas adimensionais tem suas componentes dadas pelas seguintes expressões:

$$
\begin{aligned}
& A_{i 1}^{0}=f_{i, 1}^{0}=\phi_{\ell, 1}\left(\xi_{1}, \xi_{2}\right) X_{i \ell}+\frac{h_{0}}{2} \xi_{3} \phi_{k, 1}\left(\xi_{1}, \xi_{2}\right) N_{i k}^{0} \\
& A_{i 2}^{0}=f_{i, 2}^{0}=\phi_{\ell, 2}\left(\xi_{1}, \xi_{2}\right) X_{i \ell}+\frac{h_{0}}{2} \xi_{3} \phi_{k, 2}\left(\xi_{1}, \xi_{2}\right) N_{i k}^{0} \\
& A_{i 3}^{0}=f_{i, 3}^{0}=\frac{h_{0}}{2} \phi_{k}\left(\xi_{1}, \xi_{2}\right) N_{i k}^{0}
\end{aligned}
$$

Para a configuração atual, as componentes do gradiente da função de mapeamento são 
dadas por:

$$
\begin{aligned}
& A_{i 1}^{1}=f_{i, 1}^{1}=\phi_{\ell, 1}\left(\xi_{1}, \xi_{2}\right) x_{i \ell}+\frac{h_{0}}{2} \xi_{3} \phi_{k, 1}\left(\xi_{1}, \xi_{2}\right) \bar{G}_{i k} \\
& A_{i 2}^{1}=f_{i, 2}^{1}=\phi_{\ell, 2}\left(\xi_{1}, \xi_{2}\right) x_{i \ell}+\frac{h_{0}}{2} \xi_{3} \phi_{k, 2}\left(\xi_{1}, \xi_{2}\right) \bar{G}_{i k} \\
& A_{i 3}^{1}=f_{i, 3}^{1}=\frac{h_{0}}{2} \phi_{k}\left(\xi_{1}, \xi_{2}\right) \bar{G}_{i k}
\end{aligned}
$$

Até o momento considerou-se apenas o elemento finito de casca de 6 parâmetros nodais. O sétimo parâmetro, referente à taxa de variação da espessura, aparece na função de mapeamento da configuração atual, que fica reescrita como:

$$
f_{i}^{1}=\phi_{\ell}\left(\xi_{1}, \xi_{2}\right) x_{i \ell}+\frac{h_{0}}{2}\left[\xi_{3}+\phi_{m}\left(\xi_{1}, \xi_{2}\right) a_{m} \xi_{3}^{2}\right] \phi_{k}\left(\xi_{1}, \xi_{2}\right) \bar{G}_{i k}
$$

na qual $a_{m}$ é a taxa de variação da espessura no nó $m$, sendo seu valor determinado no processo de solução do problema não-linear.

Assim, as componentes do gradiente da função de mapeamento da configuração atual ficam dados por:

$$
\begin{aligned}
& A_{i 1}^{1}=\phi_{\ell, 1} x_{i \ell}+\frac{h_{0}}{2}\left[\left(\phi_{m, 1} a_{m} \xi_{3}^{2}\right) \phi_{k} \bar{G}_{i k}+\left(\xi_{3}+\phi_{m} a_{m} \xi_{3}^{2}\right) \phi_{k, 1} \bar{G}_{i k}\right] \\
& A_{i 2}^{1}=\phi_{\ell, 2} x_{i \ell}+\frac{h_{0}}{2}\left[\left(\phi_{m, 2} a_{m} \xi_{3}^{2}\right) \phi_{k} \bar{G}_{i k}+\left(\xi_{3}+\phi_{m} a_{m} \xi_{3}^{2}\right) \phi_{k, 2} \bar{G}_{i k}\right] \\
& A_{i 3}^{1}=\frac{h_{0}}{2}\left(1+2 \phi_{m} a_{m} \xi_{3}\right) \phi_{k} \bar{G}_{i k}
\end{aligned}
$$

nas quais, por clareza, omitiu-se os parâmetros $\xi_{1}$ e $\xi_{2}$.

Com a adição deste novo parâmetro, mais uma mobilidade é inserida na cinemática do problema, o que a torna mais geral que a cinemática de Reissner-Mindlin (CODA; PACCOLA, 2008).

\subsection{Procedimento de solução do problema não-linear}

Da lei constitutiva de Saint-Venant-Kirchhoff (seção 2.6), tem-se que a energia de deformação é dada por:

$$
\mathbb{U}=\int_{V_{0}} u_{e} d V_{0}=\int_{V_{0}} \frac{1}{2} \mathbb{E}: \mathfrak{C}: \mathbb{E} d V_{0}=\int_{V_{0}} \frac{1}{2} \mathbb{E}_{\alpha \beta} \mathfrak{C}_{\alpha \beta \gamma_{z}} \mathbb{E}_{\gamma_{z}} d V_{0}
$$

A Equação (2.16), que apresenta as parcelas da primeira variação da energia mecânica total, pode ser escrita em termos da variação de posição como:

$$
\delta \Pi=\frac{\partial \mathbb{U}}{\partial x_{i}} \delta x_{i}+\frac{\partial \mathbb{P}}{\partial x_{i}} \delta x_{i}+\frac{\partial \mathbb{K}}{\partial x_{i}} \delta x_{i}=0
$$


Considerando a arbitrariedade de $\delta x_{i}$ e desprezando-se a parcela devida à energia cinética (considerando apenas problemas estáticos), obtém-se:

$$
\frac{\partial \mathbb{U}}{\partial x_{i}}-F_{i}^{e x t}=0
$$

na qual $F_{i}^{e x t}=-\frac{\partial \mathbb{P}}{\partial x_{i}}$ representa a força externa atuante.

Faz-se necessária então a determinação da derivada de $\mathbb{U}$ com relação às posições nodais, resultando na força interna:

$$
\begin{aligned}
\frac{\partial \mathbb{U}}{\partial x_{i}} & =\int_{V_{0}} \frac{1}{2} \frac{\partial}{\partial x_{i}}\left(\mathbb{E}_{\alpha \beta} \mathfrak{C}_{\alpha \beta \gamma z} \mathbb{E}_{\gamma_{z}}\right) d V_{0}=\int_{V_{0}} \frac{1}{2}\left(\frac{\partial \mathbb{E}_{\alpha \beta}}{\partial x_{i}} \mathfrak{C}_{\alpha \beta \gamma z} \mathbb{E}_{\gamma_{z}}+\mathbb{E}_{\alpha \beta} \mathfrak{C}_{\alpha \beta \gamma z} \frac{\partial \mathbb{E}_{\gamma z}}{\partial x_{i}}\right) d V_{0} \\
& =\int_{V_{0}} \mathfrak{C}_{\alpha \beta \gamma z} \mathbb{E}_{\gamma_{z}} \frac{\partial \mathbb{E}_{\alpha \beta}}{\partial x_{i}} d V_{0}=\int_{V_{0}} S_{\alpha \beta} \frac{\partial \mathbb{E}_{\alpha \beta}}{\partial x_{i}} d V_{0}=F_{i}^{i n t}
\end{aligned}
$$

sendo $x_{i}$ um vetor que engloba posição, vetor generalizado e taxa de variação da espessura, com o índice $i$ combinando nó $\ell$ e grau de liberdade $k$ por meio da fórmula $i=7(\ell-1)+k$, considerando o elemento de 7 parâmetros nodais.

Como estratégia de solução, será adotado o método de Newton-Raphson. O método consiste na linearização do resíduo em torno de uma determinada tentativa de solução, resultando num sistema linear de equações, que fornece uma correção para a solução tentativa. Repetindose o processo, chega-se a uma solução para o problema, dentro de um determinado nível de tolerância.

Inicialmente, no primeiro incremento de força ou posição, escolhe-se a posição inicial como tentativa e, substituindo na Equação (3.10), obtém-se um resíduo $g_{i}$, dado por:

$$
g_{i}^{t e n t}=\frac{\partial \mathbb{U}\left(x_{k}^{t e n t}\right)}{\partial x_{i}}-F_{i}^{e x t} \neq 0
$$

Expandindo a Equação (3.12) em Série de Taylor e truncando em $1^{\text {a }}$ ordem, obtém-se a expressão da linearização do resíduo:

$$
g_{i}=g_{i}^{t e n t}+\frac{\partial g_{i}}{\partial x_{j}} \Delta x_{j}=g_{i}^{t e n t}+\frac{\partial^{2} \mathbb{U}\left(x_{k}^{t e n t}\right)}{\partial x_{i} \partial x_{j}} \Delta x_{j}=g_{i}^{t e n t}+H_{i j} \Delta x_{j}=0
$$

na qual $\Delta x_{j}$ é a correção da posição tentativa e $H_{i j}$ é a matriz hessiana do potencial $\Pi$.

Da Equação (3.13) obtém-se um sistema linear, cuja solução é dada por

$$
\Delta x_{j}=-H_{i j}^{-1} g_{i}^{t e n t}
$$


Atualiza-se então a posição tentativa $x_{i}^{t e n t}=x_{i}^{t e n t}+\Delta x_{i}$, dentro de um mesmo passo de carga ou de posição, e repete-se o processo até que se atinja um dos seguintes critérios de parada:

$$
\frac{\|\Delta \vec{x}\|}{\left\|\vec{X}^{0}\right\|}<\text { tol } \quad \text { ou } \quad \frac{\|\vec{g}\|}{\left\|\vec{F}^{\text {ext }}\right\|}<\text { tol }
$$

sendo tol uma tolerância pré-estabelecida e $\vec{X}^{0}$ a posição inicial da estrutura.

Após convergir em um determinado passo, esse processo é repetido posteriormente para cada incremento de força ou posição. Para finalizar, a matriz hessiana é obtida derivando-se a expressão (3.11) com relação às posições atuais:

$$
H_{i j}=\frac{\partial^{2} \mathbb{U}}{\partial x_{i} \partial x_{j}}=\int_{V_{0}} \frac{\partial \mathbb{E}_{\alpha \beta}}{\partial x_{i}} \mathfrak{C}_{\alpha \beta \gamma_{z}} \frac{\partial \mathbb{E}_{\gamma z}}{\partial x_{j}} d V_{0}+\int_{V_{0}} \mathbb{E}_{\gamma z} \mathfrak{C}_{\alpha \beta \gamma z} \frac{\partial^{2} \mathbb{E}_{\alpha \beta}}{\partial x_{i} \partial x_{j}} d V_{0}
$$

ou, em função do segundo tensor de tensões de Piola-Kirchhoff,

$$
H_{i j}=\int_{V_{0}} \frac{\partial \mathbb{E}_{\alpha \beta}}{\partial x_{i}} \mathfrak{C}_{\alpha \beta \gamma z} \frac{\partial \mathbb{E}_{\gamma_{z}}}{\partial x_{j}} d V_{0}+\int_{V_{0}} S_{\alpha \beta} \frac{\partial^{2} \mathbb{E}_{\alpha \beta}}{\partial x_{i} \partial x_{j}} d V_{0}
$$

A derivada de $\mathbb{E}$, partindo da sua definição pela Equação (2.2), é fornecida, em notação mista, pela seguinte expressão:

$$
\begin{aligned}
\frac{\partial \mathbb{E}}{\partial x_{i}} & =\frac{1}{2} \frac{\partial \mathbf{C}}{\partial x_{i}}=\frac{1}{2}\left[\frac{\partial \mathbf{A}^{T}}{\partial x_{i}} \cdot \mathbf{A}+\mathbf{A}^{T} \cdot \frac{\partial \mathbf{A}}{\partial x_{i}}\right]= \\
& =\frac{1}{2}\left[\left(\mathbf{A}^{0}\right)^{-T} \cdot \frac{\partial\left(\mathbf{A}^{1}\right)^{T}}{\partial x_{i}} \cdot \mathbf{A}^{1} \cdot\left(\mathbf{A}^{0}\right)^{-1}+\left(\mathbf{A}^{0}\right)^{-T} \cdot\left(\mathbf{A}^{1}\right)^{T} \cdot \frac{\partial \mathbf{A}^{1}}{\partial x_{i}} \cdot\left(\mathbf{A}^{0}\right)^{-1}\right]
\end{aligned}
$$

Obtém-se, por fim, a segunda derivada de $\mathbb{E}$, derivando-se a Equação (3.18) em relação às posições nodais:

$$
\begin{aligned}
\frac{\partial^{2} \mathbb{E}}{\partial x_{i} \partial x_{j}} & =\frac{1}{2}\left[\left(\mathbf{A}^{0}\right)^{-T} \cdot \frac{\partial^{2}\left(\mathbf{A}^{1}\right)^{T}}{\partial x_{i} \partial x_{j}} \cdot \mathbf{A}^{1} \cdot\left(\mathbf{A}^{0}\right)^{-1}+\left(\mathbf{A}^{0}\right)^{-T} \cdot \frac{\partial\left(\mathbf{A}^{1}\right)^{T}}{\partial x_{j}} \cdot \frac{\partial \mathbf{A}^{1}}{\partial x_{i}} \cdot\left(\mathbf{A}^{0}\right)^{-1}+\right. \\
& \left.+\left(\mathbf{A}^{0}\right)^{-T} \cdot \frac{\partial\left(\mathbf{A}^{1}\right)^{T}}{\partial x_{i}} \cdot \frac{\partial \mathbf{A}^{1}}{\partial x_{j}} \cdot\left(\mathbf{A}^{0}\right)^{-1}+\left(\mathbf{A}^{0}\right)^{-T} \cdot\left(\mathbf{A}^{1}\right)^{T} \cdot \frac{\partial^{2} \mathbf{A}^{1}}{\partial x_{i} \partial x_{j}} \cdot\left(\mathbf{A}^{0}\right)^{-1}\right]
\end{aligned}
$$

\subsection{Integração numérica}

Para a determinação da solução do problema não-linear, faz-se necessário calcular as integrais para determinação da força interna (3.11) e da matriz hessiana (3.17) de cada um dos elementos finitos que compõe a discretização do corpo. Dada a generalidade para a escolha 
do tipo de elemento finito e do seu grau de aproximação e dada a complexa relação entre as variáveis envolvidas no processo, a integração analítica fica inviável. Como solução, portanto, utilizam-se métodos de integração numérica.

As integrais são determinadas por meio de regras de quadratura. Utiliza-se quadratura de Hammer ou de Dunavant para integração em domínio triangular e quadratura de Gauss-Legendre para domínio retangular.

A ideia central das regras de quadratura é transformar a integral em um somatório em pontos específicos do domínio, sendo o número de pontos função da precisão numérica desejada e do grau dos polinômios a serem integrados. No caso, especificam-se pontos dentro do espaço auxiliar $\xi_{1} \xi_{2} \xi_{3}$, por padronização.

Matematicamente, essa regra pode ser escrita da seguinte forma:

$$
\int_{V_{0}} \mathfrak{F}(\vec{x}) d V_{0}=\sum_{i=1}^{n p i} \mathfrak{F}\left(\vec{x}\left(\vec{\xi}_{i}\right)\right) J_{0}\left(\vec{\xi}_{i}\right) w_{i}
$$

sendo $\mathfrak{F}(\vec{x})$ a função a ser integrada, npi o número de pontos de integração, $\vec{\xi}_{i}$ o vetor de coordenadas de cada ponto de integração $i$ no espaço auxiliar, $w_{i}$ o peso de integração e $J_{0}$ o jacobiano da transformação do espaço auxiliar para o espaço físico na configuração inicial (descrição lagrangeana).

As quadraturas utilizadas foram extraídas de Witherden e Vincent (2015), que fornece os valores das coordenadas e dos pesos para diversas geometrias de domínio e para uma grande variedade de graus de polinômio.

\subsection{Estratégia de acoplamento entre elementos não coplanares}

O uso de vetores generalizados como parâmetros da formulação gera uma dificuldade nas regiões de encontro entre elementos não coplanares. Isso porque nessas regiões mais de um vetor normal pode ser definido para um mesmo nó, a depender de qual elemento está sendo considerado. Com isso surge a necessidade de elaboração de estratégias para contornar esse problema.

Uma proposta, desenvolvida originalmente por Silva (2014) para aplicação no elemento finito de barra geral, consiste em manter os vetores normais excedentes em um nó e conectar suas extremidades por meio de uma mola de rigidez elevada, simulando uma restrição por penalização. Neste trabalho será utilizado como penalização o elemento finito de barra simples com o produto de rigidez $E A$ elevado. Com isso, a rotação relativa fica restringida no plano formado pelos vetores, resolvendo assim o problema de forma simples.

Esse procedimento, no entanto, é realizado quando o ângulo $\theta$ entre esses vetores é maior que $15^{\circ}$. Quando o ângulo está entre $0^{\circ}$ e $15^{\circ}$, utilizam-se as componentes do vetor bissetriz 
como parâmetros nodais do respectivo nó, dado que essa simplificação não acarreta diferenças significativas nos resultados obtidos. Na Figura 6 apresentam-se essas duas situações possíveis de acoplamento.

Figura 6 - Acoplamento via (a) bissetriz e via (b) elemento de barra simples de vetores generalizados não coincidentes de um mesmo nó

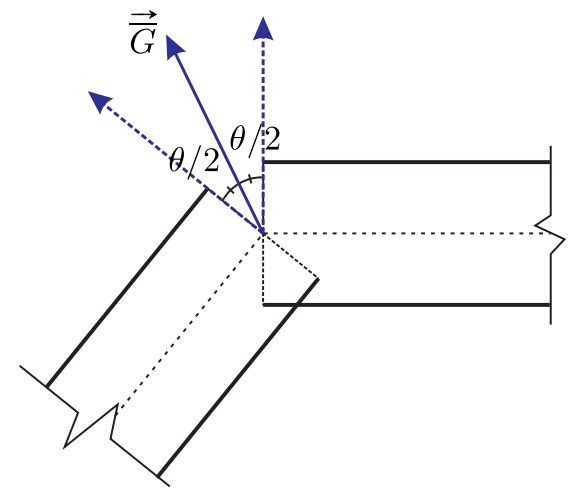

(a) $\theta \leq 15^{\circ}$

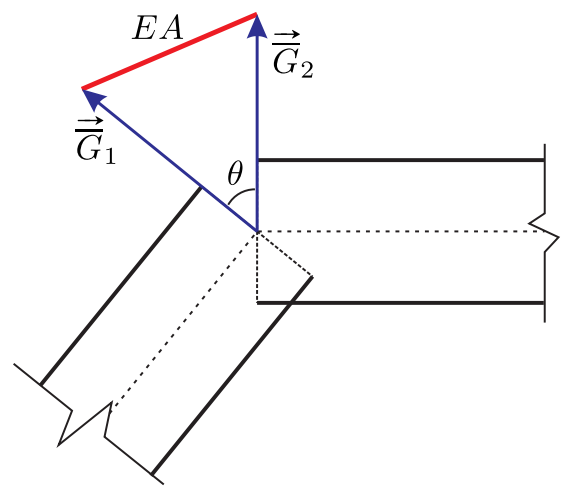

(b) $\theta>15^{\circ}$

Fonte: Elaborado pelo autor

Uma dificuldade dessa proposta é a escolha do valor de rigidez para o elemento de barra, que pode variar a depender do problema a ser resolvido. Além disso, valores muito elevados podem causar problemas de mau condicionamento da matriz hessiana e, por consequência, dificuldade de convergência do método de solução do problema não-linear. Para resolver este problema, Soares, Paccola e Coda (2019) propuseram uma estratégia para a determinação de um valor de rigidez que fosse coerente com o material presente na ligação, conforme apresentado a seguir.

\subsubsection{Determinação da rigidez da ligação entre elementos não-coplanares}

Para determinar a rigidez da ligação entre elementos não-coplanares, pode-se utilizar de uma equivalência aproximada de energias de deformação entre o sólido que preenche o espaço físico da ligação e o elemento de barra simples, conforme apresentado na Figura 7.

O material constituinte do sólido de ligação será considerado o mesmo dos elementos de casca adjacentes e, portanto, possui módulo de elasticidade transversal $G$ conhecido e altura transversal $h_{0}$. Após a ocorrência de deformações no meio, observa-se a presença de uma distorção $\gamma$. A energia específica do sólido pode então ser escrita de forma simplista como:

$$
u_{e}^{s o l}=\frac{1}{2} G \gamma^{2}
$$

e a energia total armazenada fica escrita como:

$$
U_{e}^{s o l}=\frac{1}{2} G \gamma^{2} h_{0}^{2} b \operatorname{sen}(\alpha)
$$


Figura 7 - Equivalência entre as energias de deformação de: (a) sólido que preenche o espaço de ligação e (b) elemento de barra simples

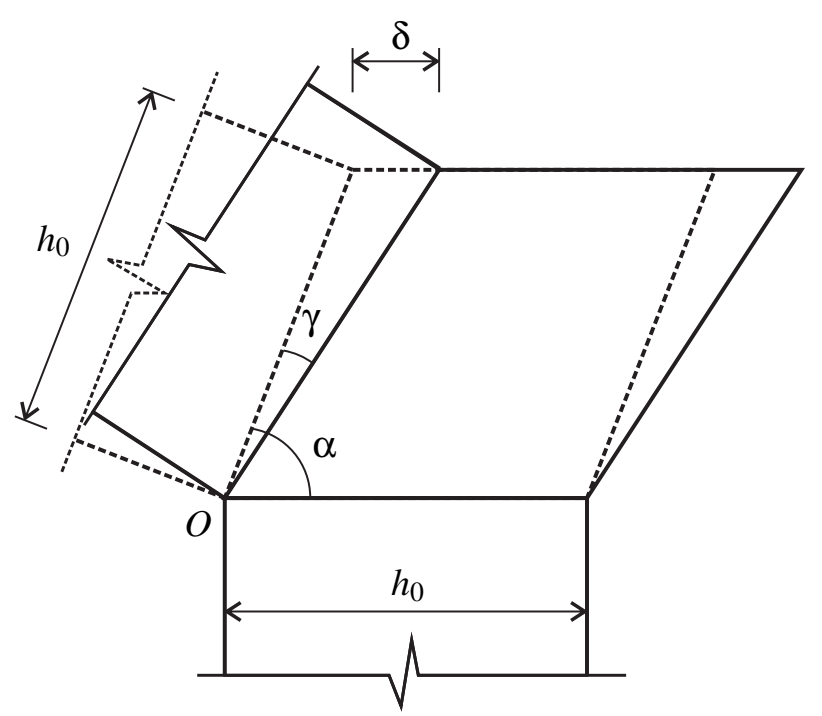

(a)

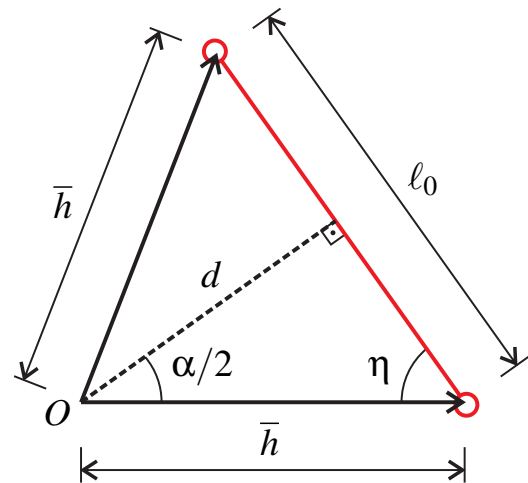

(b)

Fonte: Elaborado pelo autor

na qual $b$ é a distância longitudinal entre dois nós consecutivos.

Para a determinação da energia de deformação do elemento de barra, calcula-se inicialmente o comprimento inicial $\ell_{0}$ da barra e a distância $d$ do ponto de conexão à barra, que ficam dados por:

$$
\begin{aligned}
& \ell_{0}=2 \bar{h} \cos (\eta) \\
& d=\bar{h} \operatorname{sen}(\eta)
\end{aligned}
$$

nas quais $\eta=(\pi-\alpha) / 2$.

A partir dessas dimensões calcula-se a deformação longitudinal da barra em função de $\gamma$ como:

$$
\varepsilon=\frac{\Delta \ell}{\ell_{0}}=\frac{\gamma d}{\ell_{0}}=\frac{1}{2} \gamma \operatorname{tg}(\eta)
$$

A energia de deformação na barra fica então fornecida como:

$$
U_{e}^{\text {barra }}=\frac{1}{2} E \varepsilon^{2} A \ell_{0}=\frac{1}{4} E \gamma^{2} \operatorname{tg}^{2}(\eta) \cos (\eta) A \bar{h}
$$

Igualando-se as expressões (3.25) e (3.22) e isolando-se o produto de rigidez $E A$, resulta:

$$
E A=4 G h_{0} b\left[\operatorname{tg}\left(\frac{\alpha}{2}\right) \operatorname{sen}\left(\frac{\alpha}{2}\right)\right] \frac{h_{0}}{\bar{h}}
$$


Figura 8 - Geometria da conexão utilizada neste trabalho

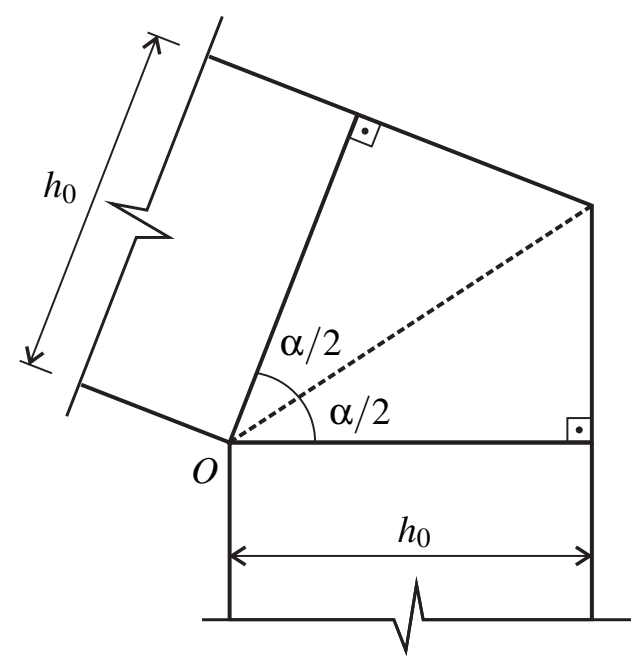

Fonte: Elaborado pelo autor

Para se representar de forma mais precisa a geometria da ligação, sugere-se utilizar a geometria apresentada na Figura 8. Neste caso a energia de deformação é calculada como:

$$
U_{e}^{s o l}=\frac{1}{2} G \gamma^{2} h_{0}^{2} b \operatorname{tg}\left(\frac{\alpha}{2}\right)
$$

Executando-se os mesmos procedimentos realizados para a situação anterior, obtém-se o produto de rigidez $E A$ para esta nova situação:

$$
E A=2 G h_{0} b\left[\operatorname{tg}^{2}\left(\frac{\alpha}{2}\right) \sec \left(\frac{\alpha}{2}\right)\right] \frac{h_{0}}{\bar{h}}
$$

Quando o ângulo inicial entre as barras é $\pi / 2$ tem-se $E A=2 \sqrt{2} G b h_{0}^{2} / \bar{h}$, considerando ambas as expressões (3.26) e (3.28). Essa rigidez aproximada serve para garantir grandezas numéricas coerentes. Assim, caso os panos de placa (ou casca) possuam alturas e/ou módulos de elasticidade diferentes, sugere-se que se escolham valores médios para cálculo.

A seguir apresenta-se a formulação do elemento finito de barra simples que será utilizado para restringir o giro relativo entre os vetores generalizados dessas regiões. Em seguida, apresentase também a restrição via multiplicador de Lagrange, neste caso utilizado para simular uma ligação rígida.

\subsubsection{Elemento finito de barra simples}

Para o elemento finito de barra simples, que faz parte da conexão entre os vetores generalizados, será utilizada também a lei constitutiva de Saint-Venant-Kirchhoff. Para este elemento a energia específica de deformação fica dada por:

$$
u_{e}(\mathbb{E})=\frac{E}{2} \mathbb{E}^{2}
$$


sendo $E$ o módulo de elasticidade adotado para o elemento de barra e $\mathbb{E}$ a deformação de Green, que no caso de elemento unidimensional fica dada por:

$$
\mathbb{E}=\frac{1}{2}\left(\frac{\ell^{2}}{\ell_{0}^{2}}-1\right)=\frac{1}{2}\left[\frac{\left(\bar{G}_{12}-\bar{G}_{11}\right)^{2}+\left(\bar{G}_{22}-\bar{G}_{21}\right)^{2}+\left(\bar{G}_{32}-\bar{G}_{31}\right)^{2}}{\left(N_{12}^{0}-N_{11}^{0}\right)^{2}+\left(N_{22}^{0}-N_{21}^{0}\right)^{2}+\left(N_{32}^{0}-N_{31}^{0}\right)^{2}}-1\right]
$$

sendo $\ell_{0}$ e $\ell$ os comprimentos do elemento nas configurações inicial e atual, respectivamente, $\bar{G}_{i j}$ a componente $i$ do vetor generalizado $j$ e $N_{i j}^{0}$ a componente $i$ do versor normal $j$, conforme Figura 9.

Figura 9 - Elemento de barra simples conectando dois vetores generalizados

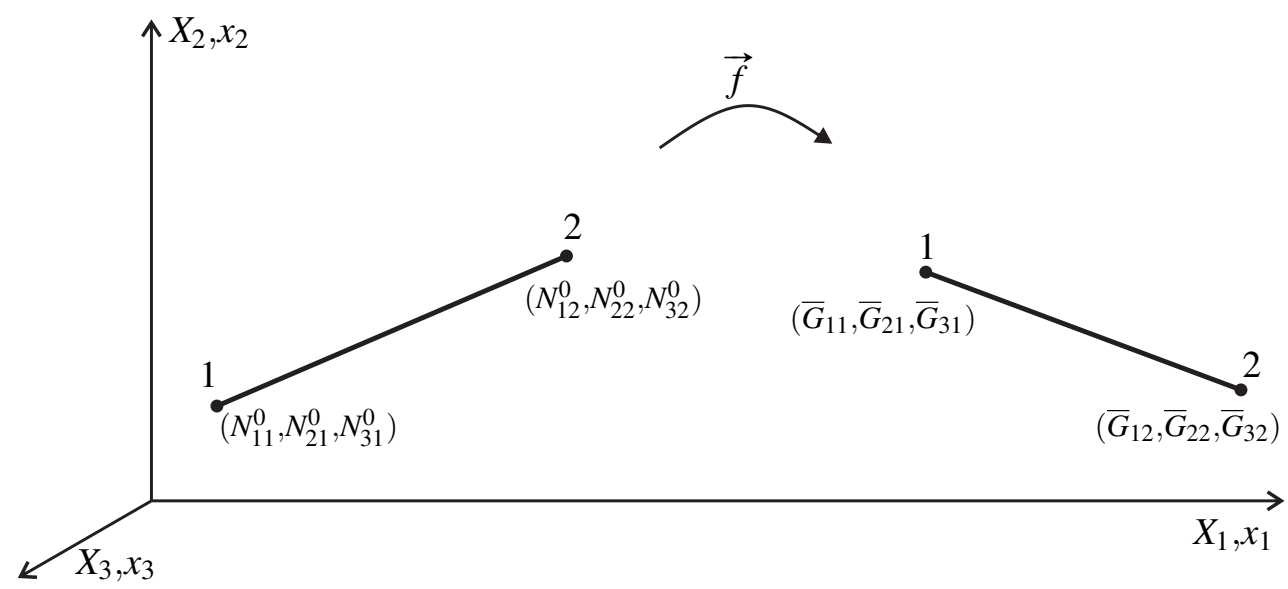

Fonte: Elaborado pelo autor

Considerando como hipótese cinemática que a área da seção transversal do elemento é constante, a energia de deformação para um elemento finito fica dada por:

$$
\mathbb{U}=\int_{V_{0}} u_{e} d V_{0}=\frac{1}{2} \ell_{0} A_{0} E \mathbb{E}^{2}
$$

sendo $A_{0}$ a área da seção transversal do elemento.

Portanto, a força interna a ser contribuída no vetor global de forças internas da estrutura é dada pela derivada da expressão (3.31) em relação as posições nodais. Nesse caso, as posições são dadas pelas coordenadas dos vetores generalizados e a força interna contribuirá nos respectivos graus de liberdade globais. A força interna do elemento fica então dada por:

$$
F_{i}^{i n t}=\frac{\partial \mathbb{U}}{\partial x_{i}}=\frac{\partial \mathbb{U}}{\partial \mathbb{E}} \frac{\partial \mathbb{E}}{\partial x_{i}}=\ell_{0} A_{0} E \mathbb{E} \frac{\partial \mathbb{E}}{\partial x_{i}}
$$

sendo $x_{i}=\bar{G}_{\alpha \beta} \operatorname{com} i=3(\beta-1)+\alpha$. 
Derivando-se mais uma vez a energia de deformação obtém-se a matriz hessiana para o elemento de barra simples, que também na matriz hessiana global nos graus de liberdade dos vetores generalizados correspondentes. A matriz hessiana do elemento fica então dada por

$$
H_{i j}=\frac{\partial^{2} \mathbb{U}}{\partial x_{i} \partial x_{j}}=\ell_{0} A_{0} E\left(\frac{\partial \mathbb{E}}{\partial x_{i}} \frac{\partial \mathbb{E}}{\partial x_{j}}+\mathbb{E} \frac{\partial^{2} \mathbb{E}}{\partial x_{i} \partial x_{j}}\right)
$$

Por fim, determinam-se as derivadas primeira e segunda da deformação de Green com relação às componentes do vetor generalizado:

$$
\begin{gathered}
\frac{\partial \mathbb{E}}{\partial x_{i}}=\frac{\partial \mathbb{E}}{\partial \bar{G}_{\alpha \beta}}=(-1)^{\beta} \frac{\left(\bar{G}_{\alpha 2}-\bar{G}_{\alpha 1}\right)}{\ell_{0}^{2}} \\
\frac{\partial^{2} \mathbb{E}}{\partial x_{i} \partial x_{j}}=\frac{\partial^{2} \mathbb{E}}{\partial \bar{G}_{\alpha \beta} \partial \bar{G}_{\gamma z}}=(-1)^{\beta+z} \frac{\delta_{\alpha \gamma}}{\ell_{0}^{2}}
\end{gathered}
$$

sendo $i=3(\beta-1)+\alpha, j=3(z-1)+\gamma$ e $\delta_{\alpha \gamma}$ o delta de Kronecker.

\subsubsection{Multiplicadores de Lagrange}

Para que a rotação relativa entre os vetores normais seja restringida, pode-se impor que a distância entre suas extremidades permaneça inalterada e de valor igual ao determinado na configuração inicial. Os vetores generalizados na configuração atual, entretanto, não permanecerão unitários, indicando que a restrição imposta constitui uma aproximação. Essa aproximação, por sua vez, não acarreta em erros consideráveis, pois a variação de espessura é pequena, conduzindo a vetores generalizados aproximadamente unitários.

Para se gerar expressões simples após as derivações, optou-se, sem perda de generalidade, por utilizar o quadrado do comprimento, sendo a equação de restrição a ser imposta dada por:

$$
\ell^{2}-\ell_{0}^{2}=0 \quad \therefore \quad\left(\bar{G}_{11}-\bar{G}_{12}\right)^{2}+\left(\bar{G}_{21}-\bar{G}_{22}\right)^{2}+\left(\bar{G}_{31}-\bar{G}_{32}\right)^{2}-\ell_{0}^{2}=0
$$

A parcela do multiplicador de Lagrange a ser adicionada ao funcional de energia pode ser fornecida como:

$$
\mathbb{L}=\frac{\lambda}{2}\left[\left(\bar{G}_{11}-\bar{G}_{12}\right)^{2}+\left(\bar{G}_{21}-\bar{G}_{22}\right)^{2}+\left(\bar{G}_{31}-\bar{G}_{32}\right)^{2}-\ell_{0}^{2}\right]
$$

na qual $\lambda$ é o multiplicador de Lagrange.

A contribuição na força interna é dada pela derivada primeira do potencial $\mathbb{L}$ com relação aos parâmetros do problema, que resulta em:

$$
\begin{aligned}
\frac{\partial \mathbb{L}}{\partial \bar{G}_{\alpha \beta}} & =(-1)^{\beta}\left(\bar{G}_{\alpha 2}-\bar{G}_{\alpha 1}\right) \lambda \\
\frac{\partial \mathbb{L}}{\partial \lambda} & =\frac{1}{2}\left(\ell^{2}-\ell_{0}^{2}\right)
\end{aligned}
$$


A contribuição na matriz hessiana é dada pela derivada segunda de $\mathbb{L}$, resultando em:

$$
\begin{aligned}
& \frac{\partial^{2} \mathbb{L}}{\partial \bar{G}_{\alpha \beta} \partial \bar{G}_{\gamma z}}=(-1)^{\beta+z} \delta_{\alpha \gamma} \lambda \\
& \frac{\partial^{2} \mathbb{L}}{\partial \bar{G}_{\alpha \beta} \partial \lambda}=\frac{\partial^{2} \mathbb{L}}{\partial \lambda \partial \bar{G}_{\alpha \beta}}=(-1)^{\beta}\left(\bar{G}_{\alpha 2}-\bar{G}_{\alpha 1}\right)
\end{aligned}
$$





\section{CAPÍTULO 4}

\section{ESTABILIDADE ESTRUTURAL}

Neste capítulo serão apresentados alguns conceitos relacionados à estabilidade estrutural. Será apresentada também uma metodologia para introduzir esses conceitos em uma análise numérica com o Método dos Elementos Finitos. Os conceitos apresentados foram extraídos das seguintes referências principais: Timoshenko e Gere (1961), Thompson e Hunt (1973), Reis e Camotim (2000), Simitses e Hodges (2006) e Bažant e Cedolin (2010).

\subsection{Aspectos gerais}

Ao se aplicar um carregamento externo de forma quase estática em uma estrutura, uma configuração deslocada em resposta ao carregamento é determinada. O conhecimento dos deslocamentos dos pontos de uma estrutura devido à atuação de ações externas caracteriza uma situação de equilíbrio (REIS; CAMOTIM, 2000).

A aplicação de pequenas perturbações (ou perturbações infinitesimais) em torno da posição deslocada classificará a estabilidade do equilíbrio atuante. Essa classificação é definida de acordo com a nova configuração assumida pela estrutura após cessada a perturbação. Ressalta-se que essa definição não é válida para perturbações com intensidade finita, pois neste caso é possível que a estrutura consiga encontrar outro ponto de equilíbrio distante do inicial, impossibilitando a classificação do equilíbrio inicial (SIMITSES; HODGES, 2006).

Caso a resposta da estrutura após cessada a perturbação seja de pequena oscilação em torno da configuração deslocada inicial, o equilíbrio é dito estável. Por outro lado, caso não haja o retorno à configuração inicial, diz-se que o equilíbrio é instável. Há ainda uma situação particular de equilíbrio instável denominada equilíbrio neutro ou indiferente, que ocorre quando a configuração imposta pela perturbação também é uma situação de equilíbrio.

Essa classificação pode ser observada intuitivamente na Figura 10, na qual considera-se uma esfera rígida sob a ação da gravidade e posicionada sobre três tipos de superfície. As superfícies côncava, convexa e horizontal proporcionam, nesse caso, situações de equilíbrio estável, instável e indiferente, respectivamente. 
Esse conceito exemplificado para corpo rígido é válido também para corpo deformável, onde, nesse último caso, a avaliação da estabilidade do equilíbrio pode ser realizada a partir de critérios energéticos baseados no teorema de Lagrange-Dirichlet, conforme descrito na próxima seção.

Figura 10 - Situações de equilíbrio (a) estável, (b) instável e (c) indiferente

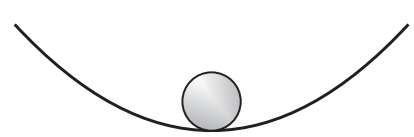

(a)

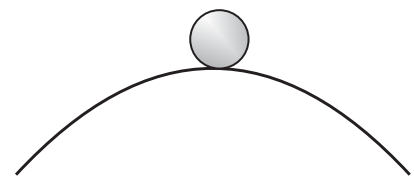

(b)

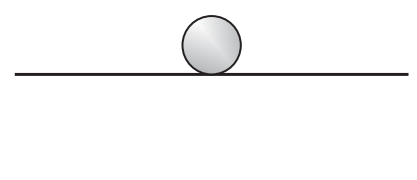

(c)

Fonte: Elaborado pelo autor

\subsection{Teoremas de energia}

O primeiro teorema de energia define a condição de equilíbrio de uma estrutura. Esse teorema afirma que se a primeira variação do funcional de energia é nula a estrutura está em equilíbrio. Essa condição, também denominada de princípio da estacionariedade da energia mecânica, foi utilizada na seção 2.5 para se obter a equação de equilíbrio que rege o problema.

O segundo teorema de energia, denominado de teorema de Lagrange-Dirichlet, pode ser enunciado como: assumindo a energia total como sendo contínua, o equilíbrio do sistema contendo apenas forças conservativas e dissipativas é estável se a energia potencial possui um mínimo local, ou seja, se possui segunda variação positiva (BAŽANT; CEDOLIN, 2010). Os sistemas que não se enquadram na condição descrita pelo teorema de Lagrange-Dirichlet estão em situação de equilíbrio instável ou crítico ${ }^{1}$.

A segunda variação de П, partindo da Equação (3.9), é fornecida pelo segundo termo da expansão em série de Taylor (BAŽANT; CEDOLIN, 2010):

$$
\delta^{2} \Pi=\frac{1}{2 !} \delta x_{i} \frac{\partial \Pi}{\partial x_{i} \partial x_{j}} \delta x_{j}=\frac{1}{2} \delta x_{i} \frac{\partial \mathbb{U}}{\partial x_{i} \partial x_{j}} \delta x_{j}=\frac{1}{2} \delta \vec{x}^{T} \cdot \mathbf{H} \cdot \delta \vec{x}
$$

o que permite concluir que a segunda variação de $\Pi$ está diretamente relacionada com a matriz hessiana determinada no capítulo anterior. Portanto, uma condição suficiente para um sistema possuir condição de equilíbrio estável é:

$$
\delta \vec{x}^{T} \cdot \mathbf{H} \cdot \delta \vec{x}>0
$$

O equilíbrio crítico pode ser de natureza estável ou instável, a depender de variações de ordem superior da energia potencial total. 
o que significa dizer, por definição, que a matriz hessiana deve ser positiva definida, dado que $\delta \vec{x}$ é um vetor arbitrário. Como $\mathbf{H}$ é uma matriz simétrica, uma condição necessária e suficiente para a mesma ser positiva definida é possuir todos os autovalores positivos.

O primeiro teorema de Liapunov define uma condição suficiente para o equilíbrio ser instável e pode ser enunciado como: se a energia potencial na configuração de equilíbrio não é mínima e se a ausência de um mínimo é causada pelos termos de segunda ordem na expansão em série de Taylor da energia potencial, então o sistema é instável (BAŽANT; CEDOLIN, 2010). Em outras palavras, o teorema afirma que uma condição suficiente para o equilíbrio ser instável é ocorrer $\delta^{2} \Pi<0$ para algum $\delta \vec{x}$, ou seja, se pelo menos um autovalor de $\mathbf{H}$ for negativo. Em particular, se todos os autovalores forem negativos, o sistema é instável.

Nas situações de equilíbrio em que se tem $\delta^{2} \Pi=0$ para algum $\delta \vec{x}$, ou seja, se pelo menos um autovalor de $\mathbf{H}$ é nulo, nada se pode afirmar acerca da estabilidade do equilíbrio. Diz-se nessas situações que o equilíbrio é crítico. Entretanto, em uma análise incremental, o conhecimento desses pontos é de grande interesse, pois, em geral, eles definem a localização na trajetória de equilíbrio na qual a condição passa de estável para instável, ou vice-versa. Devido a essa característica, esses pontos são denominados pontos críticos.

Uma matriz simétrica tem como propriedade possuir apenas autovalores reais e ser diagonalizável. Logo, o determinante de $\mathbf{H}$ pode ser determinado por meio da matriz diagonalizada como:

$$
\operatorname{det}(\mathbf{H})=\lambda_{1} \lambda_{2} \ldots \lambda_{n}
$$

na qual $\lambda_{1}, \lambda_{2}, \ldots, \lambda_{n}$ são os $n$ autovalores da matriz $\mathbf{H}$ de ordem $n \times n$.

Portanto, na situação onde se tem pelo menos um autovalor nulo, como no equilíbrio crítico, tem-se necessariamente que:

$$
\operatorname{det}(\mathbf{H})=0
$$

\subsection{Tipos de perda de estabilidade}

Em uma análise incremental-iterativa determina-se a trajetória de equilíbrio, que é definida como a sucessão de configurações de equilíbrio que a estrutura pode assumir quando submetida a uma determinada causa física que varia de forma incremental. Para cada configuração de equilíbrio da trajetória uma análise de estabilidade pode ser realizada. Eventualmente, um ponto crítico pode ser alcançado e, a depender da característica da trajetória, esse ponto pode ser classificado em um dos seguintes tipos: ponto limite ou ponto de bifurcação.

A identificação do tipo de ponto crítico atingido é importante em uma análise incrementaliterativa e define a característica da perda de estabilidade associada. Os tipos de instabilidade por ponto de bifurcação e por ponto limite estão descritos respectivamente nas próximas subseções. 


\subsubsection{Instabilidade bifurcacional}

Define-se ponto de bifurcação como o ponto a partir do qual surge mais de uma trajetória de equilíbrio possível, sendo pelo menos uma delas instável. Entre as trajetórias pós-críticas destaca-se a chamada trajetória fundamental, que pode ser caracterizada pelo seu início na origem do gráfico força-deslocamento e pela mudança da situação de equilíbrio de estável para instável ao ultrapassar o ponto de bifurcação (REIS; CAMOTIM, 2000).

Uma situação de instabilidade bifurcacional pode ser observada na Figura 11. Identificase na figura os trechos estável e instável da trajetória fundamental, bem como as demais trajetórias que partem do ponto de bifurcação.

Figura 11 - Instabilidade bifurcacional e trajetórias pós-críticas

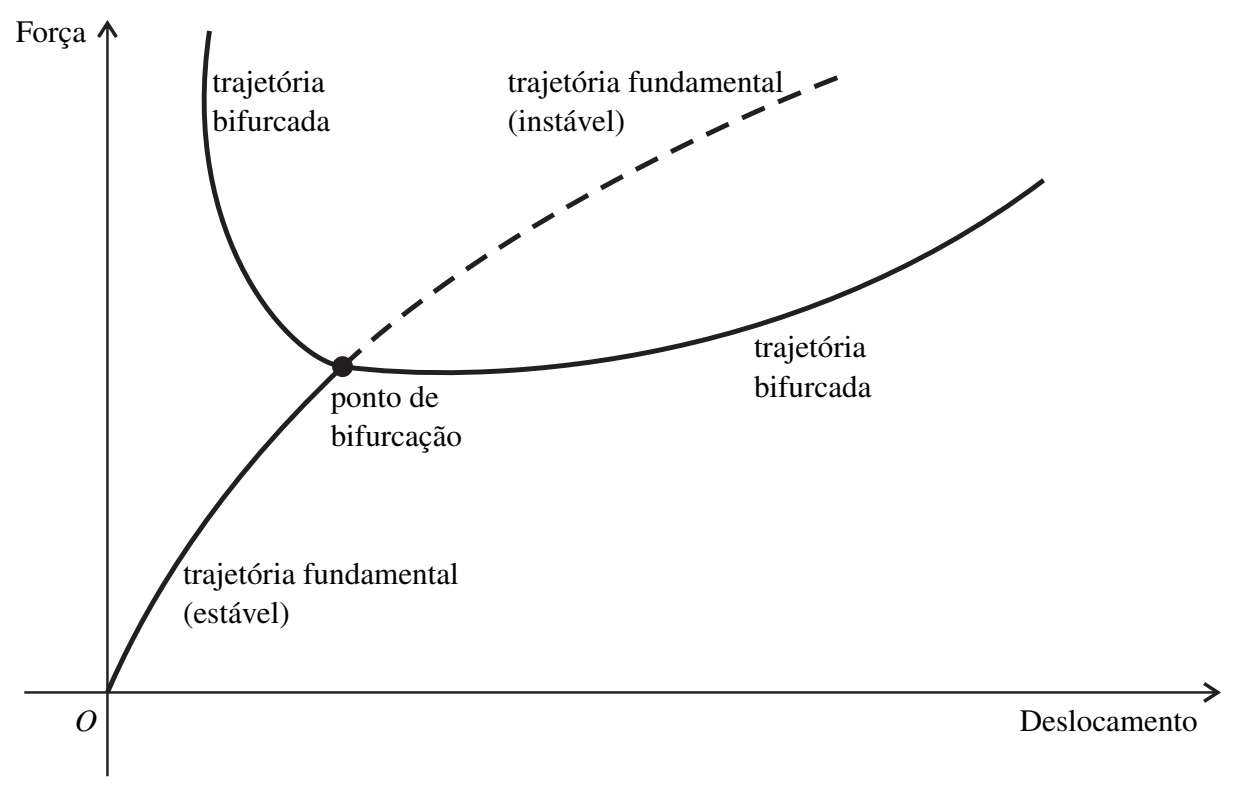

Fonte: Elaborado pelo autor

A instabilidade bifurcacional tem por característica a ocorrência de grandes deslocamentos de forma abrupta. Isso se dá pela redução repentina de rigidez causada pela presença da não-linearidade geométrica. Com isso, a determinação precisa dos pontos de bifurcação é possível apenas com análises não-lineares que incluem a determinação da trajetória de equilíbrio. Contudo, a depender da característica da trajetória fundamental, uma análise em pequenos deslocamentos, como a descrita na próxima seção, pode fornecer uma boa estimativa para os valores de carregamento críticos e modos de instabilidade correspondentes.

\subsubsection{Instabilidade por ponto limite}

Define-se ponto limite como o ponto no qual se encerra um trecho da trajetória com determinada característica de equilíbrio, sem o aparecimento de bifurcação. Em um gráfico 
força-deslocamento o ponto limite é caracterizado como um ponto de máximo ou mínimo local. Um exemplo é o gráfico apresentado na Figura 12. Nele observam-se dois pontos limites, o primeiro caracterizado pela alteração do equilíbrio de estável para instável (ponto de máximo) e o segundo pela alteração de instável para estável (ponto de mínimo). Nesse tipo de instabilidade, o trecho instável é caracterizado por estar situado entre dois pontos limites.

Devido à característica da trajetória de equilíbrio de uma estrutura que apresente instabilidade por ponto limite, alguns fenômenos podem ocorrer. Por exemplo, ao se aplicar um carregamento gradualmente crescente até se alcançar o ponto limite superior, o acréscimo seguinte fará com que a estrutura sofra um salto em deslocamento, designado na Figura 12 como snap-through. Se após esse salto um decréscimo de força for realizado, pode-se alcançar o ponto limite inferior, a partir do qual um novo salto pode ocorrer, conforme também indicado na Figura 12.

Algo semelhante pode ocorrer quando se realiza o controle em deslocamento. Nesse caso o salto será em força e também pode ocorrer em duas situações, a depender do sentido de aplicação do deslocamento. Esse tipo de salto é denominado snap-back.

Figura 12 - Instabilidade por ponto limite

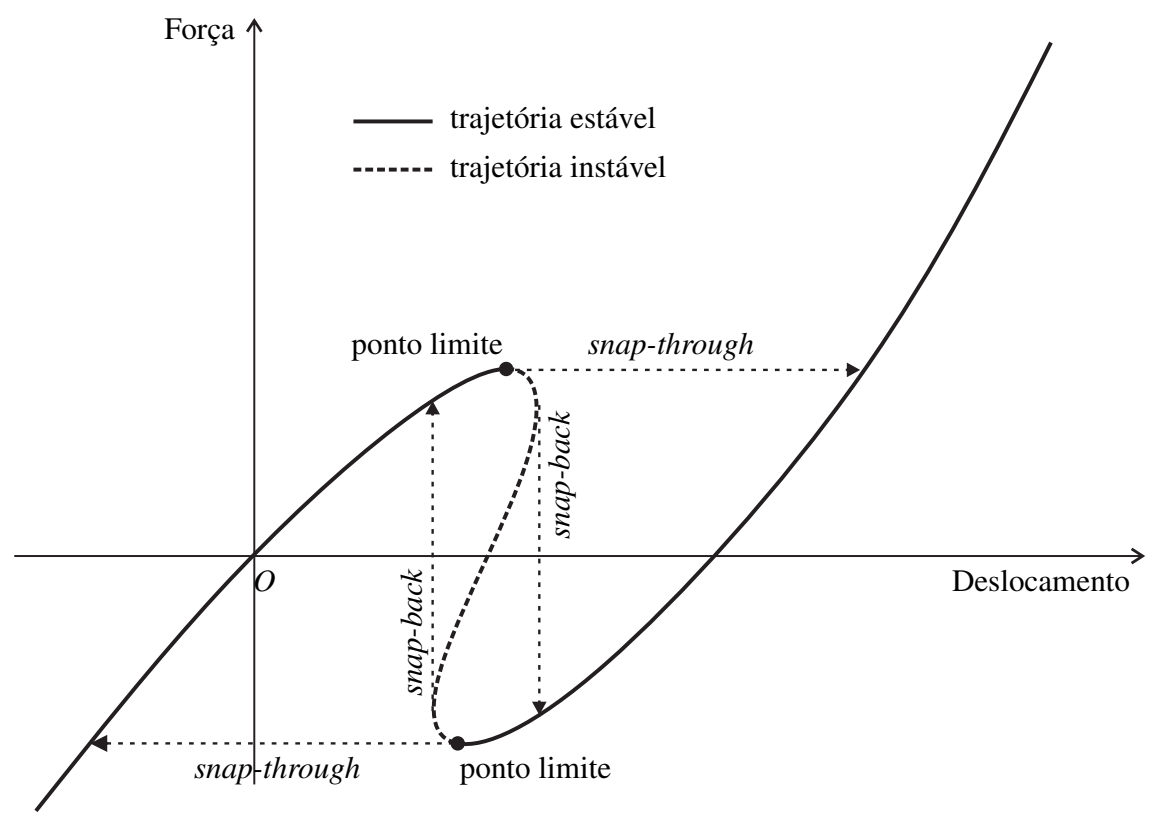

Fonte: Elaborado pelo autor

A obtenção dos pontos limites só é possível com análises que contemplem a determinação da trajetória de equilíbrio. A realização de análise em pequenos deslocamentos não é capaz de prever a existência desses pontos, visto que a ocorrência desse tipo de instabilidade é intrínseca à característica não-linear da trajetória de equilíbrio. 


\subsection{Análise linear de estabilidade}

A análise linear de estabilidade, diferentemente da análise linear de estruturas, tem como base necessária a utilização de uma formulação não-linear geométrica. $\mathrm{O}$ termo 'linear' se refere à estratégia de obtenção das cargas críticas, que pressupõe uma variação linear com a tensão da parcela de rigidez geométrica (escrita em função da tensão atuante), como detalhado mais adiante. A análise fornece também uma previsão qualitativa da configuração assumida pela estrutura no início da trajetória pós-crítica, tendo validade restrita à hipótese de linearidade descrita acima.

Em situações nas quais o comportamento linear da rigidez geométrica não é observado, como em estruturas sujeitas a grandes deslocamentos, as previsões da análise linear de estabilidade podem não serem confirmadas e até mesmo serem consideravelmente diferentes do observado na realidade. Portanto, entende-se que esses resultados estão restritos também à hipótese de pequenos deslocamentos.

Em termos gerais, esse tipo de análise pode ser realizado tanto em sistemas contínuos quanto em discretos. Dada a dificuldade ou impossibilidade de obtenção de soluções analíticas gerais para sistemas contínuos, opta-se pela adoção de modelos discretos. Esses modelos são gerados a partir do método numérico utilizado para a resolução do problema. Portanto, nesse trabalho particulariza-se a análise linear de estabilidade para obtenção de soluções em conjunto com o MEF posicional.

Retomando-se a Equação (3.17), observa-se que a matriz hessiana do elemento de casca é composta de duas parcelas. A primeira parcela é independente do nível de tensão e é denominada parcela elástica, sendo em pequenos deslocamentos equivalente à matriz de rigidez linear. A segunda parcela é dependente do nível de tensão e é denominada parcela geométrica. Escrevendose a tensão de Piola-Kirchhoff de segunda espécie $\mathbf{S}$ em função de uma tensão de referência $\overline{\mathbf{S}}$ da forma $\mathbf{S}=\mu \overline{\mathbf{S}}$, sendo essa tensão de referência proveniente de um carregamento que gere pequenos deslocamentos na estrutura e $\mu$ um escalar, a matriz hessiana passa a ser escrita da seguinte forma:

$$
\mathbf{H}=\mathbf{H}_{e}+\mu \overline{\mathbf{H}}_{g}
$$

sendo $\mathbf{H}_{e}$ a parcela elástica e fornecida pela contribuição das matrizes de cada elemento:

$$
\left(H_{e}\right)_{i j}^{\text {elem }}=\int_{V_{0}} \frac{\partial \mathbb{E}_{\alpha \beta}}{\partial x_{i}} \mathfrak{C}_{\alpha \beta \gamma_{z}} \frac{\partial \mathbb{E}_{\gamma_{z}}}{\partial x_{j}} d V_{0}
$$

e $\overline{\mathbf{H}}_{g}$ a parcela geométrica em função da tensão de referência $\overline{\mathbf{S}}$ e fornecida também pela contribuição das matrizes de cada elemento:

$$
\left(\bar{H}_{g}\right)_{i j}^{e l e m}=\int_{V_{0}} \bar{S}_{\alpha \beta} \frac{\partial^{2} \mathbb{E}_{\alpha \beta}}{\partial x_{i} \partial x_{j}} d V_{0}
$$


Essa identificação das parcelas deve ser realizada também para as matrizes oriundas do elemento de barra simples e do multiplicador de Lagrange. Para o elemento de barra simples, a identificação das parcelas é bem semelhante à realizada para o elemento de casca. A partir da Equação (3.33), as parcelas elástica e geométrica são fornecidas como:

$$
\begin{gathered}
\left(H_{e}\right)_{i j}^{b a r r a}=\ell_{0} A_{0} E \frac{\partial \mathbb{E}}{\partial x_{i}} \frac{\partial \mathbb{E}}{\partial x_{j}} \\
\left(\bar{H}_{g}\right)_{i j}^{\text {barra }}=\ell_{0} A_{0} E \mathbb{E} \frac{\partial^{2} \mathbb{E}}{\partial x_{i} \partial x_{j}}=\ell_{0} A_{0} \bar{S} \frac{\partial^{2} \mathbb{E}}{\partial x_{i} \partial x_{j}}
\end{gathered}
$$

em que $\bar{S}=E \mathbb{E}$ é a tensão de Piola-Kirchhoff de referência para o problema unidimensional.

Para o multiplicador de Lagrange, a parcela elástica é aquela que não depende do multiplicador $\lambda$, ou seja:

$$
\left(H_{e}\right)_{i j}^{\text {Lagrange }}=\left(H_{e}\right)_{j i}^{\text {Lagrange }}=(-1)^{\beta}\left(\bar{G}_{\alpha 2}-\bar{G}_{\alpha 1}\right)
$$

em que $i=3(\beta-1)+\alpha$ e $j=7$.

A parcela que depende do multiplicador é a parcela geométrica, que é dada por:

$$
\left(\bar{H}_{g}\right)_{i j}^{\text {Lagrange }}=(-1)^{\beta+z} \delta_{\alpha \gamma} \bar{\lambda}
$$

em que $i=3(\beta-1)+\alpha, j=3(z-1)+\gamma$ e $\bar{\lambda}$ é o multiplicador de Lagrange de referência.

Para que a contribuição do multiplicador de Lagrange, Equação (3.37), ao funcional $\Pi$ possua dimensão de energia, o multiplicador $\lambda$ deve possuir dimensão de força por unidade de comprimento. Com isso, a parcela da matriz hessiana que possua o multiplicador passa a ser dependente do nível de tensão atuante, justificando assim a separação realizada.

Da Equação (4.4) tem-se a condição de determinante nulo da matriz $\mathbf{H}$ para caracterizar um ponto crítico, o que leva à seguinte expressão:

$$
\operatorname{det}(\mathbf{H})=\operatorname{det}\left(\mathbf{H}_{e}+\mu \overline{\mathbf{H}}_{g}\right)=0
$$

que remete ao seguinte problema generalizado de autovalor:

$$
\left(\mathbf{H}_{e}+\mu \overline{\mathbf{H}}_{g}\right) \cdot \vec{u}=\overrightarrow{0}
$$

no qual os valores de $\mu$ que satisfazem a equação são os autovalores e $\vec{u}$ fornece os correspondentes autovetores, nesse caso possuindo significado físico de deslocamentos.

Para exemplificar, considera-se uma viga inicialmente de comprimento $L$ e submetida a uma força de compressão $\bar{P}$ que gera um pequeno deslocamento $\delta$, apresentado em escala 
ampliada na Figura 13. Após conhecido o deslocamento obtido a partir de uma análise linear (pequenos deslocamentos), determina-se as parcelas de rigidez elástica e geométrica e resolve-se o problema de valor principal indicado na Equação (4.13).

Figura 13 - Viga biapoiada sob força de compressão

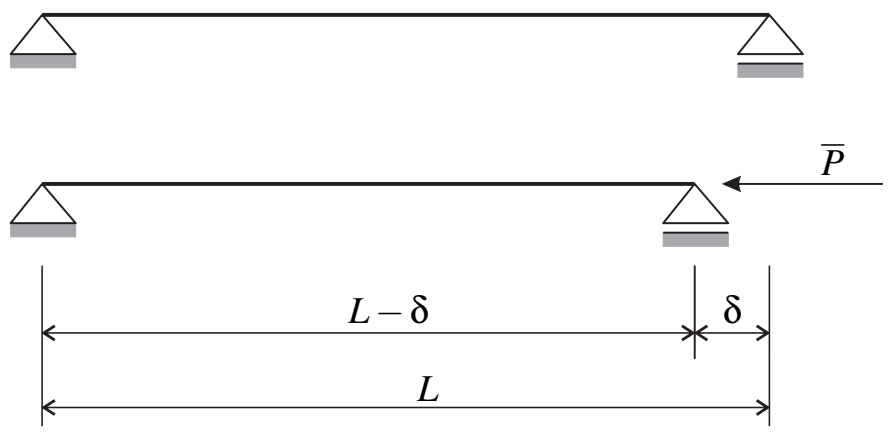

Fonte: Elaborado pelo autor

As cargas críticas são determinadas a partir dos autovalores por meio da expressão $P_{c r}=\mu \bar{P}$ e os modos de instabilidade correspondentes a cada carga crítica são fornecidas a partir dos autovetores. Contudo, sabe-se da Álgebra Linear que os autovetores possuem módulo arbitrário. Portanto, eles indicarão de forma apenas qualitativa os modos de instabilidade, não fornecendo quaisquer informações com relação a intensidades e sentidos reais de deslocamentos. Na Figura 14 apresenta-se o resultado esperado para os primeiros modos de instabilidade do exemplo da Figura 13.

Figura 14 - Modos de instabilidade de viga biapoiada sob força de compressão

Modo 1:

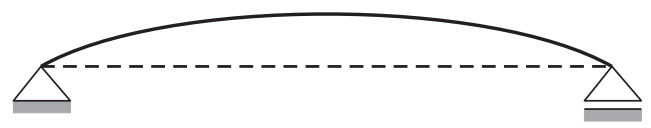

Modo 2:

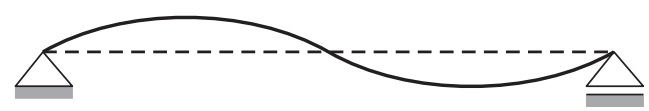

Modo 3:

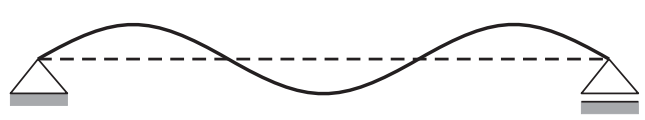

Modo 4:

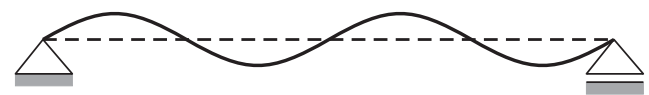

Fonte: Elaborado pelo autor 


\subsection{Análise não-linear de estabilidade}

Uma análise não-linear de estabilidade consiste na verificação das condições de estabilidade ao longo da trajetória de equilíbrio, interessando principalmente a determinação dos pontos críticos e das trajetórias pós-críticas. É com esse tipo de análise que se pode classificar os tipos de instabilidade mencionados anteriormente.

Uma estratégia que pode ser utilizada para tal é a realização de uma análise linear de estabilidade baseada na configuração deformada da estrutura para cada passo de carregamento. Em síntese, essa estratégia significa assumir, por hipótese, um comportamento linear da rigidez geométrica nas proximidades do ponto de equilíbrio determinado, fornecendo melhores previsões da carga crítica à medida em que se aproxima do ponto crítico.

Da mesma forma que para a análise linear de estabilidade, o autovalor obtido fornece o fator com o qual se deve multiplicar a carga atuante para se determinar a carga crítica. Portanto, ao se realizar essa análise a partir da trajetória fundamental, tem-se que os autovalores sempre serão maiores que 1 (trecho estável). À medida em que a análise se aproxima de um ponto crítico, o menor autovalor se aproxima de 1 . No caso de um ponto crítico ser ultrapassado e a análise se mantiver seguindo a trajetória fundamental, o menor autovalor passará a ser menor que 1 (trecho instável). Realizando-se essa análise em cada passo de carregamento, portanto, pode-se facilmente determinar se a trajetória se aproxima de um ponto crítico ou até mesmo quantos pontos críticos já foram ultrapassados.

A determinação das trajetórias pós-criticas expõe uma dificuldade inerente ao método de solução do problema não-linear. Na situação de instabilidade por ponto limite, por exemplo, o método de Newton-Raphson com controle em força não é capaz de determinar o trecho instável da trajetória. Com isso, surge a necessidade de utilização de métodos capazes de percorrer toda a trajetória de equilíbrio, como o método do comprimento de arco (Arc-Length), cujo estudo não faz parte do escopo deste trabalho.

No caso de o ponto crítico ser um ponto de bifurcação, há mais de uma trajetória a se seguir, podendo o método de solução escolher arbitrariamente uma trajetória preferencial. Com isso, surge a necessidade da utilização de estratégias para se especificar a trajetória a ser seguida. Uma estratégia comumente utilizada para a determinação de trajetórias bifurcadas é a imposição de uma imperfeição geométrica na estrutura na configuração inicial. Essa imperfeição age como uma perturbação, fazendo com que durante a análise a estrutura busque um caminho preferencial diferente da trajetória fundamental ao atingir o ponto de bifurcação.

Neste trabalho, a imperfeição geométrica será imposta na forma de força externa, calculada com base no autovetor correspondente ao modo desejado. Assumindo que o autovetor, escalado de forma que os deslocamentos resultem pequenos, fornece uma configuração deformada fictícia para a estrutura, pode-se determinar a força interna correspondente e, em sequência, a força externa por condição de equilíbrio. 
A configuração deformada fictícia pode ser determinada como:

$$
\vec{x}=\vec{X} \pm \alpha \frac{\vec{u}}{\|\vec{u}\|}
$$

onde $\vec{u}$ é o autovetor adotado e $\alpha$ é uma constante arbitrária cujo valor deve ser adotado criteriosamente para que a imperfeição geométrica imposta não resulte com grande intensidade e altere significativamente o comportamento da estrutura. $\mathrm{O}$ sinal \pm indica que pode-se impor a imperfeição em qualquer sentido que se deseje.

Após obtido o vetor atualizado de posições determina-se a força interna por meio da Equação (3.11). Da expressão de equilíbrio fornecida pela Equação (3.10), obtém-se a força externa a ser aplicada fazendo-se $\vec{F}^{\text {ext }}=\vec{F}^{\text {int }}$.

\subsection{Resolução do problema de valor principal}

O problema de valor principal a ser resolvido em uma análise de estabilidade consiste no chamado Problema Generalizado de Autovalor, escrito de forma genérica como:

$$
\mathbf{A} \vec{v}=\mu \mathbf{B} \vec{v}
$$

em que A e B são as matrizes envolvidas no problema.

Grimes, Lewis e Simon (1986) apresentam algumas situações na engenharia estrutural cuja solução recai num problema generalizado de autovalor, como a determinação de frequências naturais e modos de vibração e a determinação de cargas críticas e modos de instabilidade, sendo este último o problema abordado no presente trabalho. Os referidos autores também citam os métodos utilizados para a resolução de problemas desse tipo, especialmente para a resolução de problemas em larga escala que fazem uso de matrizes esparsas.

Para o problema de instabilidade em que A é uma matriz simétrica positiva semi-definida e B é uma matriz simétrica indefinida, Grimes, Lewis e Simon (1986) indicam o algoritmo desenvolvido por Lanczos (1950) para a determinação dos autovalores. O algoritmo inicialmente possuia problemas de instabilidade numérica, o que fez com que seu uso não fosse bem difundido. Paige (1976) propôs uma alteração no método original de forma a resolver esse problema e ampliar sua aplicabilidade. Após essa alteração, o algoritmo passou a receber outras melhorias até que, no final do século passado, Lehoucq, Sorensen e Yang (1998) implementaram uma versão mais estável do algoritmo, denominada Implicit Restarted Lanczos Method (IRLM), em uma biblioteca computacional denominada ARPACK, escrita originalmente em linguagem Fortran 77 e posteriormente também em $\mathrm{C}++$.

A biblioteca ARPACK disponibiliza modos específicos para utilização, a depender do tipo de problema a ser analisado. Esses modos foram implementados com o objetivo de se obter 
melhor taxa de convergência para cada classe específica de problemas. Portanto, utilizou-se no presente trabalho um modo específico voltado para análise de estabilidade estrutural, o qual exige uma modificação no problema original conforme descrito a seguir.

Multiplica-se ambos os termos da Equação (4.15) por um parâmetro real $\sigma$ e em seguida subtrai-se $\mu \mathbf{A} \vec{v}$ de ambos os termos. Após uma reorganização, obtém-se o seguinte problema modificado equivalente ao original:

$$
(\mathbf{A}-\sigma \mathbf{B})^{-1} \mathbf{A} \vec{v}=\frac{\mu}{\mu-\sigma} \vec{v}
$$

o qual pode ser entendido como um problema de valor principal da forma:

$$
\mathbf{C} \vec{v}=v \vec{v}
$$

em que $\mathbf{C}=(\mathbf{A}-\sigma \mathbf{B})^{-1} \mathbf{A}$ e $v=\mu /(\mu-\sigma)$.

Portanto, a resposta do problema original pode ser obtida a partir dos autovalores do novo problema por meio da seguinte expressão:

$$
\mu=\frac{v \sigma}{v-1}=\frac{\sigma}{1-1 / v}
$$

As rotinas da biblioteca ARPACK permitem apenas a determinação dos maiores e/ou menores autovalores do problema modificado. No entanto, o parâmetro $\sigma$ introduzido nas expressões permite a escolha de um espectro diferente de soluções para o problema original.

Há duas situações referentes ao parâmetro $\sigma$ a se considerar: $\sigma>0$ e $\sigma<0$. Nota-se que $\sigma=0$ não deve ser utilizado, pois geraria todos os autovalores iguais a 1 no problema modificado, impossibilitando a determinação dos autovalores do problema original. Observa-se também que, devido à característica do problema de instabilidade, deve-se ter apenas $\mu>0$ (cargas críticas sempre positivas), o que vai limitar o espectro de $v$ a depender do valor adotado para $\sigma$.

Para a primeira situação, $\sigma>0$, o espectro possível para $v$ fica dado pelo intervalo $\mathbb{R} \backslash[0,1]$. De acordo com a Equação (4.18), observa-se que quanto maior o valor de $v$, mais o autovalor original $\mu$ se aproxima de $\sigma$ por valores maiores que $\sigma$. De forma semelhante, quanto menor o valor de $v$, mais o autovalor $\mu$ se aproxima de $\sigma$, agora por valores menores que $\sigma$. Conclui-se então que, nessa primeira situação, os autovalores extremos do problema modificado fornecerá autovalores nas proximidades de $\sigma$ para o problema original.

Para a segunda situação, $\sigma<0$, o espectro para $v$ fica limitado ao intervalo aberto $] 0,1[$. Quando $v$ tende a zero, $\mu$ também tende a zero. E quando $v$ tende a $1, \mu$ tende a infinito. Portanto, os autovalores extremos do problema modificado também correspondem aos autovalores extremos do problema original.

É recomendável, no entanto, a utilização de $\sigma>0$, pois os autovalores do problema original nas proximidades de $\sigma$ correspondem a autovalores com boa separação relativa no 
problema modificado, o que garante uma rápida convergência (GRIMES; LEWIS; SIMON, 1994). Isso se deve ao comportamento assintótico observado na Equação (4.18) para v tendendo $\mathrm{a} \pm \infty$.

As rotinas da biblioteca ARPACK foram construídas de forma a não se limitar a tipos específicos de estruturas de matrizes. Para isso, utilizou-se uma estratégia denominada reverse communication, que passa a responsabilidade de manipulação das matrizes para o usuário, tendo o mesmo liberdade para desenvolver uma interface com a estrutura de matriz desejada.

Para o tipo de problema especificado neste trabalho, duas operações com matrizes são exigidas para a realização do processo iterativo: multiplicação matriz-vetor e resolução de sistema linear. Da primeira operação obtém-se um vetor $\vec{z}=\mathbf{A} \vec{v}$ que é utilizado na segunda operação para se obter um vetor $\vec{w}$ a partir da resolução do sistema $(\mathbf{A}-\sigma \mathbf{B}) \vec{w}=\vec{z}$. Observa-se, portanto, que apesar de ser apresentada uma matriz inversa na Equação (4.16), cuja determinação geraria um custo computacional elevado, a operação de resolução de sistema linear elimina a necessidade da determinação explícita dessa matriz.

Mais detalhes sobre a formulação envolvida no processo de determinação dos autovalores e autovetores, bem como sobre as rotinas da biblioteca ARPACK, podem ser encontrados em Grimes, Lewis e Simon (1994) e Lehoucq, Sorensen e Yang (1998). 


\section{CAPÍtULO 5}

\section{PROGRAMA COMPUTACIONAL}

Neste capítulo será apresentado o programa desenvolvido, destacando-se suas principais funcionalidades. Inicialmente apresenta-se a etapa de pré-processamento de dados, onde o usuário define o problema a ser analisado. Em seguida é apresentado o processamento, etapa na qual o programa desenvolvido resolve o problema proposto. Por fim, apresenta-se a etapa de pósprocessamento, que consiste na exibição dos resultados obtidos. Para facilitar o entendimento, essas etapas são apresentadas com a utilização de um exemplo modelo. A janela principal do programa desenvolvido está apresentada na Figura 15.

Figura 15 - Janela principal do programa

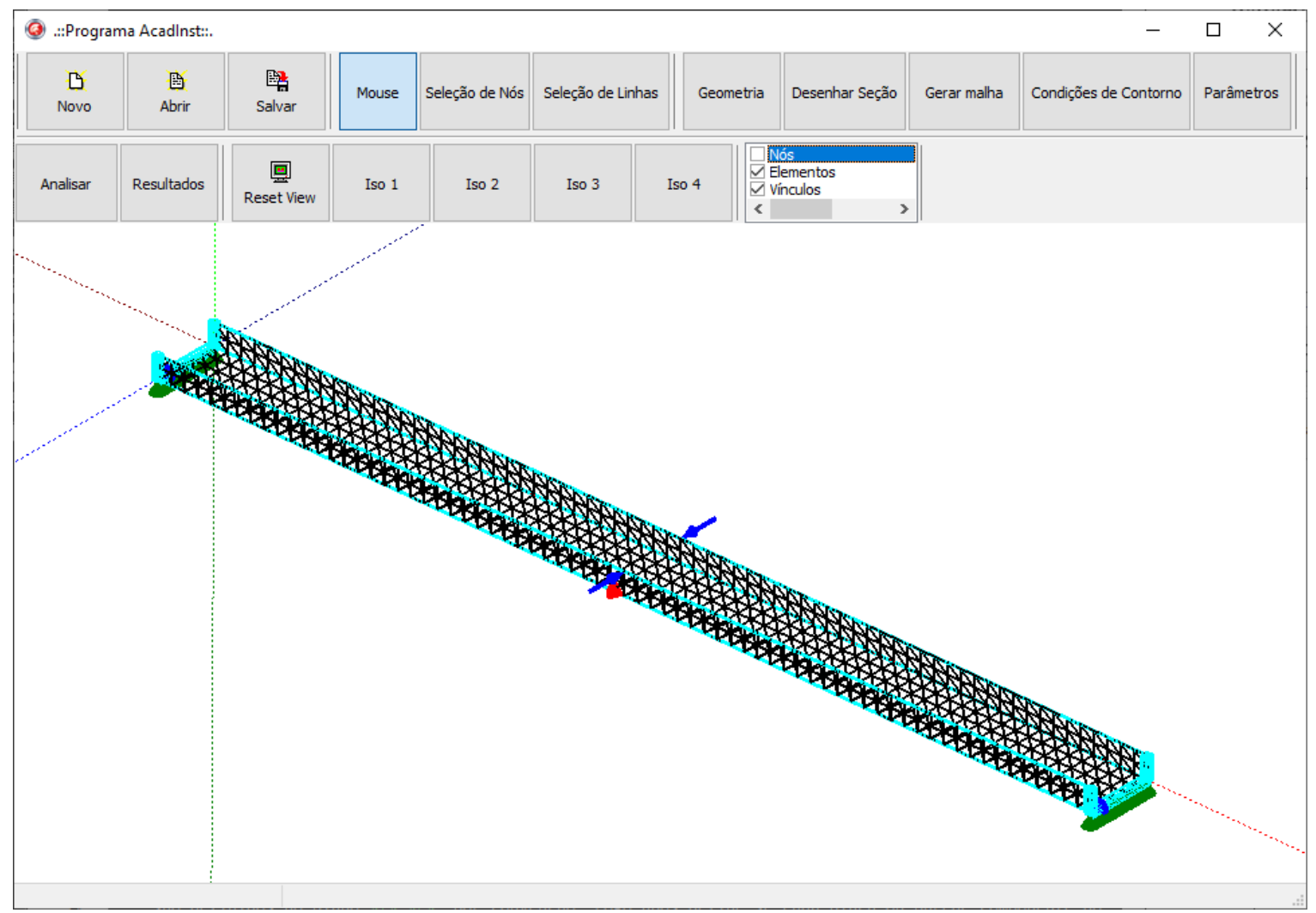

Fonte: Elaborado pelo autor 
A interface na Figura 15 apresenta uma área de representação gráfica de geometria, discretização e condições de contorno aplicadas e uma barra de ferramentas, com a qual é possível a execução de todas as funcionalidades disponíveis no programa.

A barra de ferramentas é dividida em grupos, sendo o primeiro deles o que contém os botões "Novo", "Abrir" e "Salvar", que correspondem às funções básicas para manipulação de arquivos com os dados de exemplos inseridos pelo usuário. O segundo grupo de botões se refere à forma de manipulação da área de representação gráfica, permitindo movimentação livre ou seleção de nós ou linhas. O terceiro grupo corresponde à inserção das informações do prolema, pertinentes à etapa de pré-processamento descrita na próxima seção.

\subsection{Etapa de pré-processamento de dados}

Insere-se inicialmente as informações referentes à geometria, discretização e material. Clicando-se no botão "Geometria" é aberta a janela para a inserção dessas informações, conforme apresentada na Figura 16.

Na seção de materiais insere-se o módulo de elasticidade $(E)$ e o coeficiente de Poisson (v) para cada material que irá compor cada placa ou parede componente do perfil. Em seguida insere-se os nós naturais, que são os pontos necessários para se definir a geometria da seção transversal. Esses pontos são definidos no plano $Y-Z$, por convenção. Logo após define-se cada placa ou parede componente do perfil informando-se a conectividade entre os nós naturais, o número de elementos finitos entre cada nó, o material e a espessura.

Figura 16 - Janela para inserção dos dados de geometria e material

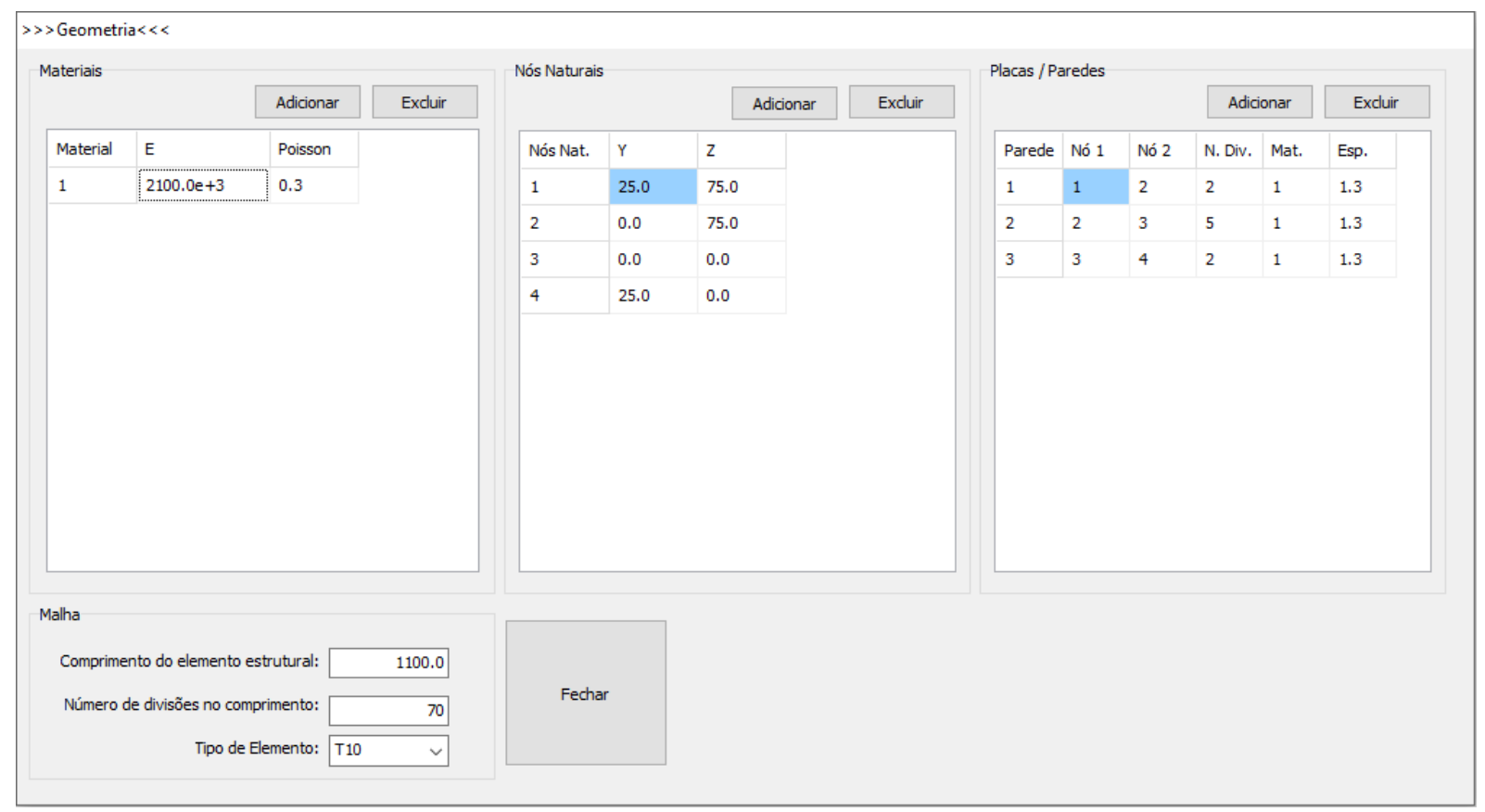

Fonte: Elaborado pelo autor 
As propriedades geométricas da seção transversal a serem preenchidas podem ser melhor compreendidas por meio da descrição apresentada na Figura 17. Na figura, os nós naturais são aqueles que definem a forma geométrica da seção transversal e ficam posicionados sempre nas extremidades de cada placa ou parede. Os nós intermediários são determinados a partir do número de divisões realizadas em cada placa (coluna "N. Div." na Figura 16), sendo cada divisão correspondendo à largura de um elemento finito.

Figura 17 - Definições da seção transversal do exemplo modelo

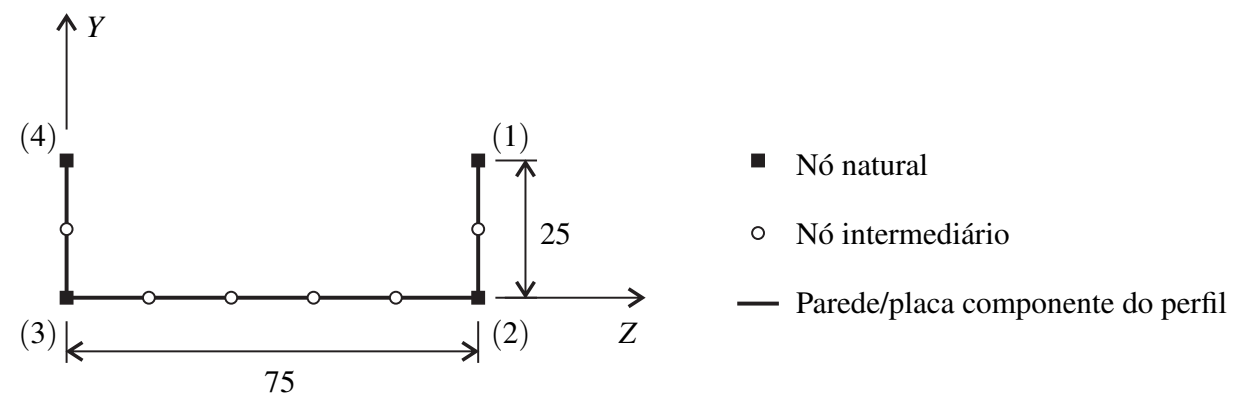

Fonte: Elaborado pelo autor

Encerrando-se a definição da seção transversal, na seção de malha insere-se o comprimento do elemento estrutural, o número de elementos finitos ao longo desse comprimento e o tipo de elemento utilizado. Os elementos disponíveis são: T3, T6, T10, Q4, Q9 e Q16. A letra inicial indica o tipo de elemento, se triangular $(\mathrm{T})$ ou quadrilateral $(\mathrm{Q})$, e o número em seguida representa a quantidade de nós que o elemento possui. Recomenda-se entretanto a utilização dos elementos de mais alta ordem, como o T10 e o Q16, para evitar problemas de travamento volumétrico que podem gerar grandes distorções nos resultados obtidos.

Após o término do preenchimento das informações de geometria e material, clica-se no botão "Desenhar seção" e uma representação da geometria da seção transversal é apresentada. Em seguida, clica-se no botão "Gerar malha" e o programa executa o algoritmo desenvolvido para a geração de malha e apresenta a discretização final de forma gráfica na interface.

Por fim, insere-se as condições de contorno do problema. Essas condições podem ser aplicadas por nó ou por linha de nós. Para isso, o usuário deve clicar em "Seleção de nós" ou "Seleção de linhas". Após realizada a seleção de interesse, clica-se no botão "Condições de contorno", que abrirá a janela apresentada na Figura 18. As condições de contorno possíveis de serem inseridas são em deslocamentos nodais, em forças concentradas nodais e em forças distribuídas ao longo de uma linha.

Na Figura 15, do início deste capítulo, é apresentado o pré-processamento completo, incluindo a discretização e as condições de contorno aplicadas. Os apoios são representados por cones, sendo que as cores vermelho, verde e azul indicam as direções $X, Y$ e $Z$, respectivamente. As forças concentradas são representadas por setas e fazendo-se uso da mesma correspondência 
de cores dos apoios. Por fim, as forças distribuídas são representadas por um cilindro na cor ciano em torno da linha na qual essas forças estão aplicadas.

Para a certificação das condições de contorno aplicadas, uma verificação pode ser realizada apontando-se o cursor do mouse sobre os símbolos que representam essas condições. O programa então retornará na barra de status, situada na parte inferior da janela, os valores referentes àquela condição selecionada.

Figura 18 - Janela para inserção das condições de contorno

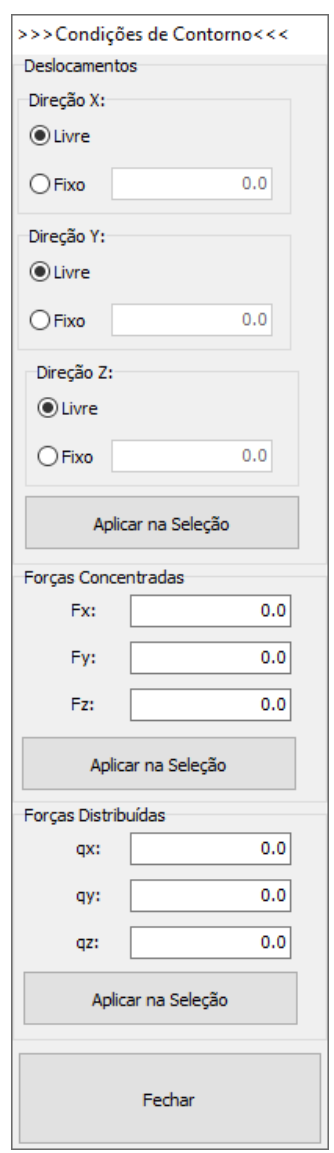

Fonte: Elaborado pelo autor

\subsection{Etapa de processamento}

Antes de se iniciar o processo de solução do problema, define-se alguns parâmetros de execução. Para isso o usuário deve clicar no botão "Parâmetros", que abrirá a janela apresentada na Figura 19. Nesta janela, define-se a tolerância a ser utilizada para o método iterativo de Newton-Raphson e a tolerância para a rotina determinação dos autovalores e autovetores da biblioteca ARPACK. O usuário deve informar também o número de modos críticos que o programa deve determinar. Em geral essa quantidade de modos críticos deve ser pequena o suficiente para se evitar problemas de convergência e custo computacional excessivo. Com isso, encerra-se a inserção das informações necessárias para a execução do programa. 
Figura 19 - Janela para inserção de parâmetros

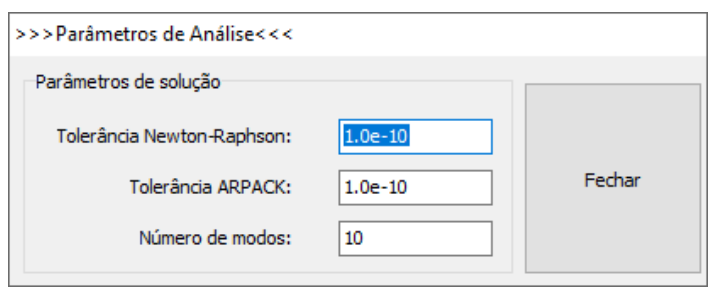

Fonte: Elaborado pelo autor

Retornando-se à janela principal, clica-se no botão "Analisar". Nessa etapa, o programa desenvolvido em Fortran para realizar o processamento é chamado e o programa principal aguarda o término de sua execução para ler os resultados gerados.

\subsection{Etapa de pós-processamento de dados}

Para a visualização dos autovalores basta clicar no botão "Resultados", que abrirá a janela apresentada na Figura 20. Nesta janela, os autovalores são apresentados em uma tabela, juntamente com seus respectivos valores residuais para conferência da precisão da resposta gerada. Esse valor residual é calculado para cada par $(\mu, \vec{u})$ de autovalor e autovetor com base na seguinte norma:

$$
r e s=\frac{\left\|\left(\mathbf{H}_{e}+\mu \mathbf{H}_{g}\right) \cdot \vec{u}\right\|}{|\mu|}
$$

Figura 20 - Janela para exibição dos autovalores computados

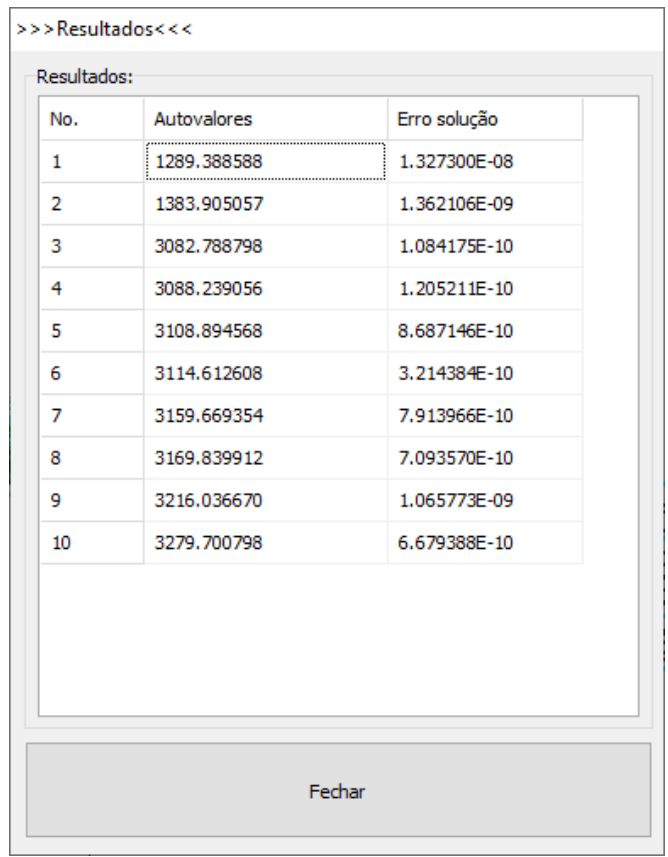

Fonte: Elaborado pelo autor 
Os modos de instabilidade computados nesta versão do programa são exportados para um arquivo em formato compatível para utilização no programa AcadView (PACCOLA; CODA, 2018). Em versões futuras sugere-se acoplar a visualização dos modos de instabilidade ao programa desenvolvido, tornando suas funcionalidades independentes. 


\section{CAPÍtULO 6}

\section{EXEMPLOS NUMÉRICOS}

Neste capítulo serão apresentados os exemplos para validação do código computacional e análises de algumas aplicações. Alguns dos exemplos apresentados foram extraídos de Soares, Paccola e Coda (2019), publicação originada do trabalho desenvolvido.

\subsection{Exemplo 1: Tubo cilíndrico com diafragmas rígidos}

Esse primeiro exemplo é apresentado para validar o código computacional de elemento finito de casca implementado. Os resultados para comparação foram extraídos de Sansour e Kollmann (2000), que utilizou uma formulação de elemento finito de casca que inclui um parâmetro adicional referente à taxa de variação linear da espessura, semelhante ao que foi feito com o elemento de casca de 7 parâmetros nodais apresentado nesse trabalho.

O exemplo consiste em um tubo cilíndrico vazado no qual atuam duas forças de compressão, conforme Figura 21. As extremidades do tubo contêm diafragmas rígidos que impedem a ocorrência de deslocamentos dos pontos das extremidades ao longo dos eixos $X_{2}$ e $X_{3}$. Os dados do problema são: $R=100, L=200, h=1, E=3 \cdot 10^{4}$ e $v=0,3$, sendo $h$ a espessura da parede do tubo.

Dada a simetria do problema, modelou-se apenas a parcela correspondente a um octante do tubo. A discretização adotada utiliza 336 elementos e 1600 nós, conforme apresentado também na Figura 21, totalizando 9600 graus de liberdade se utilizado o elemento finito de 6 parâmetros nodais e 11200 se utilizado o de 7 parâmetros nodais. A carga $P$ possui intensidade 12000, sendo nesse caso aplicada em 50 passos de carregamento.

Os gráficos de deslocamentos dos nós $A$ e $B$ (indicados na Figura 21) obtidos nesse trabalho com as formulações de elemento finito de casca de 6 e 7 parâmetros nodais estão apresentados na Figura 22, juntamente com a solução de referência obtida por Sansour e Kollmann (2000). 
Figura 21 - Tubo cilíndrico com diafragmas rígidos e discretização adotada

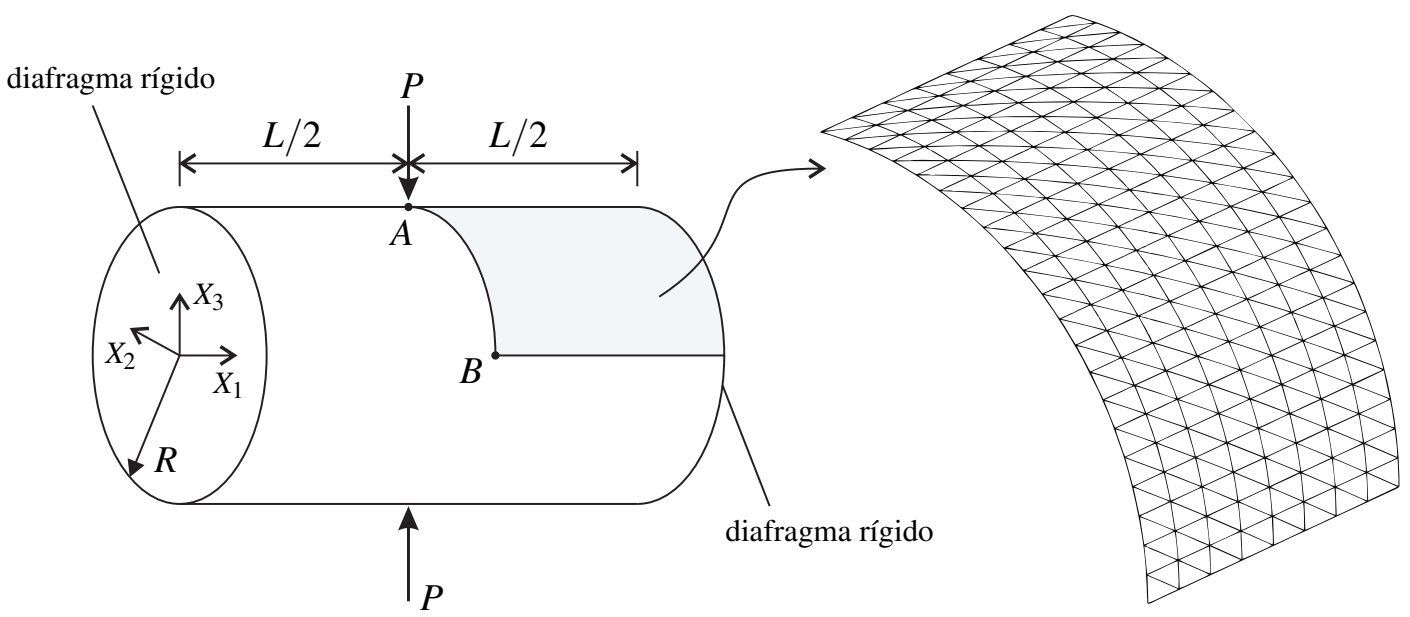

Fonte: Elaborado pelo autor

Figura 22 - Gráfico força x deslocamento dos nos $A$ e $B$

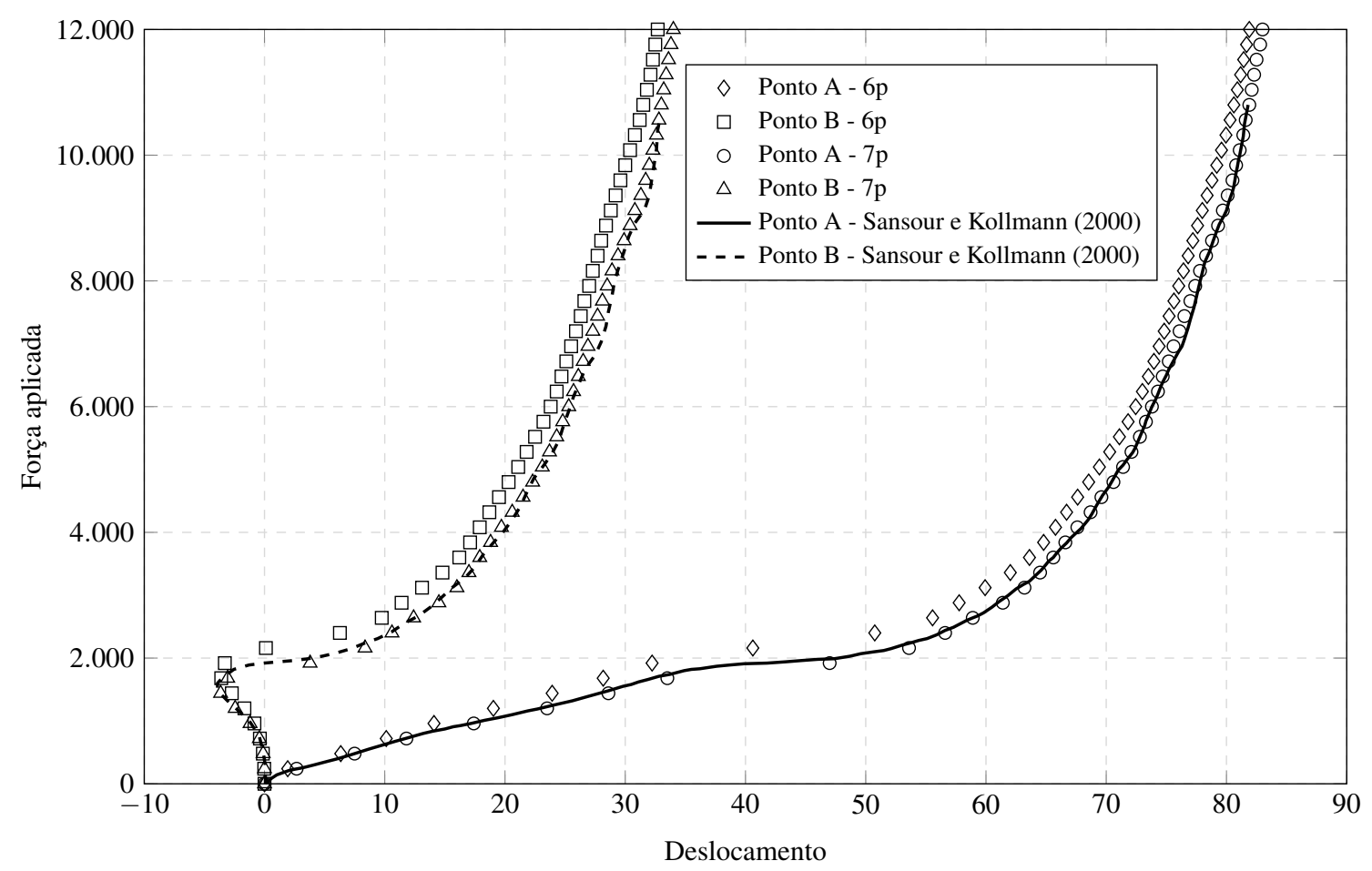

Fonte: Elaborado pelo autor

A partir da Figura 22 observa-se uma boa aderência dos resultados obtidos com os resultados da referência consultada. A diferença maior ocorreu com o elemento finito de 6 parâmetros nodais, que apresentou maior rigidez quando comparado aos demais resultados, como era esperado em virtude da não consideração da taxa de variação da espessura da casca.

Apresenta-se também a configuração deformada do tubo no último passo de carregamento, que pode ser observada na Figura 23. 
Figura 23 - Configuração deformada final do cilindro

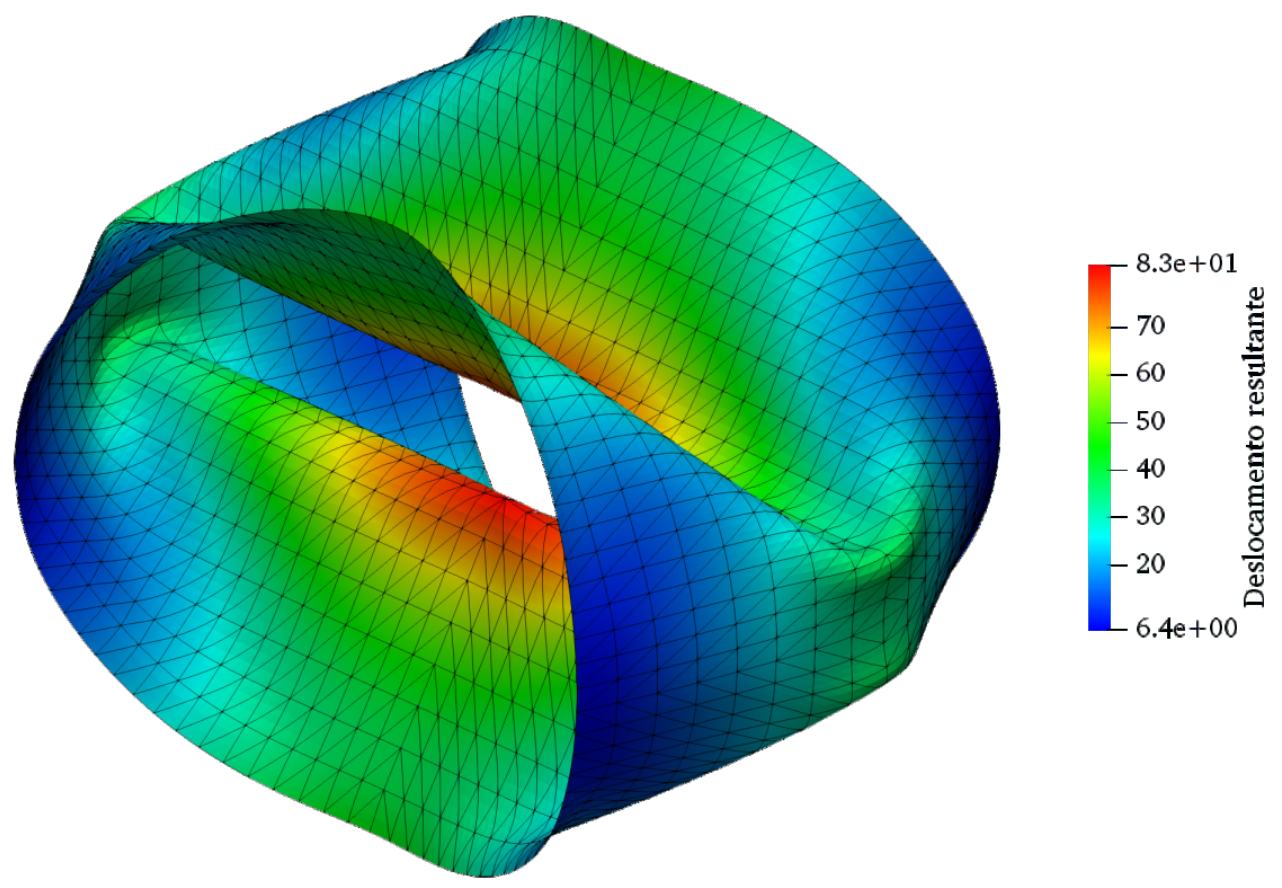

Fonte: Elaborado pelo autor

\subsection{Exemplo 2: Perfil U sob ação de duas forças concentradas}

Este exemplo consiste em um perfil U com uma extremidade engastada e a outra livre. $\mathrm{Na}$ extremidade livre duas forças foram aplicadas no sentido de "fechar" a seção, conforme apresentado na Figura 24. Esse exemplo foi elaborado com o intuito de validar a implementação do acoplamento entre vetores generalizados com o elemento finito de barra simples (penalização) e com multiplicador de Lagrange. As propriedades adotadas foram as seguintes: $L=1,0 \mathrm{~m}$, $h=30 \mathrm{~cm}, b=15 \mathrm{~cm} \mathrm{E}=210 \mathrm{GPa}, \mathrm{v}=0,3, P=10^{5} \mathrm{~N}$ e espessura de $1 \mathrm{~cm}$.

Inicialmente, para testar o desacoplamento dos vetores generalizados, aplicou-se rigidez nula para o elemento de barra simples, tornando a ligação rotulada. Em seguida, aplicou-se o valor de rigidez coerente fornecido pela Equação (3.28). Por último, utilizou-se multiplicadores de Lagrange para simular uma ligação rígida. Esses três testes realizados estão apresentados na Figura 25.

Da Figura 25, nota-se que as implementações foram realizadas corretamente. Com relação ao desacoplamento, caso (a), observa-se que a alma do perfil permaneceu reta ao longo do eixo vertical, indicando que não houve transferência de momentos das mesas do perfil para a alma. Essa transferência, no entanto, ocorreu ao aplicar-se o elemento de barra simples e os multiplicadores de Lagrange, conforme era esperado. 
Figura 24 - Perfil U com uma extremidade engastada e outra livre

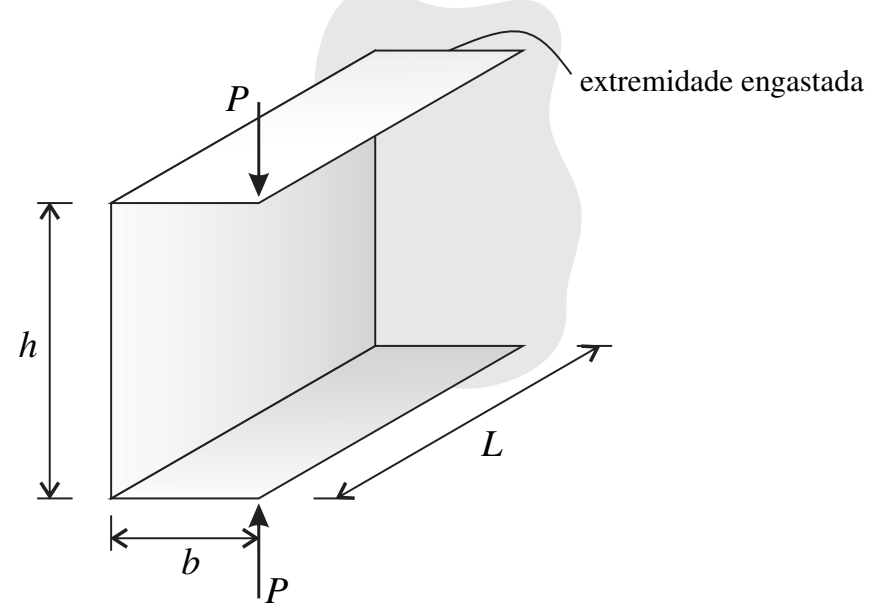

Fonte: Elaborado pelo autor

Figura 25 - Configurações deformadas do perfil U (a) rotulado, (b) com elemento de barra simples e (c) com multiplicador de Lagrange

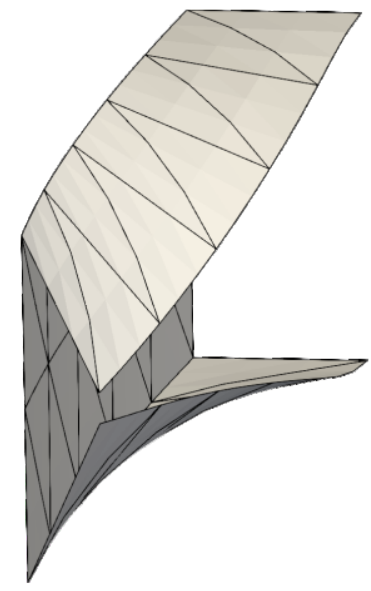

(a)

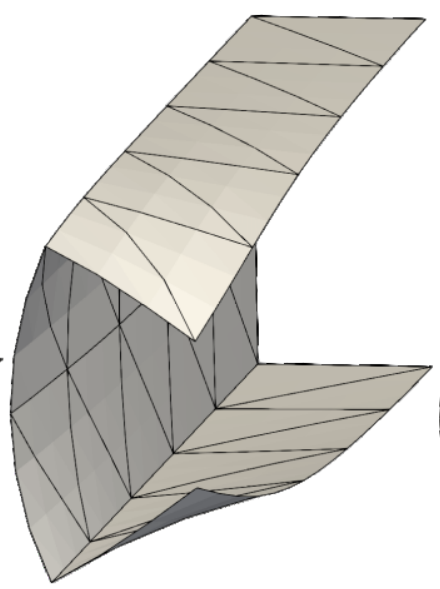

(b)

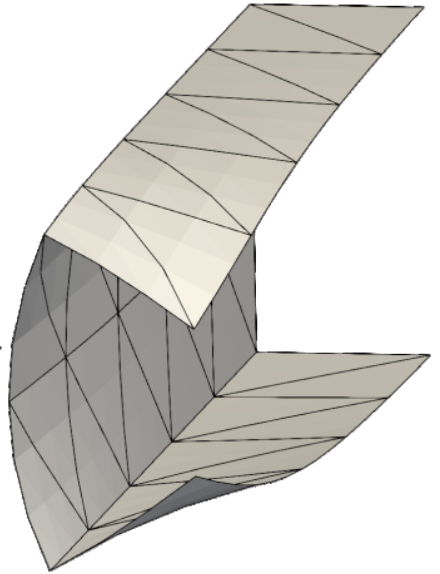

(c)

Fonte: Elaborado pelo autor

Nos casos (b) e (c), o ângulo entre cada mesa e a alma ficou aproximadamente reto, apresentando diferenças mínimas de deslocamento vertical no ponto de aplicação da força. Para a estrutura na qual foi imposto o elemento de barra simples no acoplamento, o deslocamento no ponto de aplicação foi de $8,627 \mathrm{~cm}$ e para a estrutura na qual foi imposta multiplicadores de Lagrange, o deslocamento foi de 8,593 cm.

Observa-se então que a rigidez calculada com a estratégia proposta neste trabalho se aproxima bem de um acoplamento rígido. Em exemplos mais adiante será analisado o efeito da variação dessa rigidez nas análises de estabilidade. 


\subsection{Exemplo 3: Instabilidade em placas}

Este exemplo foi extraído de Kzam (2016), o qual realizou as análises de estabilidade também com o MEF posicional e comparou as respostas obtidas com a solução analítica fornecida pela formulação demonstrada por Timoshenko e Gere (1961).

O exemplo consiste em uma placa considerada simplesmente apoiada nos seus 4 bordos. Na Figura 26 está apresentada a placa, juntamente com os dados e com a discretização adotada. A placa foi discretizada em uma malha de 300 elementos triangulares com aproximação cúbica, totalizando 1456 nós.

Figura 26 - Placa delgada simplesmente apoiada sob compressão

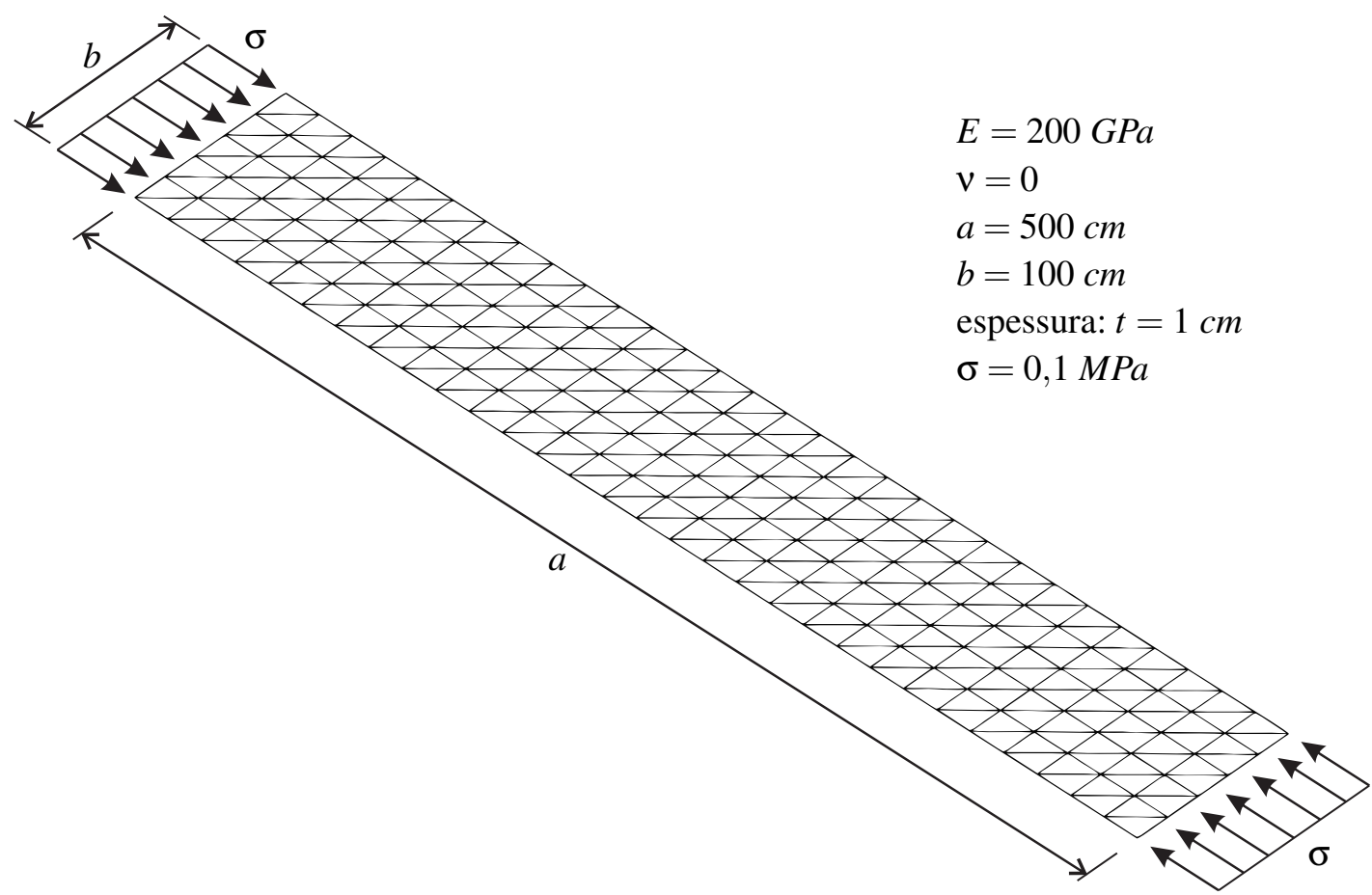

Fonte: Elaborado pelo autor

A carga aplicada desenvolve pequenos deslocamentos na placa. Sendo assim, aplica-se a metodologia para análise linear de estabilidade, resolvendo-se o problema de valor principal. Timoshenko e Gere (1961) apresenta uma solução analítica para essa situação e, para ocorrência de meia-ondas apenas na direção longitudinal, a expressão fica fornecida como:

$$
P_{m}=k D \frac{\pi^{2}}{b^{2}}
$$

com $D=\frac{E t^{3}}{12\left(1-v^{2}\right)}$ e $k=\left(\frac{a}{m b}+\frac{m b}{a}\right)$, sendo $m$ o número de meia-ondas observado no modo crítico.

Os resultados obtidos nesse trabalho, juntamente com os resultados obtidos por Kzam (2016) e com a solução analítica, estão apresentados na Tabela 1, sendo apresentados os valores 
das forças críticas resultantes referentes aos 4 primeiros modos de instabilidade. Os modos de instabilidade correspondentes a essas cargas críticas estão apresentados na Figura 27.

Observa-se a partir da Tabela 1 a boa adequação da formulação posicional do MEF para a determinação precisa de cargas críticas em pequenos deslocamentos, sendo observada uma diferença relativa máxima de apenas $0,51 \%$ com relação à solução analítica apresentada por Timoshenko e Gere (1961).

Tabela 1 - Cargas críticas (em $\mathrm{kN}$ ) de placa simplesmente apoiada

\begin{tabular}{crrr}
\hline Modo & Analítico & Kzam (2016) & Presente trabalho \\
\hline 1 & 657,97363 & 656,59286 & 659,61179 \\
2 & 680,08885 & 678,62658 & 682,65482 \\
3 & 691,28354 & 689,95826 & 692,20126 \\
4 & 735,31910 & 733,73254 & 739,08079 \\
\hline
\end{tabular}

Figura 27 - Modos de instabilidade de placa simplesmente apoiada

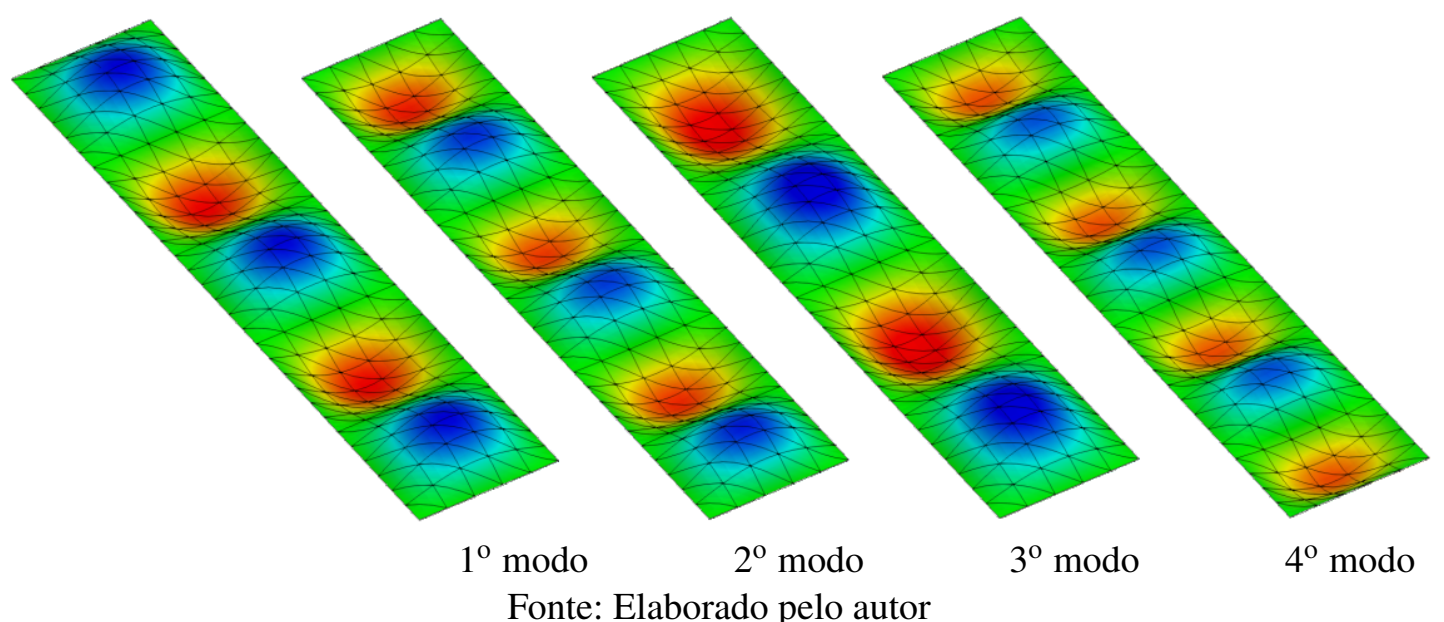

Analisa-se em seguida uma situação na qual seja retirado o apoio de um dos bordos descarregados. Para essa situação, a Equação (6.1) também pode ser utilizada para a determinação das cargas críticas, utilizando-se, porém, o valor de $k$ considerando placas longas, que é fornecido como (HOUBOLT; STOWELL, 1950):

$$
k=\frac{1}{\pi^{2}}\left[6(1-v)+\left(\frac{m \pi b}{a}\right)^{2}\right]
$$

Os resultados para esse caso estão apresentados na Tabela 2 e na Figura 28. Observa-se nessa situação uma boa concordância entre os valores apresentados, com diferença relativa máxima com relação à resposta analítica de 5,0\%. O fato de a expressão analítica ser particularizada para placas longas pode explicar essa diferença maior nos resultados com relação ao caso anterior. 
Tabela 2 - Cargas críticas (em kN) de placa simplesmente apoiada em 3 bordos

\begin{tabular}{crrr}
\hline Modo & Analítico & Kzam (2016) & Presente trabalho \\
\hline 1 & 106,57974 & 105,00878 & 104,99999 \\
2 & 126,31895 & 121,65422 & 121,65344 \\
3 & 159,21763 & 151,38587 & 151,40974 \\
4 & 205,27578 & 194,92271 & 194,99932 \\
\hline
\end{tabular}

Figura 28 - Modos de instabilidade de placa simplesmente apoiada em 3 bordos

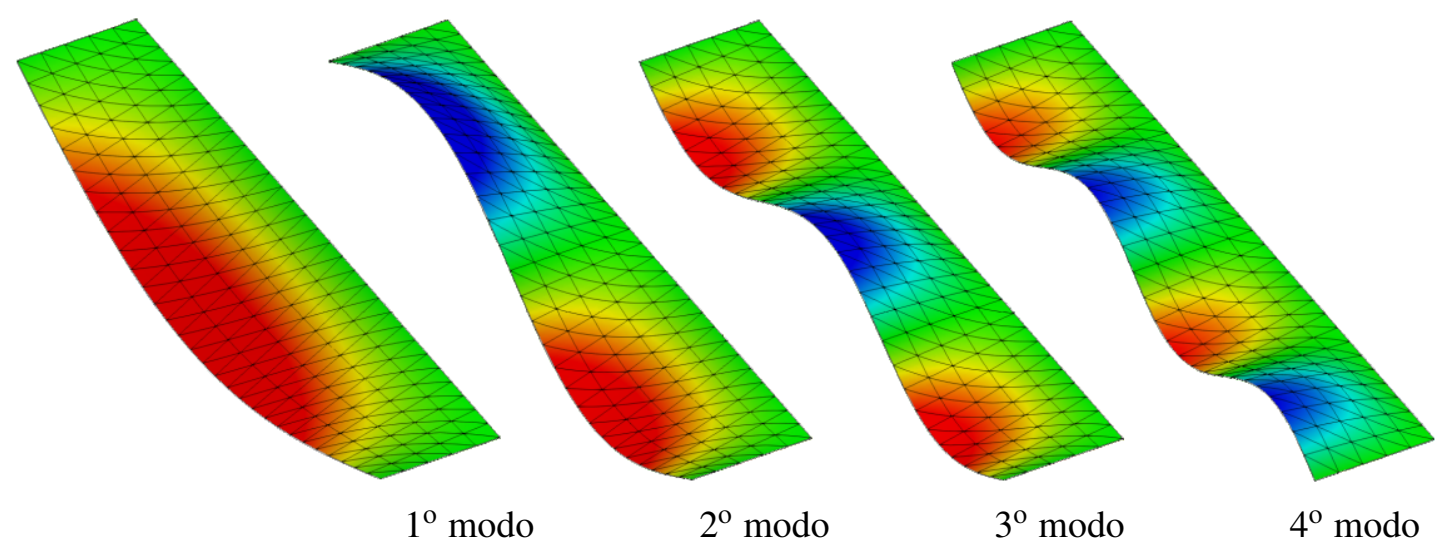

Fonte: Elaborado pelo autor

Um último caso a se analisar é a situação onde apenas os dois bordos menores estão apoiados. Nesse caso, a situação recai no caso clássico de flambagem elástica, para o qual se tem a fórmula de Euler para determinação de carga crítica:

$$
P_{m}=\frac{m^{2} \pi^{2} E b t^{3}}{12 a^{2}}
$$

Os resultados referentes às cargas críticas para essa situação estão apresentados na Tabela 3 e os 4 primeiros modos correspondentes na Figura 29. Os resultados obtidos para esse caso praticamente coincidiram com a resposta analítica, confirmando a boa adequação da formulação. Os modos de instabilidade também ficaram de acordo com o esperado, reproduzindo perfeitamente a solução analítica conhecida.

Apesar de não ser mencionado o elemento finito utilizado, as respostas obtidas com os elementos de 6 e 7 parâmetros nodais foram coincidentes, dado que foi adotado coeficiente de Poisson nulo, inibindo assim a manifestação do fenômeno de travamento volumétrico.

Tabela 3 - Cargas críticas (em kN) de placa biapoiada

\begin{tabular}{crrr}
\hline Modo & Analítico & Kzam (2016) & Presente trabalho \\
\hline 1 & 6,57974 & 6,5796 & 6,57967 \\
2 & 26,31895 & 26,3178 & 26,31795 \\
3 & 59,21763 & 59,2122 & 59,21303 \\
4 & 105,27578 & 105,2600 & 105,26301 \\
\hline
\end{tabular}


Figura 29 - Modos de instabilidade de placa biapoiada

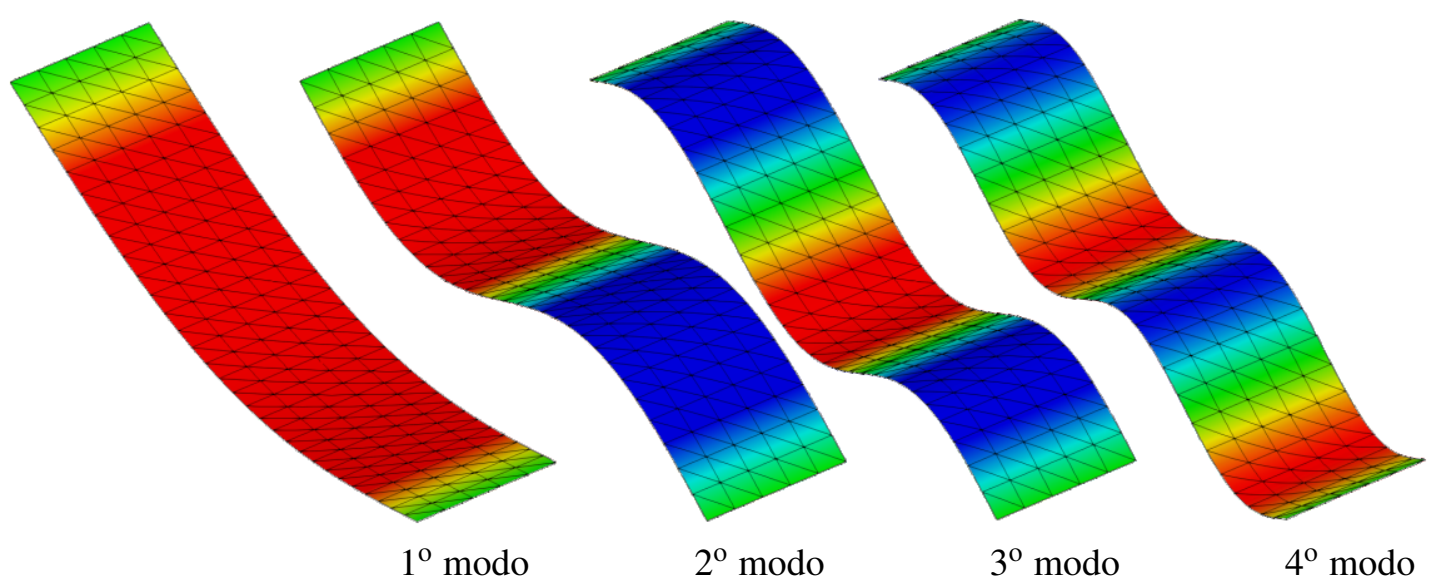

Fonte: Elaborado pelo autor

As soluções analíticas apresentadas neste exemplo foram obtidas por Timoshenko e Gere (1961) considerando-se a cinemática de Kirchhoff-Love. Portanto, as diferenças de resultados, principalmente para os modos de instabilidade locais, podem ser explicadas pela diferença entre as cinemáticas utilizadas.

\subsection{Exemplo 4: Instabilidade em perfil U}

Este exemplo foi extraído de Garcea (2001) e utilizado para validar a análise de estabilidade em uma situação na qual foi necessária a realização do acoplamento entre as partes componentes do perfil. Na Figura 30 são apresentados o esquema estático e as dimensões do problema. Os dados do problema são: $E=2,1 \cdot 10^{6}, v=0,3$ e $q_{x}=1,0$. A vinculação utilizada foi: $u_{z}(0, y, 0)=0, u_{z}(\ell, y, 0)=0, u_{y}(0,0,0)=0, u_{y}(\ell, 0,0)=0$ e $u_{x}(\ell / 2,0,0)=0$.

Para esse problema, três situações com imperfeição foram analisadas. Foram introduzidas imperfeições por flexão, local e por torção, ambas realizadas por meio da introdução de um par de forças concentradas no meio do vão (pontos A e B na Figura 30), direcionadas de forma estratégica para induzir esses defeitos. A rigidez adotada para o elemento de barra simples foi a fornecida pela Equação (3.28), sendo calculada internamente no programa desenvolvido.

As três situações de imperfeições estão apresentadas na Figura 31, juntamente com a discretização adotada para o perfil, que consiste em uma malha de 1260 elementos finitos triangulares com aproximação cúbica e 5908 nós. Sabendo que os deslocamentos da estrutura serão pequenos, adotou-se uma tolerância de $10^{-10}$ em posição para não causar imprecisão nos autovalores a serem obtidos. 
Figura 30 - Esquema estático e detalhe da seção transversal

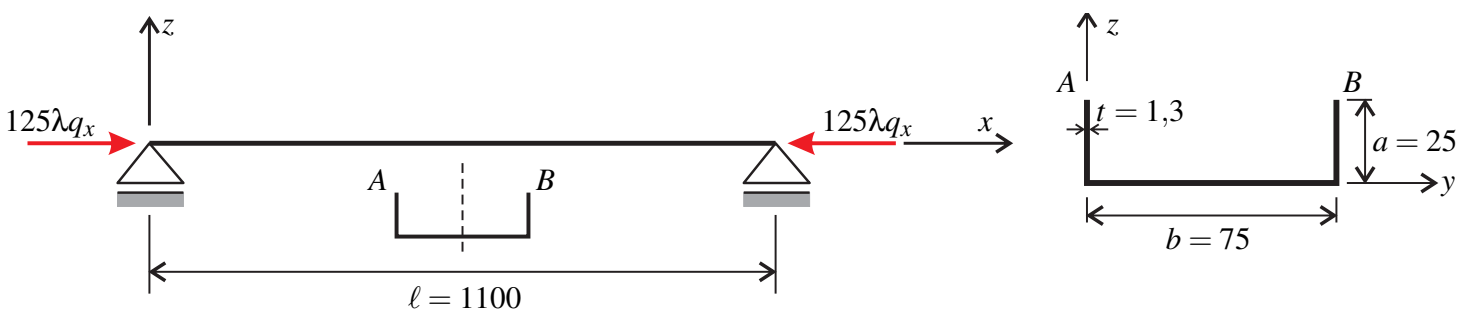

Fonte: Elaborado pelo autor

Figura 31 - Discretização adotada e tipos de imperfeição impostas


Caso 2: imperfeição local

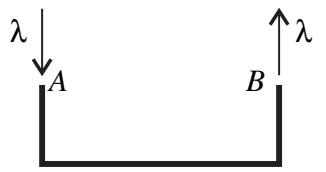

Caso 3: imperfeição por torção

Fonte: Elaborado pelo autor

Os resultados obtidos foram comparados com os apresentados por Garcea (2001), o qual apresentou resultados referentes a duas implementações de elemento finito de casca baseadas na teoria de Koiter, designadas por Mixed e Frozen, e os comparou com os resultados fornecidos por meio do software comercial Nastran.

Os autovalores encontrados para imperfeição por flexão (caso 1) estão apresentados na Tabela 4 juntamente com os valores de referência.

Tabela 4 - Autovalores para modo de imperfeição por flexão

\begin{tabular}{|c|c|c|c|c|c|c|c|}
\hline \multirow[b]{2}{*}{ Modo } & \multicolumn{3}{|c|}{ Garcea (2001) } & \multicolumn{3}{|c|}{ MEF Posicional } & \multirow[b]{2}{*}{ Tipo de modo } \\
\hline & Mixed & Frozen & Nastran & $\begin{array}{l}\text { Penalização } \\
\text { (6p) }\end{array}$ & $\begin{array}{l}\text { Penalização } \\
\text { (7p) }\end{array}$ & $\begin{array}{l}\text { M. Lagrange } \\
\text { (7p) }\end{array}$ & \\
\hline 1 & 1291,6 & 1292,2 & 1298,2 & 1292,2 & 1291,5 & 1291,5 & Flexão \\
\hline 2 & 1396,0 & 1192,5 & 1195,2 & 1189,9 & 1189,0 & 1189,2 & Torção \\
\hline 3 & 1994,4 & 1992,8 & 1919,4 & 2065,3 & 1908,6 & 1918,9 & Local (3 meia-ondas) \\
\hline 4 & 2046,4 & 2044,7 & 2094,5 & 2113,7 & 1954,2 & 1964,7 & Local (4 meia-ondas) \\
\hline
\end{tabular}


Os modos de instabilidade, representado pelos autovetores, estão apresentados na Figura 32, estando os modos de referência apresentados por Garcea (2001) apresentados na Figura 33.

Figura 32 - Modos de instabilidade de perfil U com imperfeição de flexão

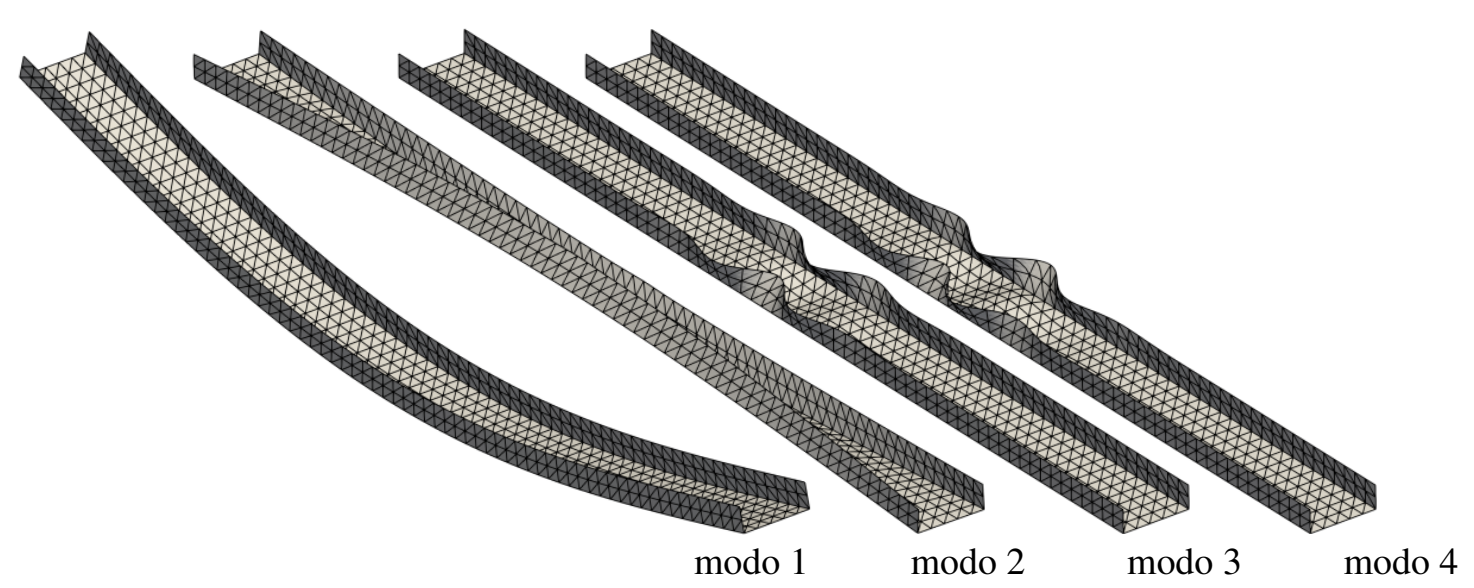

Fonte: Elaborado pelo autor

Figura 33 - Modos de instablidade referência de perfil U com imperfeição de flexão

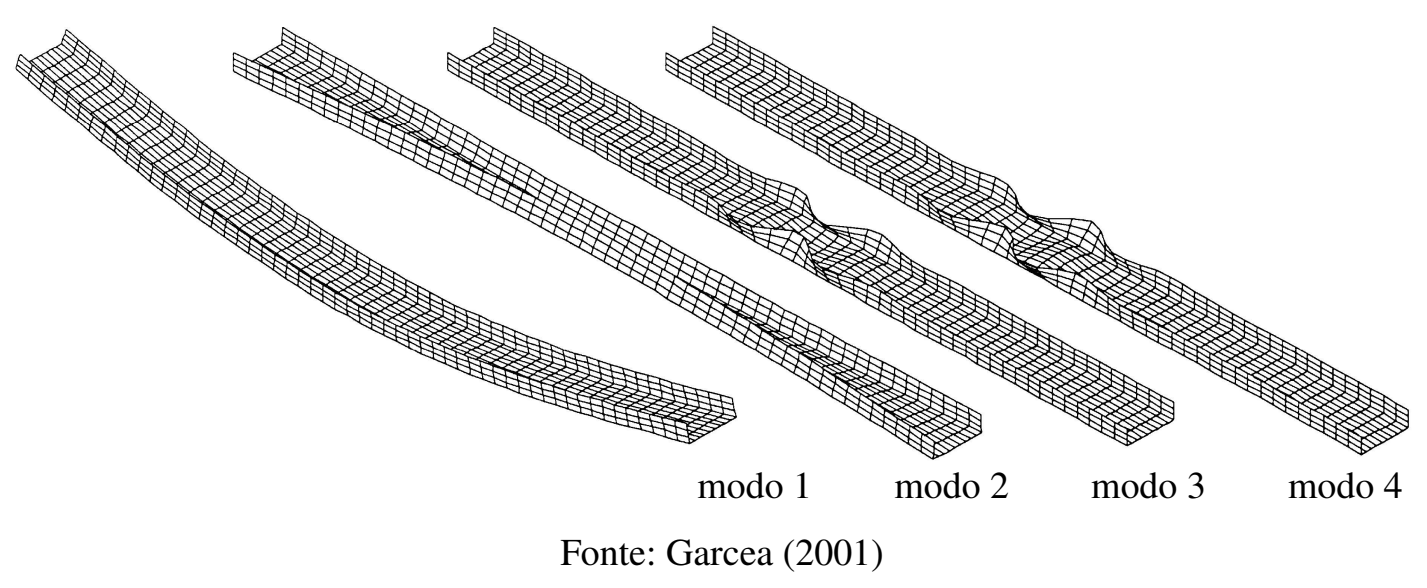

A partir da Tabela 4, nota-se que os valores referentes aos dois primeiros modos, para os elementos de 6 e 7 parâmetros nodais, ficaram semelhantes aos valores apresentados por Garcea (2001). Para os modos 3 e 4, se observou que o elemento de 6 parâmetros apresentou resposta mais rígida que todos os demais e o de 7 parâmetros a resposta mais flexível. Isso provavelmente se deve à liberação de mobilidade inserida no elemento de 7 parâmetros, ao considerar uma taxa de variação linear da espessura, sendo que o elemento de 6 parâmetros não possui essa consideração.

A aplicação do multiplicador de Lagrange apresentou resposta mais rígida quando comparada à aplicação da penalização, como era de se esperar. E também apresentou respostas mais próximas aos valores de referência, sendo estes também obtidos para acoplamento rígido. 
Observa-se ainda que os resultados foram mais sensíveis para os modos locais ( 3 e 4), onde a região do acoplamento é mais solicitada.

Quanto aos modos de instabilidade, de forma qualitativa pode-se afirmar que eles se apresentaram idênticos aos de referência, vide Figuras 32 e 33.

Para o modo de imperfeição local (caso 2), os autovalores encontrados e os de referência estão presentes na Tabela 5. Apresenta-se na Figura 34 os modos de instabilidades associados. Os modos apresentados por Garcea (2001) estão presentes na Figura 35. Observa-se que os modos de instabilidades obtidos possuem exatamente as respectivas quantidades de meia-ondas indicadas na Tabela 5.

Tabela 5 - Autovalores para modo de imperfeição local

\begin{tabular}{lcccccccc}
\hline \multirow{2}{*}{ Modo } & \multicolumn{3}{c}{ Garcea (2001) } & & \multicolumn{3}{c}{ MEF Posicional } & \\
\cline { 2 - 3 } \cline { 6 - 7 } & Mixed & Frozen & Nastran & $\begin{array}{c}\text { Penalização } \\
\mathbf{( 6 p )}\end{array}$ & $\begin{array}{c}\text { Penalização } \\
\mathbf{( 7 p )}\end{array}$ & $\begin{array}{c}\text { M. Lagrange } \\
\mathbf{( 7 p )}\end{array}$ & Tipo de modo \\
\hline 1 & 1293,2 & 1289,9 & 1296,1 & & 1291,3 & 1289,4 & 1289,4 & Flexão \\
2 & 1409,5 & 1387,7 & 1391,2 & & 1383,4 & 1383,9 & 1383,9 & Torção \\
3 & 3150,7 & 3134,3 & 3084,8 & & 3562,9 & 3082,8 & 3082,9 & Local (13 meia-ondas) \\
4 & 3150,9 & 3148,6 & 3097,4 & & 3573,8 & 3088,2 & 3088,5 & Local (14 meia-ondas) \\
\hline
\end{tabular}

Nesse modo de imperfeição, observa-se que, da mesma forma que para o caso 1 , o elemento finito de 7 parâmetros se adequou melhor, sempre apresentando valores menores que os de referência, indicando a boa flexibilidade que a formulação utilizada proporcionou. Contudo, as diferenças observadas podem ser explicadas pela utilização de formulações distintas e também pela discretização e tipo de elemento finito adotados. Com relação à aplicação do multiplicador de Lagrange, observa-se diferenças mínimas se comparada à aplicação da penalização, ou seja, neste caso a rigidez adotada na penalização torna o acoplamento praticamente rígido.

Figura 34 - Modos de instabilidade de perfil U com imperfeição local

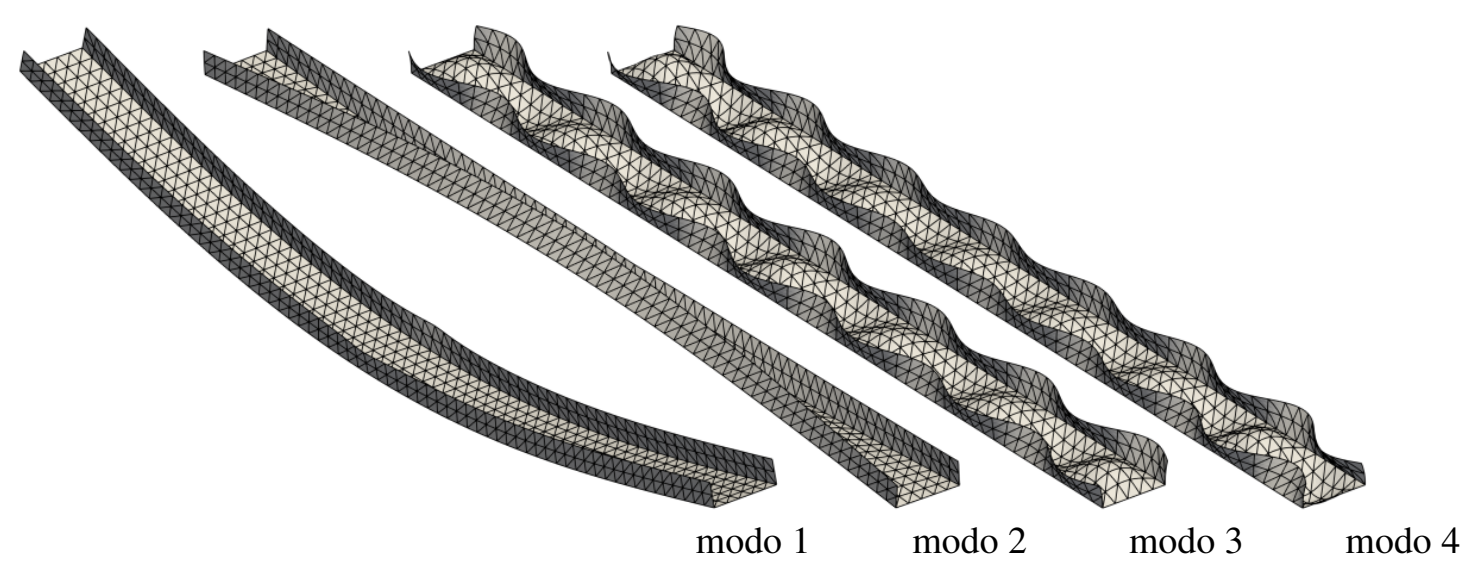

Fonte: Elaborado pelo autor 
Figura 35 - Modos de instablidade de perfil U com imperfeição local

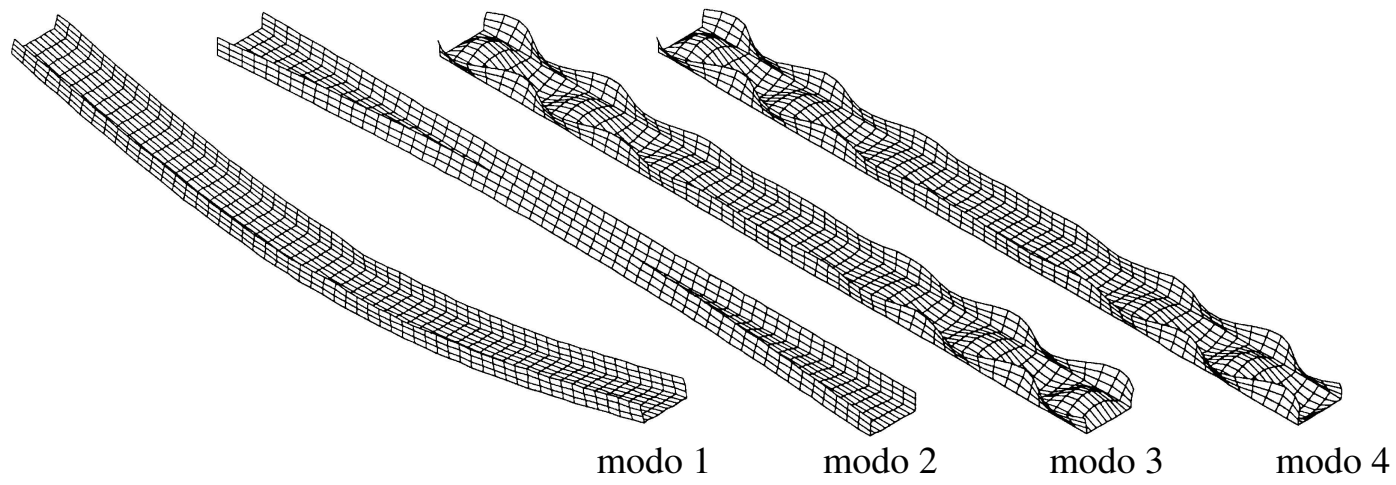

Fonte: Garcea (2001)

Por fim, apresenta-se o modo de imperfeição de torção (caso 3), sendo os resultados obtidos e os tomados como referência apresentados na Tabela 6.

Tabela 6 - Autovalores para modo de imperfeição de torção

\begin{tabular}{lcccccccc}
\hline & \multicolumn{3}{c}{ Garcea (2001) } & & \multicolumn{3}{c}{ MEF Posicional } & \\
\cline { 2 - 3 } Modo & Mixed & Frozen & Nastran & $\begin{array}{c}\text { Penalização } \\
\mathbf{( 6 p )}\end{array}$ & $\begin{array}{c}\text { Penalização } \\
\mathbf{( 7 p )}\end{array}$ & $\begin{array}{c}\text { M. Lagrange } \\
\mathbf{( 7 p )}\end{array}$ & Tipo de modo \\
\hline 1 & 1264,9 & 1289,9 & 1296,0 & & 1291,2 & 1289,4 & 1289,4 & Flexão \\
2 & 1833,9 & 1711,8 & 1715,6 & & 1707,5 & 1706,4 & 1706,4 & Torção \\
3 & 2808,5 & 2912,1 & 2842,4 & & 3192,9 & 2837,5 & 2843,0 & Local (7 meia-ondas) \\
4 & 2823,9 & 2930,0 & 2863,5 & & 3220,9 & 2855,4 & 2860,6 & Local (8 meia-ondas) \\
\hline
\end{tabular}

Apresenta-se na Figura 36 os modos de instabilidade para este caso. Os modos apresentados por Garcea (2001) podem ser observados na Figura 37. Nessa situação de imperfeição observa-se novamente que o elemento finito de 7 parâmetros nodais apresentou resultados melhores, quando comparado com os valores de referência.

Figura 36 - Modos de instabilidade de perfil U com imperfeição de torção

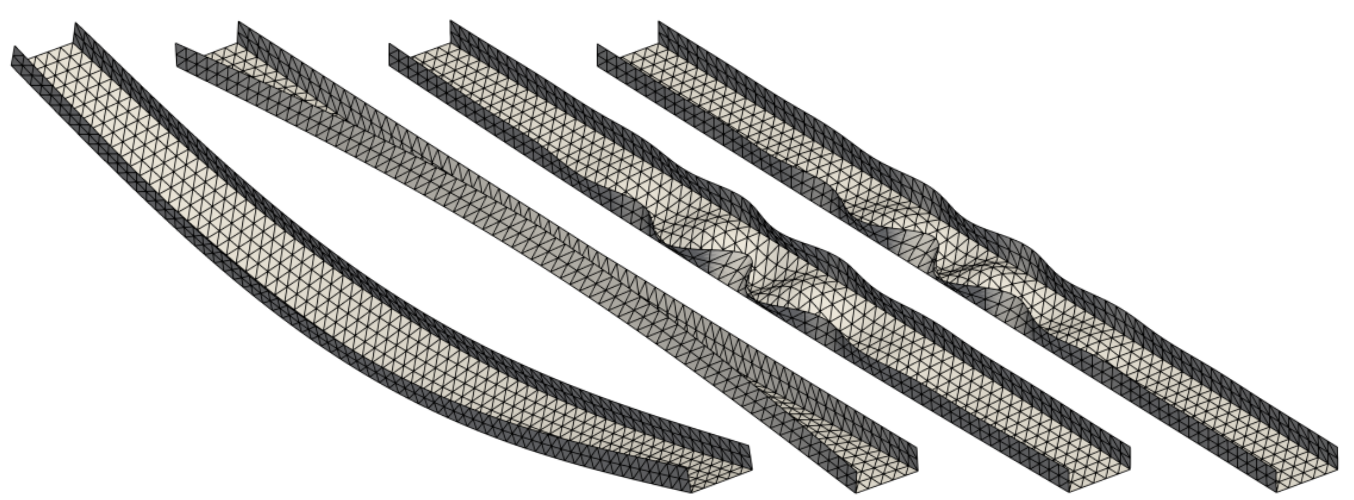

modo $1 \quad$ modo $2 \quad \operatorname{modo} 3 \quad \operatorname{modo} 4$

Fonte: Elaborado pelo autor 
Figura 37 - Modos de instablidade de perfil U com imperfeição de torção

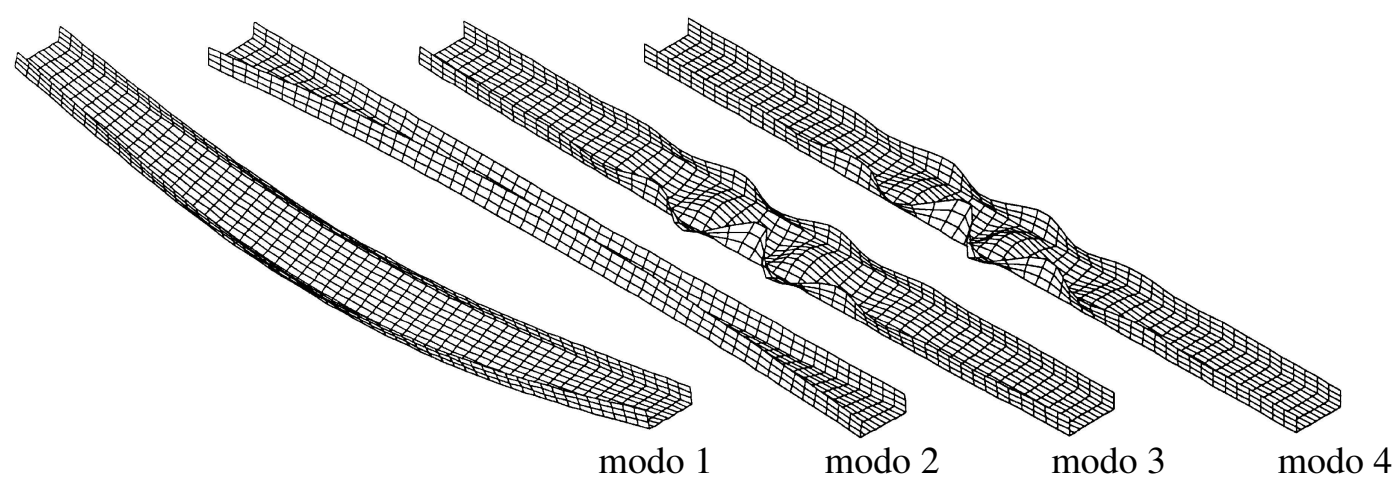

Fonte: Garcea (2001)

Realiza-se também uma análise não-linear de estabilidade para cada uma das situações de imperfeição deste exemplo. O objetivo desta análise é a determinação do primeiro ponto crítico da trajetória de equilíbrio. Para isso foram determinados os autovalores em cada passo de carregamento, sendo utilizado um passo $\Delta \lambda=0,1$, com a análise sendo encerrada no passo em que o menor autovalor mais se aproximou da unidade. Utilizou-se para a análise apenas o elemento finito de 7 parâmetros nodais e acoplamento com penalização. Na Tabela 7 apresenta-se os resultados obtidos com a análise e a solução de referência obtida por Garcea (2001).

Tabela 7 - Cargas críticas para análise não-linear de estabilidade

\begin{tabular}{lccccccc}
\hline \multirow{2}{*}{ Imperfeição } & \multicolumn{3}{c}{ Garcea (2001) } & & \multicolumn{3}{c}{ MEF Posicional } \\
\cline { 2 - 3 } \cline { 7 - 8 } & Mixed & Frozen & Nastran & & Autovalor & Carga atual & Carga crítica \\
\hline Flexão & 900,30 & 908,40 & 896,30 & & 1,000169 & 883,40 & 883,55 \\
Local & 1246,10 & 1284,80 & 1235,42 & & 1,000126 & 1223,60 & 1223,75 \\
Torção & 1128,67 & 1204,17 & 1116,96 & & 1,008666 & 1105,80 & 1115,38 \\
\hline
\end{tabular}

Fonte: Soares, Paccola e Coda (2019)

De forma geral, observa-se que o elemento finito de casca posicional de 6 parâmetros se apresentou mais rígido principalmente para os modos locais de instabilidade, nos quais a estrutura apresenta maiores variações de deslocamentos. Por outro lado, o elemento finito de 7 parâmetros nodais se apresentou mais flexível em praticamente todas as situações analisadas sendo, portanto, o mais adequado para esse tipo de análise.

Com relação ao acoplamento entre elementos não coplanares, ambas as estratégias utilizadas se apresentaram satisfatórias. A aplicação de multiplicadores de Lagrange apresentou sempre respostas mais rígidas que a aplicação da penalização, como era esperado. Além disso, a utilização de ambas as estratégias se mostraram mais flexíveis que as soluções de referência apresentadas por Garcea (2001), indicando que o elemento finito utilizado é livre de travamento.

$\mathrm{Na}$ análise não-linear de estabilidade, observa-se também respostas mais flexíveis e, 
conforme comentado no Capítulo 4, nota-se uma diferença considerável entre a primeira carga crítica obtida com a análise linear, Tabelas 4, 5 e 6, e não-linear, Tabela 7. Isso se deve à não-linearidade introduzida na trajetória de equilíbrio por meio das imperfeições impostas.

\subsection{Exemplo 5: Montante típico perfurado de rack de armazenamento}

Este exemplo foi extraído de Cai e Moen (2016) com o intuito de validar a formulação com respeito a geometrias mais complexas. O exemplo consiste em um perfil de $1220 \mathrm{~mm}$ de comprimento com a seção transversal indicada na Figura 38 e espessura $t=2 \mathrm{~mm}$. A barra possui 16 furos retangulares de $40 \mathrm{~mm}$ por $20 \mathrm{~mm}$ espaçados longitudinalmente por $100 \mathrm{~mm}$ e transversalmente por $40 \mathrm{~mm}$, veja a Figura 38. As propriedades do material são $E=2,1 \cdot 10^{5} M P a$ e $v=0,3$. As condições de contorno impedem o deslocamento no plano da seção para as extremidades da barra e o deslocamento longitudinal na seção transversal da extremidade descarregada, veja a Figura 38. O valor do carregamento aplicado $q$ é tal que sua resultante seja de $1 \mathrm{kN}$.

Foram adotadas duas discretizações: uma malha (a) de 1644 elementos finitos e uma malha (b) de 3044 elementos finitos triangulares com aproximação cúbica, totalizando 56472 e 101160 graus de liberdade, respectivamente, conforme a Figura 39.

Figura 38 - Definição do problema e algumas dimensões

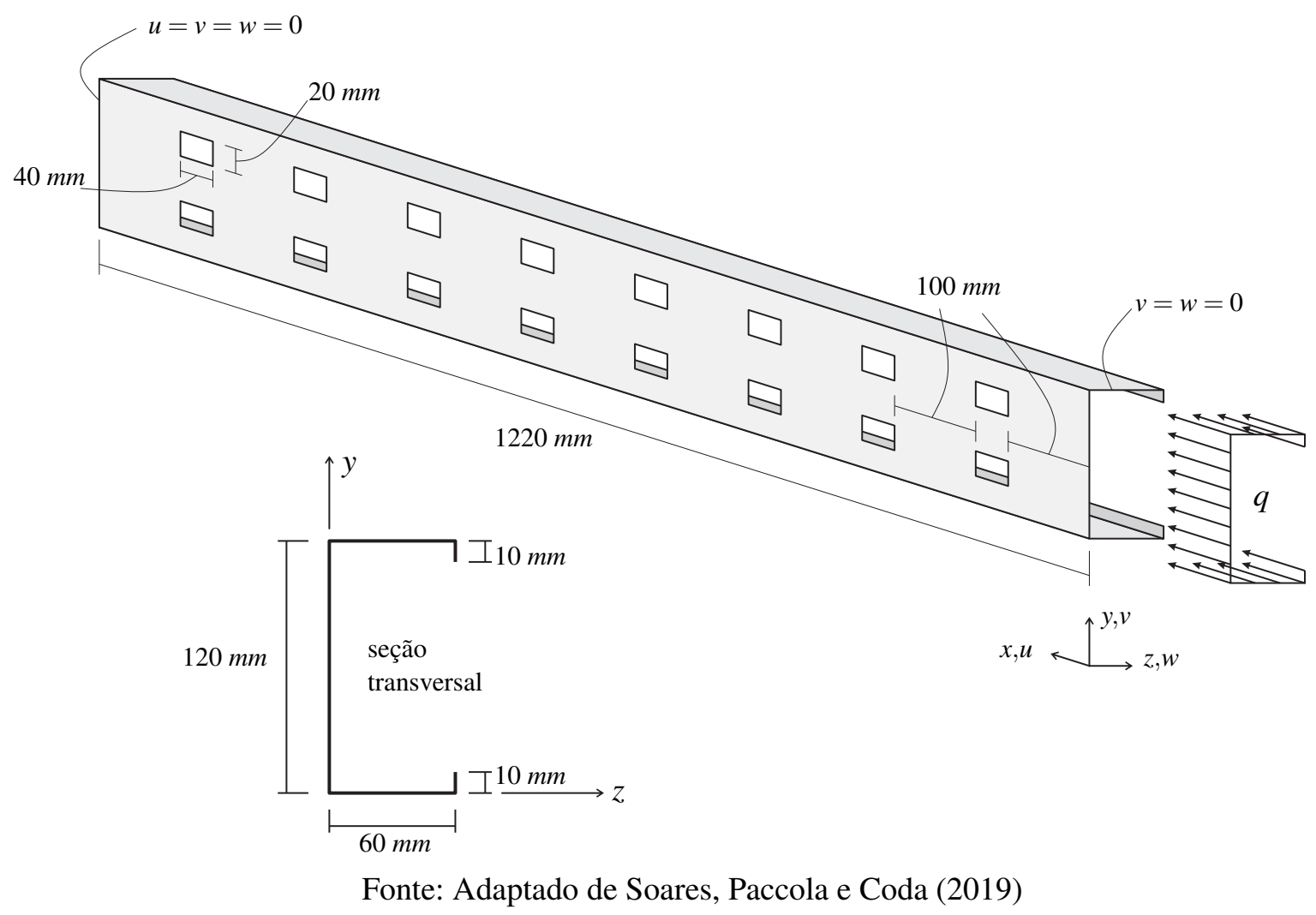


Figura 39 - Discretizações utilizadas

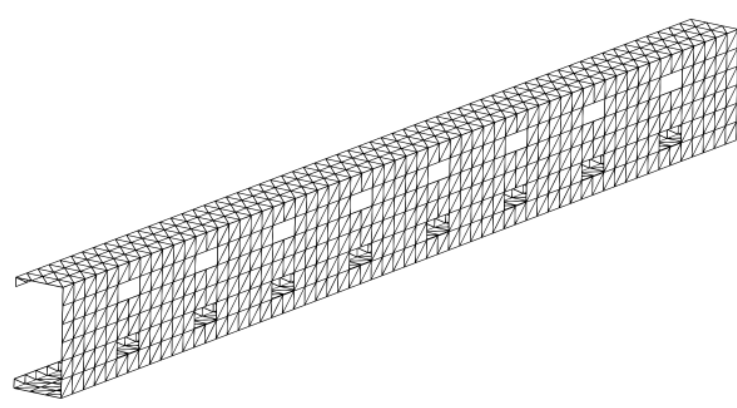

(a) 1644 elementos finitos

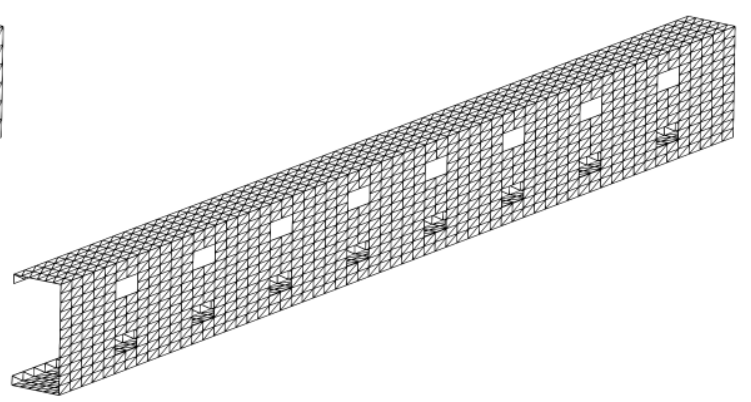

(b) 3044 elementos finitos

Fonte: Soares, Paccola e Coda (2019)

Para efeito de comparação, mostram-se na Figura 40 o primeiro modo de instabilidade encontrado por Cai e Moen (2016) utilizando-se GBT e elemento finito clássico com modelo constitutivo simplificado (SFEA). A primeira carga crítica e o primeiro modo de instabilidade estão apresentados na Tabela 8 e na Figura 40, respectivamente.

Ainda para efeito de comparação, na Tabela 8 apresentam-se os valores da carga crítica para as três formulações diferentes, sendo que para a formulação posicional apresentam-se os resultados para as duas discretizações utilizadas.

Figura 40 - Comparação do primeiro modo

(CAI; MOEN, 2016)

SFEA

(CAI; MOEN, 2016)

MEF Posicional

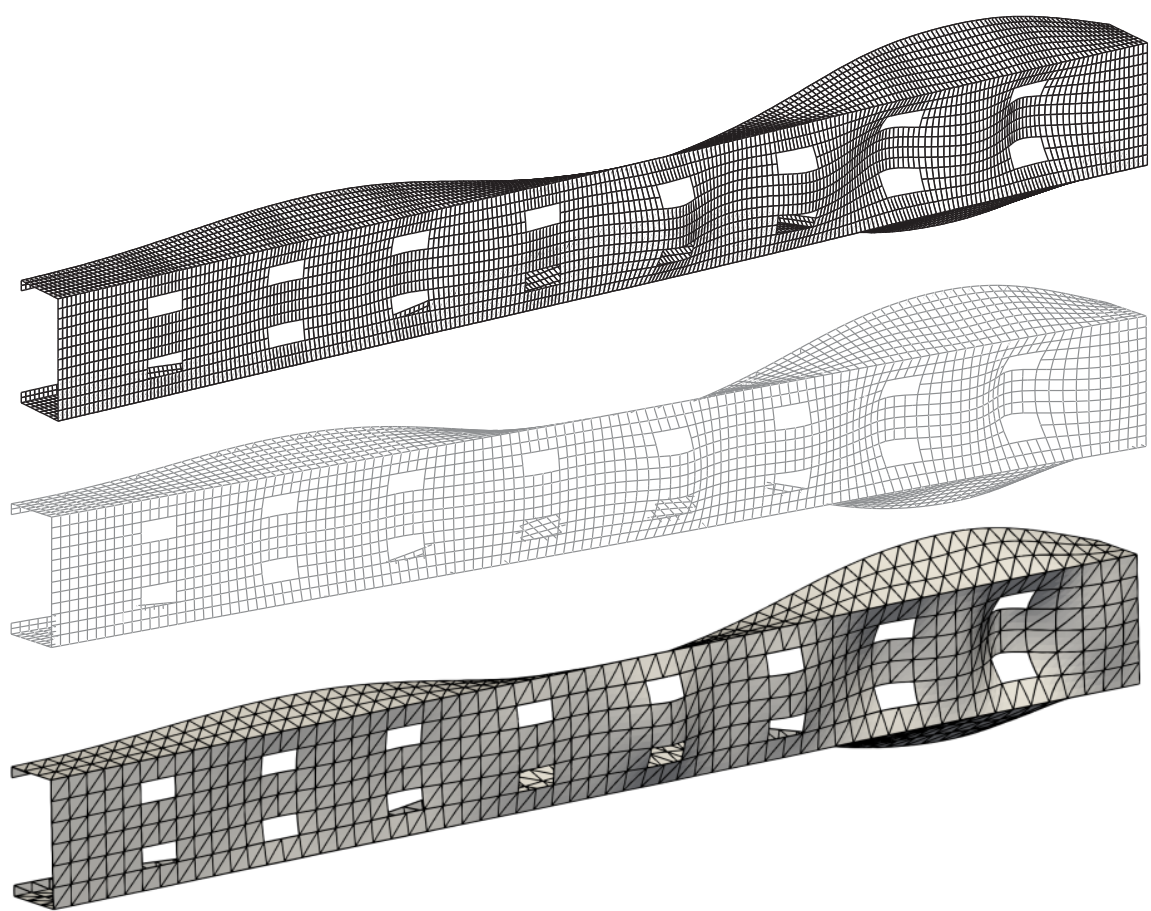

Fonte: Soares, Paccola e Coda (2019) 
Tabela 8 - Primeira carga crítica de flambagem (em $k N)$

\begin{tabular}{lcccccc}
\hline & \multirow{2}{*}{ GBT } & SFEA & \multicolumn{4}{c}{ MEF Posicional } \\
\cline { 4 - 7 } & & $\begin{array}{c}\text { Penalização } \\
(\mathbf{a})\end{array}$ & $\begin{array}{c}\text { Penalização } \\
(\mathbf{b})\end{array}$ & $\begin{array}{c}\text { M. Lagrange } \\
(\mathbf{a})\end{array}$ & $\begin{array}{c}\text { M. Lagrange } \\
\text { (b) }\end{array}$ \\
\hline Carga crítica & 125,5 & 120,0 & 120,6 & 118,7 & 120,9 & 119,0 \\
\hline
\end{tabular}

Comparando-se os valores obtidos para a carga crítica, observa-se que a formulação utilizada apresenta resultados condizentes e sem ocorrência de travamento. Da mesma forma como observado no exemplo anterior, a aplicação de multiplicadores de Lagrange para o acoplamento forneceu resultados ligeiramente mais rígidos, mas ainda permanecendo próximos aos valores de referência.

Apenas como ilustração adicional, apresentam-se na Figura 41 três outros modos de instabilidade e suas respectivas cargas críticas considerando-se acoplamento com penalização. Indica-se para cada modo a diferença relativa entre as cargas críticas calculadas usando-se as duas discretizações. Como se pode observar a diferença relativa indica boa convergência dos resultados para os quatro primeiros modos. Observa-se também que as cargas críticas para esses modos são muito próximas, apesar da diferença apresentada nos modos.

Figura 41 - Outras cargas críticas e seus respectivos modos de instabilidade para as duas discretizações utilizadas e acoplamento via elemento de barra simples

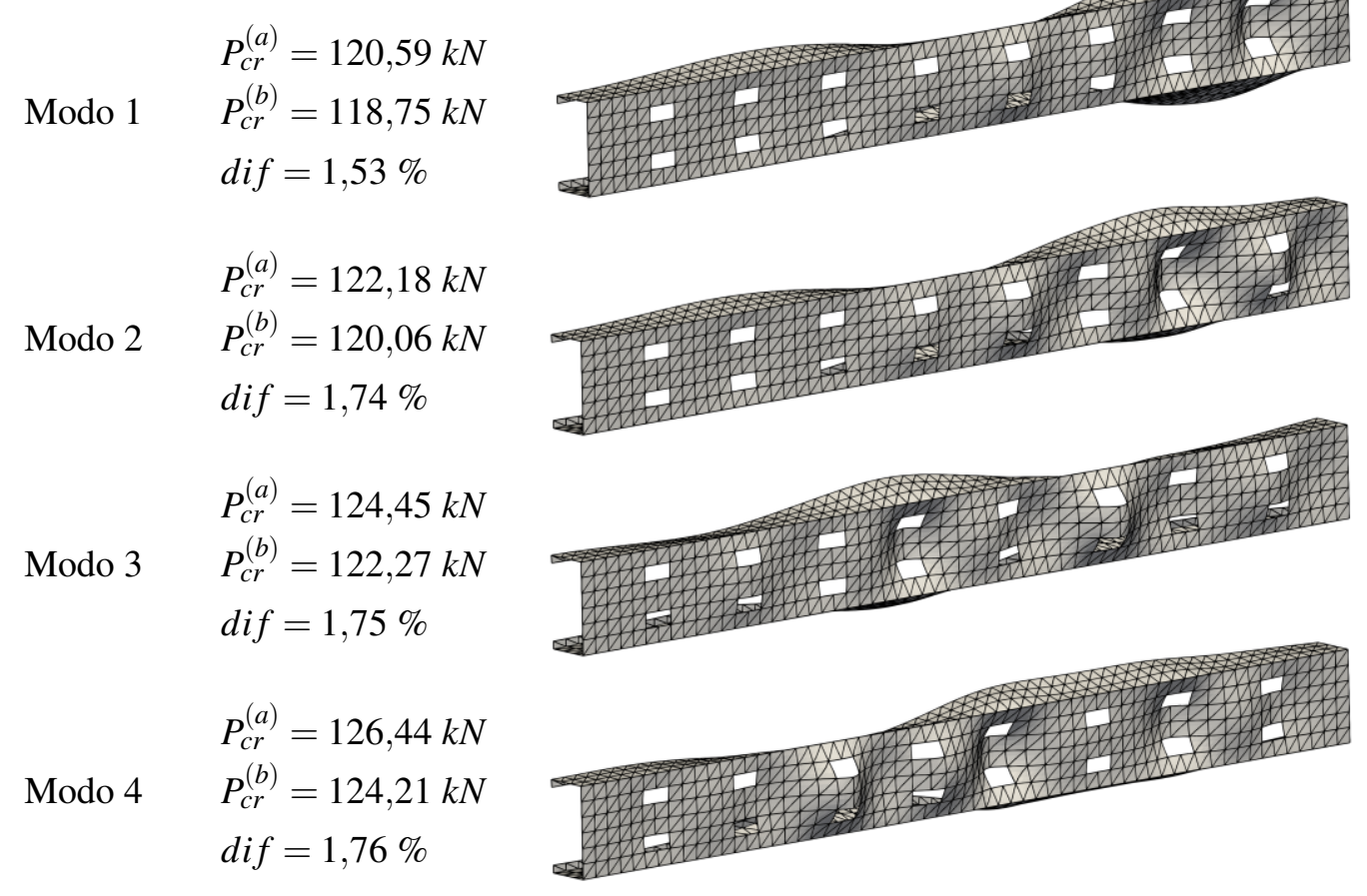

Fonte: Soares, Paccola e Coda (2019) 


\subsection{Exemplo 6: Avaliação da sensibilidade do acoplamento mesa-alma}

Neste exemplo a influência da variação da rigidez do acoplamento entre os planos constituintes da seção transversal é verificada em uma barra com seção transversal tipo canal. As propriedades físicas do material constituinte são: $E=2,1 \cdot 10^{6} \mathrm{e} v=0,3$. As dimensões do problema são: $a=100, b=30, t=1$ e o carregamento compressivo é aplicado de forma uniforme nas faces e vale: $q=1$. Foram adotados três comprimentos para a análise: $\ell_{1}=100$, $\ell_{2}=300, \ell_{3}=600$. As condições de contorno adotadas foram as mesmas do Exemplo 4, ou seja: $u_{y}(0,0,0)=0, u_{y}(\ell, 0,0)=0, u_{z}(0,0, z)=0, u_{z}(\ell, 0, z)=0$ e $u_{x}(\ell / 2,0,0)=0$.

As discretizações adotadas consistem em 144, 432 e 864 elementos finitos, respectivamente às barras de comprimento $\ell_{1}, \ell_{2}$ e $\ell_{3}$. Os números de graus de liberdade são, respectivamente, 5035, 14575 e 28885. Essas discretizações podem ser observadas na Figura 42.

Figura 42 - Definição do problema e discretização adotada

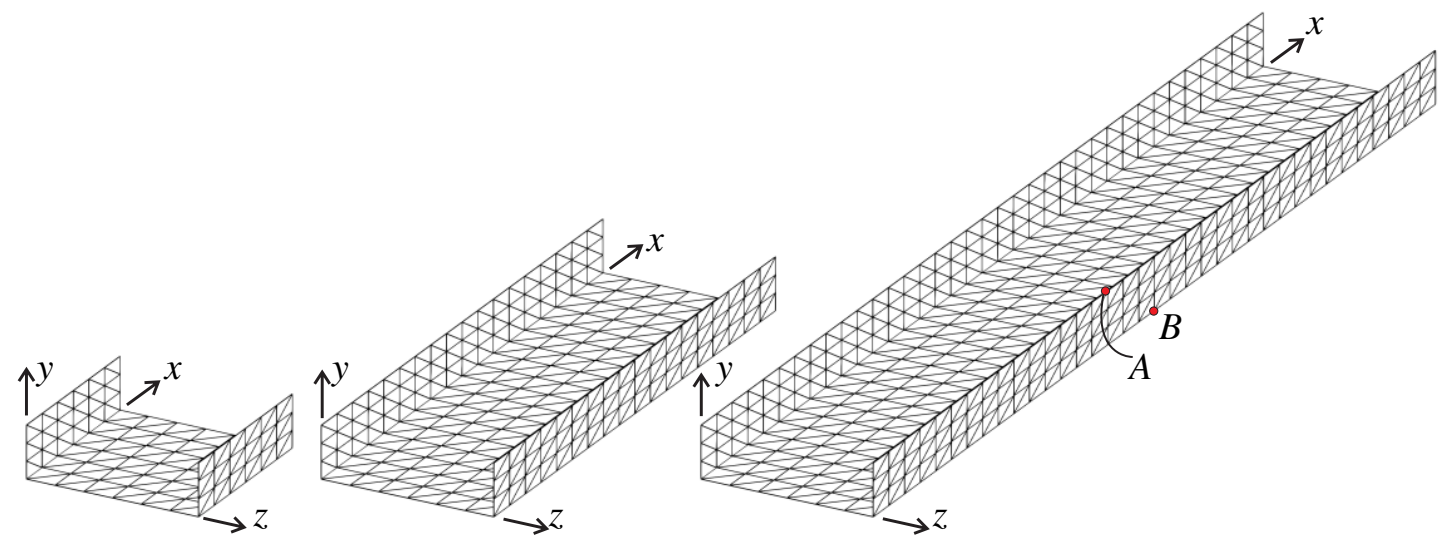

Fonte: Soares, Paccola e Coda (2019)

Utilizando-se a Equação (3.28), para o caso de acoplamento realizado pelo material constituinte da seção, encontra-se a rigidez $E A=1,27 \cdot 10^{7}$ para a penalização descrita na subseção 3.4.1. Com a finalidade de verificar a sensibilidade do comportamento do perfil em relação à rigidez do acoplamento, variou-se a propriedade do material da conexão resultando em rigidez da penalização entre $0,01 E A$ e 5,0EA. A Tabela 9 apresenta os valores da primeira carga crítica sem defeito para cada rigidez e cada comprimento adotado.

Observa-se a partir da Tabela 9 que os valores da primeira carga crítica sofreram pequenas alterações, mesmo para grandes variações do valor de rigidez, tendo uma diferença um pouco mais significativa apenas para o menor valor de rigidez adotado. Com isso, conclui-se que, na confecção de perfis dobrados ou mesmo de perfis constituídos de planos soldados, a rigidez do acoplamento entre os planos, quando adotada em ordem de grandeza próxima a dos valores de rigidez à flexão da casca, exerce pouca influência no valor da carga crítica da barra estudada. 
Tabela 9 - Cargas críticas para diferentes comprimentos e rigidez da conexão

\begin{tabular}{cccc}
\hline Rigidez / Comprimento & 100 & 300 & 600 \\
\hline $0,01 E A$ & 784,1306 & 806,4836 & 811,7679 \\
$0,25 E A$ & 797,4937 & 818,2500 & 823,0475 \\
$0,50 E A$ & 797,9371 & 818,5737 & 823,3442 \\
$E A$ & 798,1773 & 818,7439 & 823,4988 \\
$5 E A$ & 798,3882 & 818,8883 & 823,6285 \\
\hline
\end{tabular}

Fonte: Soares, Paccola e Coda (2019)

Avaliou-se também a influência da rigidez da penalização na presença de imperfeições para o perfil analisado. Para isso foram adotadas situações de imperfeição semelhantes às do Exemplo 4, conforme mostrado na Figura 43, para a barra de comprimento igual a 600.

Figura 43 - Defeitos de Koiter aplicado na seção central $x=300$ : (a) local, (b) de flexão e (c) de torção

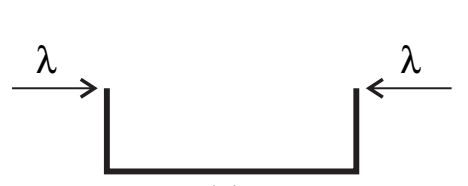

(a)

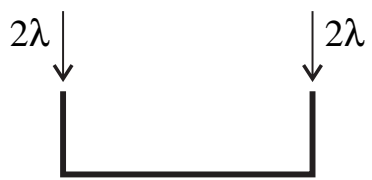

(b)

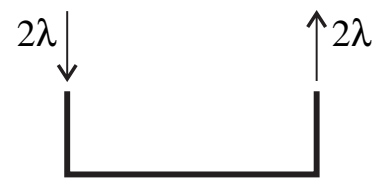

(c)

Fonte: Elaborado pelo autor

As cargas críticas obtidas para as imperfeições impostas estão apresentadas na Tabela 10. Para essa situação nota-se também pequena variação nos valores de carga crítica, chegando-se à mesma conclusão obtida para o caso sem imperfeição.

Tabela 10 - Cargas críticas para três situações de imperfeição e comprimento igual a 600

\begin{tabular}{cccc}
\hline Rigidez / Imperfeição & Local & Flexão & Torção \\
\hline $0,01 E A$ & 811,1709 & 784,3590 & 772,6135 \\
$0,25 E A$ & 822,6180 & 812,8052 & 804,2624 \\
$0,50 E A$ & 822,9204 & 813,3667 & 804,9290 \\
$E A$ & 823,0779 & 813,6504 & 805,2720 \\
$5 E A$ & 823,2099 & 813,8807 & 805,5545 \\
\hline
\end{tabular}

Fonte: Soares, Paccola e Coda (2019)

Para a barra de comprimento igual a 600 e sem imperfeição, determinou-se também a carga crítica pelo método de Newton-Raphson juntamente com análise de autovalores. Os resultados obtidos estão apresentados na Tabela 11.

Observa-se a partir da Tabela 11 que os valores de carga crítica calculados por meio de análise ao longo da trajetória de equilíbrio foram semelhantes aos calculados em pequenos deslocamentos, indicando que a estratégia utilizada é efetiva na determinação precisa de cargas críticas em problemas de compressão centrada sem imperfeição. 
Tabela 11 - Cargas críticas obtidas por Newton-Raphson

\begin{tabular}{cccc}
\hline Rigidez & $\bar{\lambda}$ & Carga atual & Carga crítica \\
\hline $0,01 E A$ & 1,00079 & 811,0000 & 811,6427 \\
$0,25 E A$ & 1,00112 & 822,0000 & 822,9189 \\
$0,50 E A$ & 1,00026 & 823,0000 & 823,2155 \\
$E A$ & 1,00045 & 823,0000 & 823,3700 \\
$5 E A$ & 1,00061 & 823,0000 & 823,4997 \\
\hline
\end{tabular}

Fonte: Soares, Paccola e Coda (2019)

Como última análise, impõe-se um defeito sobre a configuração inicial da estrutura na forma de força externa, conforme a estratégia apresentada na seção 4.5. Utilizou-se para a imposição desse defeito o primeiro modo de instabilidade.

Na Figura 44, apresenta-se o caminho de equilíbrio para um nó na extremidade superior de uma das mesas localizado a uma distância de 250 (ponto $A$ ) de uma das extremidades da barra analisada utilizando-se o defeito proporcional ao primeiro modo de instabilidade para três pares de valores de $\alpha$ (vide Equação (4.14) da página 54).

Figura 44 - Trajetórias de equilíbrio do ponto $A$ para imposições de defeitos em força

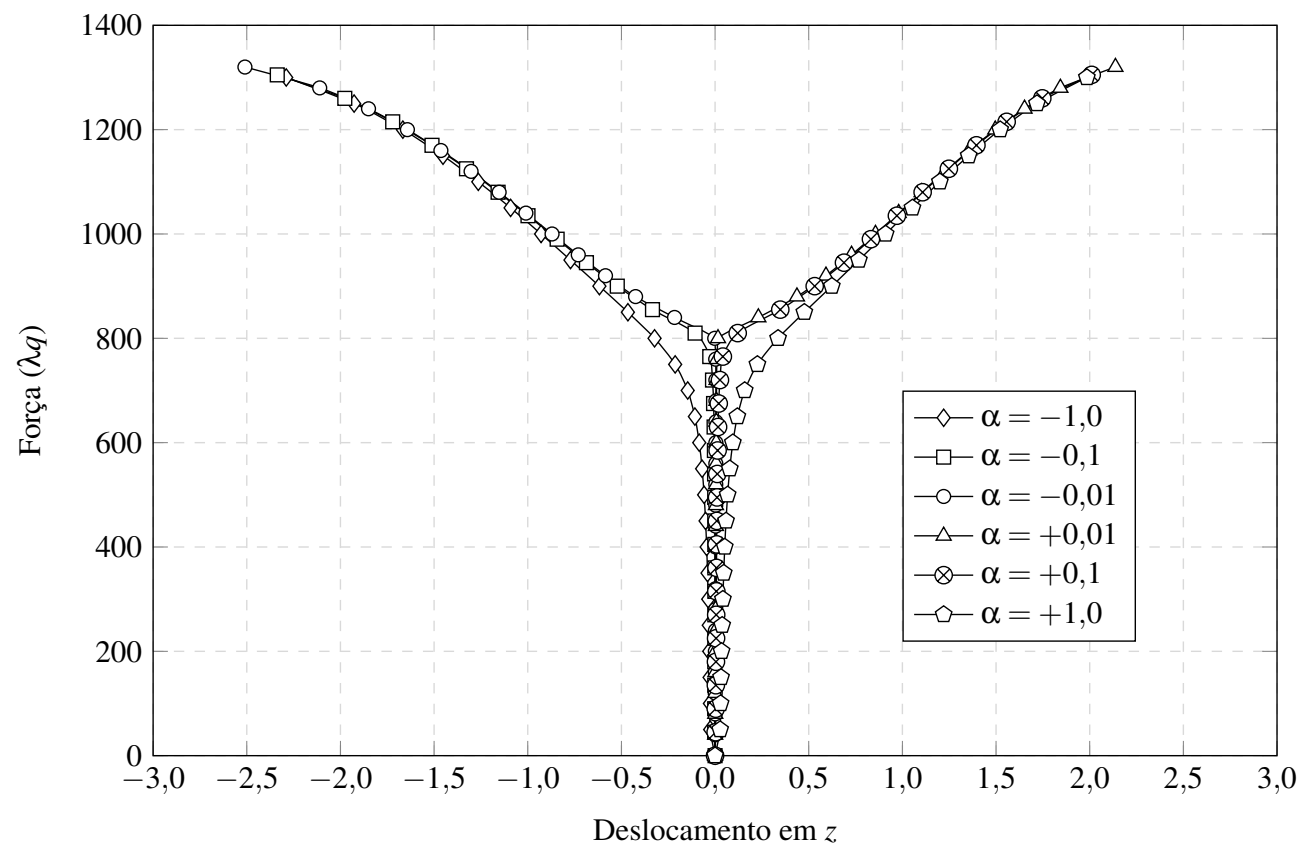

Fonte: Soares, Paccola e Coda (2019)

O caminho de equilíbrio fica mais próximo da bifurcação existente quanto menor o defeito fictício imposto para regularizar o Método de Newton-Raphson. Observa-se ainda que o comportamento pós-crítico é não-simétrico, ou seja, o comportamento local das abas é diferente a depender de seu sentido. 
A carga crítica extraída para o menor defeito foi escolhida a partir do menor valor encontrado de $\lambda$ que vale 820 , veja a Figura 45. Conforme se observa na referida figura, após se atingir a carga crítica, não há recuperação significativa de rigidez em relação à movimentação das abas da seção transversal. Na Figura 46 mostra-se o caminho de equilíbrio referente ao deslocamento transversal do centro do vão (Ponto $B$ ) correspondente ao comportamento global da barra estudada.

Figura 45 - Valor do multiplicador $\lambda$ em função do nível de carga para diferentes defeitos

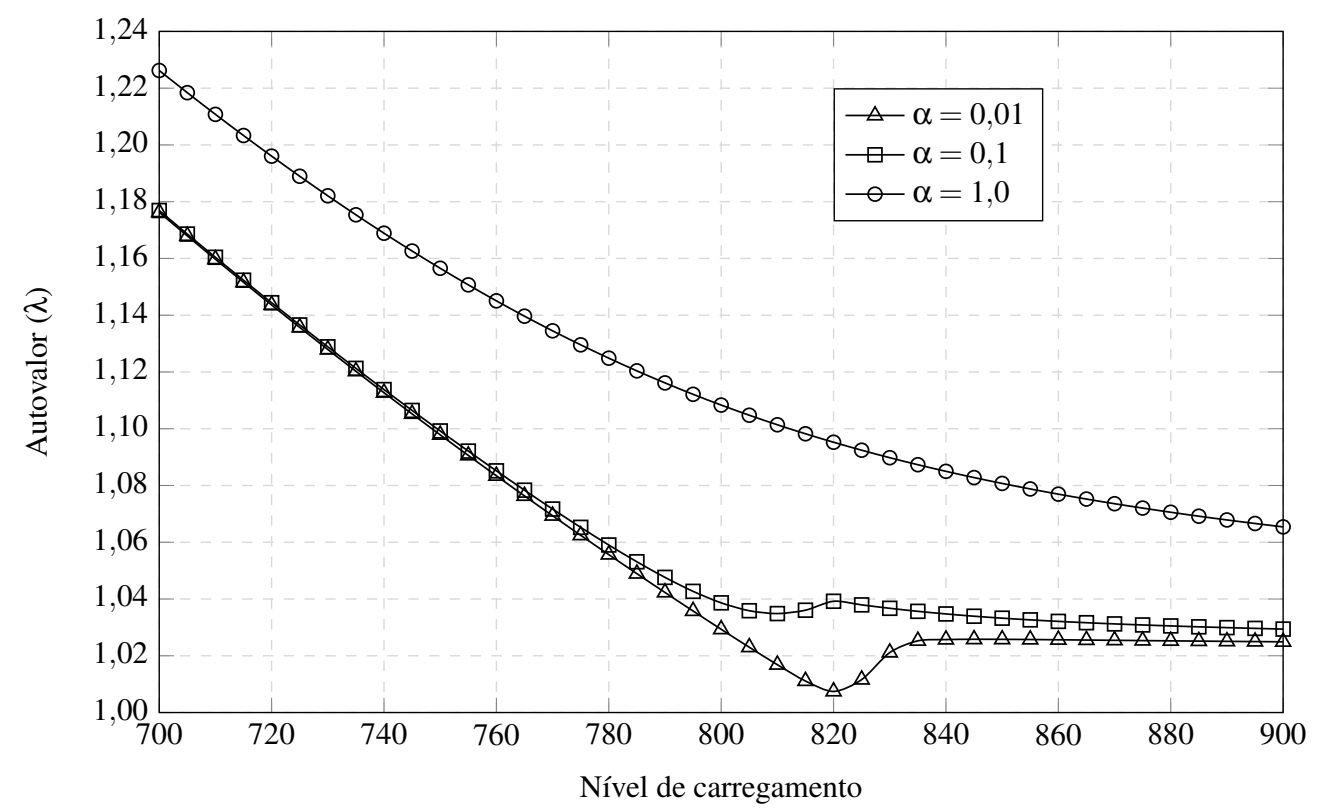

Fonte: Soares, Paccola e Coda (2019)

Figura 46 - Deslocamento transversal global no meio do vão (ponto $B$ )

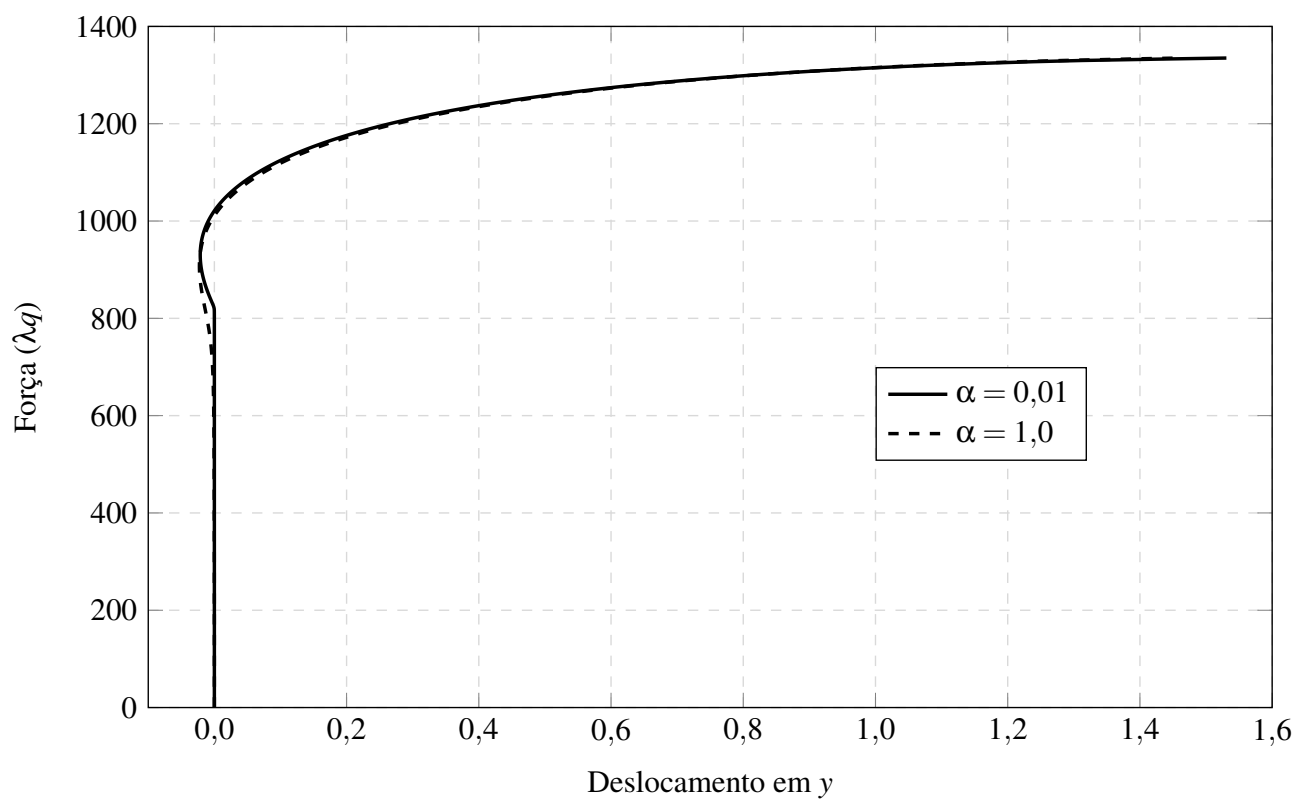

Fonte: Soares, Paccola e Coda (2019) 
Como se pode observar, após a perda de estabilidade local a carga compressiva aplicada passa a ser excêntrica, solicitando o modo global de flexão que também não manifesta rigidez significativa, ou seja, o elemento estrutural perde a estabilidade.

Para efeito de ilustração, apresenta-se na Figura 47 a configuração deformada da estrutura para o último passo de carregamento obtido na análise, correspondente a uma carga de 1335 (vide Figura 46). Na figura, os deslocamentos apresentados estão ampliados em 5 vezes para melhor visualização. Contudo, os valores indicados na legenda correspondem aos deslocamentos reais obtidos por meio do processo iterativo de Newton-Raphson.

Figura 47 - Configuração deformada da estrutura no último passo de carregamento ampliada em 5 vezes

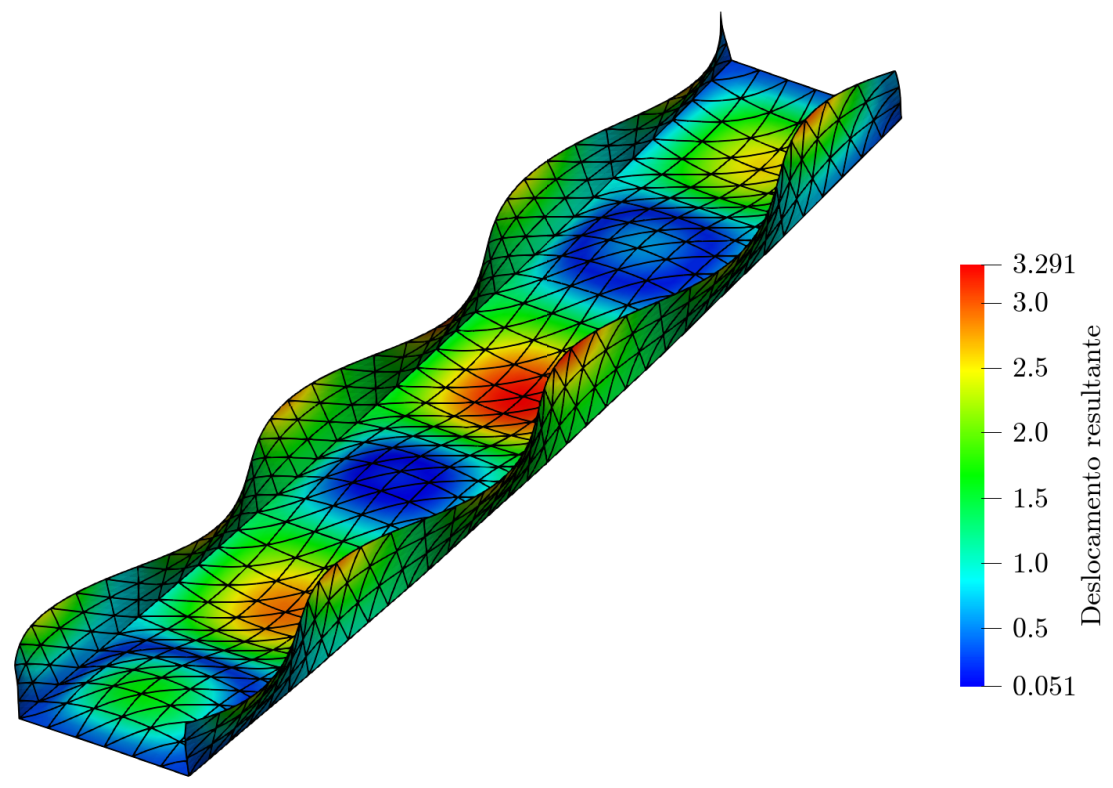

Fonte: Elaborado pelo autor

Apesar de os deslocamentos apresentados pela estrutura serem pequenos, nota-se, na configuração final apresentada na Figura 47, a presença de modo local de instabilidade juntamente com o início do modo global de flexão (deslocamentos maiores no meio do vão, verificáveis pela legenda apresentada). 



\section{CAPÍTULO 7}

\section{CONCLUSÕES}

No presente trabalho desenvolveu-se inicialmente um programa computacional baseado na formulação posicional do MEF para elementos finitos de casca. Implementou-se também a estratégia para análise linear de estabilidade, consistindo na decomposição da matriz hessiana em duas parcelas e realizando-se a resolução do problema generalizado de autovalor originado. Baseado nessa mesma estratégia, realizou-se análises não-lineares de estabilidade por meio da resolução do problema de autovalor em cada posição de equilíbrio encontrada em cada passo de carregamento pelo método de Newton-Raphson.

Uma dificuldade já conhecida do elemento finito de casca utilizado é a consideração do acoplamento entre elementos não coplanares, dada a duplicidade de vetores normais nesta região. Realizou-se portanto verificações sobre como as considerações sobre esse acoplamento afeta as análises de estabilidade. Para isso, implementou-se duas estratégias para a realização do acoplamento. A primeira estratégia consiste na inserção de um elemento de barra simples conectando as extremidades dos vetores normais de um mesmo nó, sendo a rigidez do acoplamento dependente da rigidez adotada para o referido elemento. A segunda estratégia consiste na imposição de uma equação de restrição por meio de multiplicadores de Lagrange de forma a se garantir um acoplamento rígido.

Para a primeira estratégia de acoplamento, se adotado um valor muito elevado para a rigidez da barra, a matriz hessiana resulta mal condicionada, podendo causar problemas tanto no método de Newton-Raphson quando no método de obtenção dos autovalores. Visando resolver este problema, elaborou-se uma estratégia para determinação de uma rigidez que fosse compatível com o material presente na região do acoplamento, sendo utilizado para isso uma equivalência entre energias de deformação. Conforme observou-se nos resultados, a rigidez adotada resultou numa situação próxima a um acoplamento rígido. Além disso, como a rigidez adotada foi compatível com o acoplamento real, não observou-se problemas de convergência oriundos de um possível mau condicionamento da matriz hessiana.

Com relação à segunda estratégia, o acoplamento foi observado rígido e com resultados idênticos aos da primeira estratégia com adoção de uma rigidez elevada. Conclui-se portanto que 
as duas estratégias foram implementadas corretamente.

Quanto aos resultados obtidos para análises de estabilidade observa-se em geral respostas mais flexíveis se comparadas às encontradas na literatura. Isso se deve principalmente à utilização de elementos finitos de alta ordem, como o elemento triangular de aproximação polinomial cúbica utilizado em todos os exemplos realizados. A utilização desses elementos torna desnecessária a adoção de estratégias como a integração reduzida, além de evitar os problemas conhecidos introduzidos por essas técnicas de flexibilização.

Como conclusão adicional referente à análise de estabilidade, observou-se que variações do valor de rigidez do acoplamento entre as paredes do perfil comparativamente à rigidez do elemento estrutural, desde que ambas estejam em ordens de grandeza próximas, não afetam significativamente o valor da carga crítica final, quando considera-se análise linear de estabilidade.

Uma dificuldade encontrada na implementação computacional da estratégia para análises de estabilidade foi a utilização das rotinas da biblioteca ARPACK para a determinação dos autovalores e autovetores. A dificuldade principal foi o entendimento do funcionamento das rotinas juntamente com elaboração de uma interface com utilização e manipulação de matrizes esparsas. Essa elaboração foi realizada com base nas operações descritas nos exemplos teste disponibilizados na referida biblioteca. A implementação computacional, entretanto, foi realizada corretamente, como pôde ser observado nos resultados apresentados nos exemplos numéricos.

Por fim, realizou-se a implementação computacional da interface gráfica em linguagem Object Pascal e ambiente Delphi. Para essa implementação considerou-se apenas análises lineares de estabilidade, ou seja, determinam-se as cargas críticas e os respectivos modos de instabilidade por meio da resolução de apenas um problema de autovalor. Foi também elaborado e implementado um algoritmo para a geração de malha de elementos finitos triangulares e quadrilaterais, facilitando-se assim o pré-processamento e evitando-se o uso de pré-processadores externos. Conclui-se portanto que os objetivos deste trabalho foram plenamente atingidos.

\subsection{Sugestões de desenvolvimentos futuros}

Como primeira proposta de trabalhos futuros, que surge naturalmente da sequência dos desenvolvimentos obtidos no mestrado, tem-se a ideia de expandir a formulação desenvolvida para análise de um elemento estrutural de tal forma que se possibilite a análise de estabilidade em sistemas estruturais compostos por tais elementos.

Por se tratar de uma formulação tridimensional geral, o gargalo natural dessa expansão está relacionado ao custo computacional envolvido nas análises pretendidas. Com isso, outra proposta que surge é a de paralelização do código obtido de tal forma que o tempo de solução dos problemas não se torne impeditivo ao uso da formulação.

Não-linearidades física e de contato também podem ser incorporadas à formulação 
objetivando-se capturar de forma mais realista o fenômeno de instabilidade. A inclusão também de efeitos térmicos, juntamente com as não-linearidades mencionadas e inclusão de modelos de dano, pode originar uma ferramenta numérica robusta para análise de colapso estrutural.

Com o objetivo de se determinar as trajetórias de equilíbrio de forma mais completa, principalmente com a inclusão de outras não-linearidades, sugere-se também a implementação da estratégia do comprimento de arco (Arc-Length).

No que se refere às ligações estudadas entre paredes dos perfis analisados, novas propostas podem ser estudadas, inclusive com base em resultados experimentais que possam ser encontrados na literatura, permitindo-se avaliar melhor a real contribuição destas ligações entre paredes. 



\section{REFERÊNCIAS}

ÁDÁNY, S.; SCHAFER, B. Buckling mode classification of members with open thin-walled cross-sections. In: Proceedings of the fourth international conference on coupled instabilities in metal structures (CIMS 04). Roma, Itália: [s.n.], 2004. p. 467-476.

BASAGLIA, C.; CAMOTIM, D.; CODA, H. Behaviour, failure and DSM design of cold-formed steel beams: Influence of the load point of application. Thin-Walled Structures, v. 81, p. 78-88, 2014.

BAŽANT, Z. P.; CEDOLIN, L. Stability of Structures: Elastic, Inelastic, Fracture and Damage Theories. Singapore: World Scientific, 2010.

BEBIANO, R.; SILVESTRE, N.; CAMOTIM, D. GBT formulation to analyze the buckling behavior of thin-walled members subjected to non-uniform bending. International Journal of Structural Stability and Dynamics, v. 07, n. 01, p. 23-54, 2007.

BONET, J.; WOOD, R.; MAHANEY, J.; HEYWOOD, P. Finite element analysis of air supported membrane structures. Computer Methods in Applied Mechanics and Engineering, v. 190, n. 5 , p. 579-595, 2000.

BRAGA, D. C. Avaliação de métodos numéricos de análise linear de estabilidade para perfis de aço formados à frio. 2015. Dissertação (Mestrado) - Escola Politécnica, Universidade de São Paulo, São Paulo, 2015.

BRYAN, G. H. On the stability of elastic systems. Proceedings of the Cambridge Philosophical Society, Mathematical and physical sciences, v. 6, 1888.

BUDIANSKY, B.; HUTCHINSON, J. W. Dynamic buckling of imperfection-sensitive structures. In: GÖRTLER, H. (Ed.). Applied Mechanics. Berlin, Heidelberg: Springer Berlin Heidelberg, 1964. p. 636-651.

CAI, J.; MOEN, C. D. Elastic buckling analysis of thin-walled structural members with rectangular holes using generalized beam theory. Thin-Walled Structures, v. 107, p. 274-286, 2016.

CODA, H. B. An exact FEM geometric non-linear analysis of frames based on position description. In: 17H INTERNATIONAL CONGRESS OF MECHANICAL ENGINEERING. São Paulo: ABCM, 2003.

CODA, H. B. O Método dos Elementos Finitos Posicional: Sólidos e Estruturas - Não Linearidade Geométrica e Dinâmica. São Carlos: EESC/USP, 2018.

CODA, H. B.; PACCOLA, R. R. An Alternative Positional FEM Formulation for Geometrically Non-linear Analysis of Shells: Curved Triangular Isoparametric Elements. Computational Mechanics, v. 40, n. 1, p. 185-200, 2007. 
CODA, H. B.; PACCOLA, R. R. A positional FEM Formulation for geometrical non-linear analysis of shells. Latin American Journal of Solids and Structures, v. 5, p. 205-223, 2008.

DINIS, P.; CAMOTIM, D.; SILVESTRE, N. GBT formulation to analyse the buckling behaviour of thin-walled members with arbitrarily 'branched' open cross-sections". Thin-Walled Structures, v. 44, n. 1, p. 20-38, 2006.

ELISHAKOFF, I. Elastic Stability: from Euler to Koiter there was none like Koiter. Meccanica, v. 35, p. 375-380, 2000.

EULER, L. Methodus inveniendi lineas curvas maximi minimive proprietate gaudentes, sive solutio problematis isoperimetrici latissimo sensu accepti. Laussanae et Genevae, Apud Marcum-Michaelem, Bousquet et Socios: [s.n.], 1744.

GARCEA, G. Mixed formulation in Koiter analysis of thin-walled beams. Computer Methods in Applied Mechanics and Engineering, v. 190, n. 26, p. 3369-3399, 2001.

GONÇALVES, R.; DINIS, P.; CAMOTIM, D. GBT formulation to analyse the first-order and buckling behaviour of thin-walled members with arbitrary cross-sections. Thin-Walled Structures, v. 47, n. 5, p. 583-600, 2009.

GRECO, M. Análise de problemas de contato/impacto em estruturas de comportamento não linear pelo método dos elementos finitos. 2004. Tese (Doutorado) - Escola de Engenharia de São Carlos, Universidade de São Paulo, São Carlos, 2004.

GRIMES, R.; LEWIS, J.; SIMON, H. A Shifted Block Lanczos Algorithm for Solving Sparse Symmetric Generalized Eigenproblems. SIAM Journal on Matrix Analysis and Applications, v. 15, n. 1, p. 228-272, 1994.

GRIMES, R. G.; LEWIS, J. G.; SIMON, H. D. Eigenvalue Problems and Algorithms in Structural Engineering. In: CULLUM, J.; WILLOUGHBY, R. A. (Ed.). Large Scale Eigenvalue Problems. [S.1.]: North-Holland, 1986, (North-Holland Mathematics Studies, v. 127). p. 81-93.

HOUBOLT, J. C.; STOWELL, E. Z. Critical stress of plate columns. National Advisory Committee for Aeronautics, Technical note 2163, Washington, 1950.

KÁRMÁN, T. V.; TSIEN, H.-S. The Buckling of Thin Cylindrical Shells under Axial Compression. Journal of the Aeronautical Sciences, v. 8, n. 8, p. 898-907, 1941.

KZAM, A. K. L. Análise da instabilidade estrutural global e local pelo MEF posicional com determinação de pontos críticos na trajetória de equilíbrio. 2016. Tese (Doutorado) Escola de Engenharia de São Carlos, Universidade de São Paulo, São Carlos, 2016.

LANCZOS, C. An iteration method for the solution of the eigenvalue problem of linear differential and integral operators. J. Res. Natl. Bur. Stand. B, v. 45, p. 255-282, 1950.

LEHOUCQ, R.; SORENSEN, D.; YANG, C. ARPACK Users' Guide. [S.1.]: Society for Industrial and Applied Mathematics, 1998.

LYAPUNOV, A. M. Problème général de la stabilité du mouvement. Harkov, 1982.

MACIEL, D. N. Análise de problemas elásticos não lineares geométricos empregando o método dos elementos finitos posicional. 2008. Tese (Doutorado) - Escola de Engenharia de São Carlos, Universidade de São Paulo, São Carlos, 2008. 
MARQUES, G. C. S. C. Estudo e desenvolvimento de código computacional baseado no método dos elementos finitos para análise dinâmica não linear geométrica de sólidos bidimensionais. 2006. Dissertação (Mestrado) - Escola de Engenharia de São Carlos, Universidade de São Paulo, São Carlos, 2006.

MESACASA JR, E. C. Aplicação da teoria generalizada de vigas à análise de pórticos metálicos planos com ligações semirrígidas. 2016. Tese (Doutorado) — Escola de Engenharia de São Carlos, Universidade de São Paulo, São Carlos, 2016.

OGDEN, R. W. Non-Linear Elastic Deformations. Chichester: Ellis Horwood, 1984.

PACCOLA, R. R.; CODA, H. B. AcadView. 2018. Disponível em: <http://www.set.eesc.usp.br/ portal/pt/softwares/27-pesquisa/softwares/157-acadview>. Acesso em: 02 de fevereiro de 2019.

PAIGE, C. C. Error Analysis of the Lanczos Algorithm for Tridiagonalizing a Symmetric Matrix. IMA Journal of Applied Mathematics, v. 18, n. 3, p. 341-349, 1976.

REIS, A.; CAMOTIM, D. Estabilidade estrutural. Lisboa: McGraw-Hill, 2000.

SANSOUR, C.; KOLLMANN, F. G. Families of 4-node and 9-node finite elements for a finite deformation shell theory. An assesment of hybrid stress, hybrid strain and enhanced strain elements. Computational Mechanics, v. 24, n. 6, p. 435-447, 2000.

SCHAFER, B. Cold-Formed Steel Behavior and Design: Analytical and Numerical Modeling of Elements and Members with Longitudinal Stiffeners. 1997. Tese (Doutorado) - Cornell University, Ithaca, 1997.

SCHAFER, B.; PEKÖZ, T. Computational modeling of cold-formed steel: characterizing geometric imperfections and residual stresses. Journal of Constructional Steel Research, v. 47, n. 3, p. 193-210, 1998.

SCHARDT, R. Eine erweiterung der technischen biegetheorie zur berechnung prismatischer faltwerke. Stahlbau, v. 35, p. 161-171, 1966.

SEWELL, M. J. A method of post-buckling analysis. Journal of the Mechanics and Physics of Solids, v. 17, n. 4, p. 219-233, 1969.

SILVA, W. Q. Sobre análise não linear geométrica de edifícios considerando o empenamento dos núcleos estruturais e a interação solo-estrutura. 2014. Tese (Doutorado) — Escola de Engenharia de São Carlos, Universidade de São Paulo, São Carlos, 2014.

SILVESTRE, N. Teoria Generalizada de Vigas: Formulações, implementação numérica e aplicações. 2005. Tese (Doutorado) — Instituto Superior Técnico, Universidade Técnica de Lisboa, Lisboa, 2005.

SIMITSES, G. J.; HODGES, D. H. Fundamentals of Structural Stability. 1. ed. Burlington: Butterworth-Heinemann, 2006.

SOARES, H. B.; PACCOLA, R. R.; CODA, H. B. Unconstrained Vector Positional Shell FEM formulation applied to thin-walled members instability analysis. Thin-Walled Structures, v. 136, p. 246-257, 2019.

SOUTHWELL, R. V. On the general theory of elastic stability. Philosophical Transaction of the Royal Society of London, n. 213, p. 187-244, 1913. 
THOMPSON, J. Basic principles in the general theory of elastic stability. Journal of the Mechanics and Physics of Solids, v. 11, n. 1, p. 13-20, 1963.

THOMPSON, J.; HUNT, G. W. A general theory of elastic stability. London: J. Wiley \& Sons, 1973.

TIMOSHENKO, S. P. On the correction for shear of the differential equation for transverse vibrations of prismatic bars. The London, Edinburgh, and Dublin Philosophical Magazine and Journal of Science, Taylor \& Francis, v. 41, n. 245, p. 744-746, 1921.

TIMOSHENKO, S. P. History of Strength of Materials. New York: McGraw-Hill, 1953.

TIMOSHENKO, S. P.; GERE, J. M. Theory of elastic stability. New York: McGraw-Hill, 1961.

WITHERDEN, F.; VINCENT, P. On the identification of symmetric quadrature rules for finite element methods. Computers \& Mathematics with Applications, v. 69, n. 10, p. 1232-1241, 2015. 


\section{APÊNDICE A}

\section{GERAÇÃO DE MALHA}

Para a geração da malha foi elaborado um algoritmo específico mais apropriado para discretização de perfis de parede fina. Nele, o usuário fornece a geometria da seção, o comprimento do perfil e informações sobre o refinamento da malha. Após a geração da malha, insere-se também as propriedades do material, as ações externas e as condições de contorno.

Para a geração da malha do perfil, inicialmente elaborou-se as rotinas para geração de malha de uma placa para cada parte folicular plana que compõe o perfil. Em seguida, realizou-se a busca por nós repetidos, unindo-se assim as placas geradas, formando o perfil.

Para a geração das coordenadas dos nós de uma placa, utilizou-se o algoritmo apresentado no algoritmo 1, na qual $n n x_{1}$ e $n n_{s e c}$ são, respectivamente, o número de nós ao longo do comprimento e ao longo da seção transversal da placa, $d x_{1}, d x_{2}$ e $d x_{3}$ são, respectivamente, a distância entre os nós adjacentes nas direções $x_{1}, x_{2}$ e $x_{3}$ e no $o_{1}$ é o nó inicial de referência (um vértice da placa).

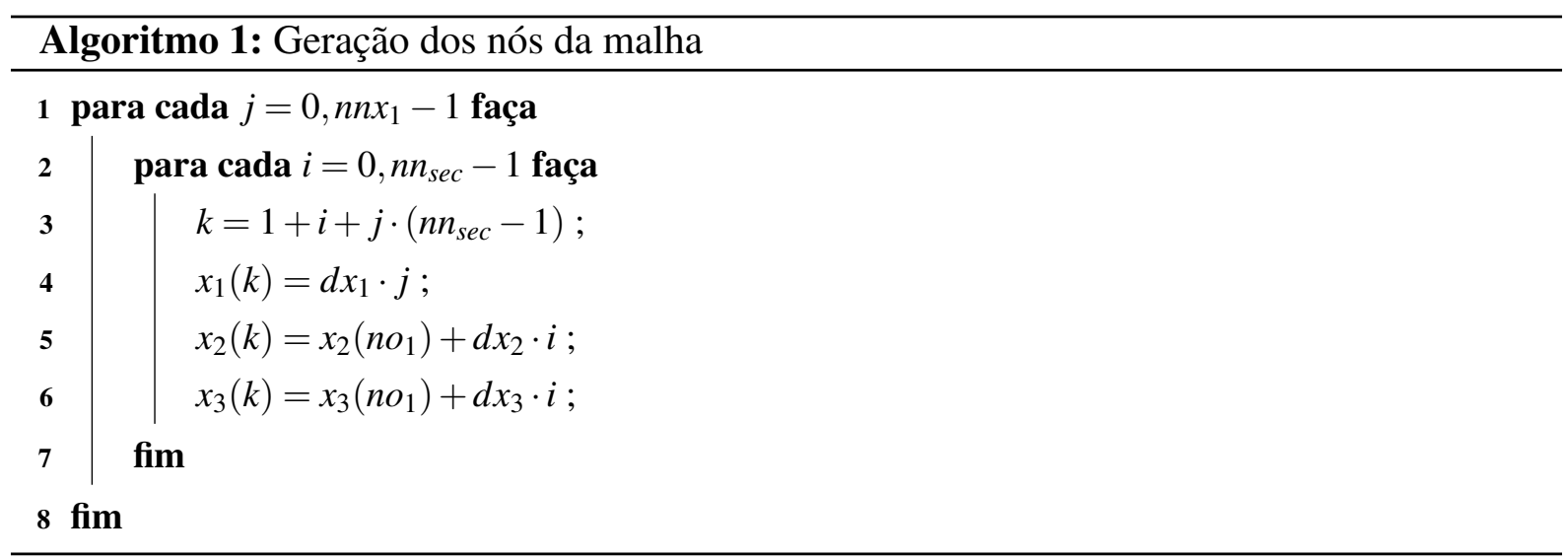

Determinou-se também a conectividade dos elementos de cada uma das placas geradas. Para a malha triangular, elaborou-se o algoritmo apresentado no algoritmo 2, na qual iel é um índice que auxilia a identificação dos elementos, ino é um índice que fornece a numeração dos nós no elemento, $n d x_{1}$ e $n d_{s e c}$ são, respectivamente, o número de elementos finitos ao longo do comprimento e ao longo da seção transversal, grau é o grau de aproximação considerado, conec é a variável que armazena a conectividade dos elementos e $a u x_{i}$ são variáveis para auxiliar a 
elaboração do código.

De forma semelhante tem-se a determinação da conectividade dos elementos quadrilaterais, apresentado no algoritmo 3, na qual as variáveis envolvidas possuem os mesmos significados descritos para o algoritmo de malha triangular.
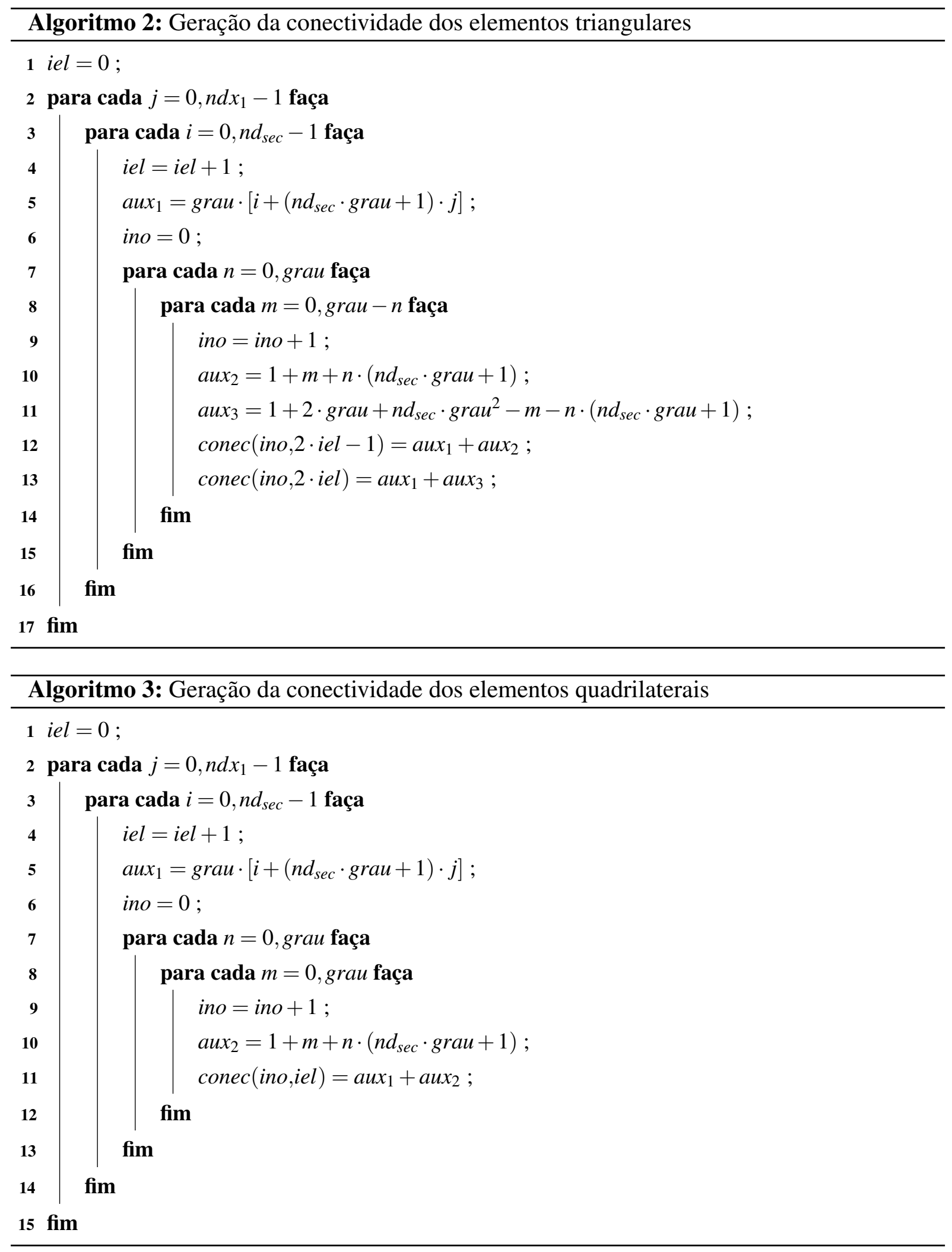

Após a geração da malha, aplicam-se as propriedades do material e o valor da espessura, 
onde cada placa gerada pode ter suas propriedades individuais. Aplicam-se também as condições de contorno, que, para facilitar, podem ser aplicadas em linha, bastando apenas o usuário referenciar qual linha deverá ser restringida. É possível também a inserção das condições de contorno por nó. Por fim, aplicam-se as ações externas, que constituem as forças concentradas, forças distribuídas em linha e forças distribuídas em superfície. 



\section{APÊNDICE B}

\section{GERAÇÃO DAS FUNÇÕES DE FORMA}

A ideia central do método dos elementos finitos é transformar um problema contínuo de infinitos graus de liberdade em um problema discreto com um número finito de graus de liberdade. Isso é realizado por meio da definição dos nós e dos elementos finitos, o que permite que cada variável possa ser escrita em função dos seus valores em pontos específicos do contínuo, caracterizando assim o problema discreto.

A determinação das variáveis nos demais pontos do contínuo é realizada por meio de funções interpoladoras, estas buscando representar a variação das grandezas ao longo do elemento finito. Essas funções comumente são polinômios, mas outras funções, como as trigonométricas, por exemplo, podem ser utilizadas.

É de interesse então definir as funções aproximativas escrevendo-as em função dos parâmetros nodais. Com isso, surgem as chamadas funções de forma $\phi_{\ell}$, e a função interpoladora passa a ser escrita como:

$$
\vartheta(x)=\phi_{\ell}(x) \vartheta_{\ell}
$$

na qual $\vartheta(x)$ é a função interpoladora, $\vartheta_{\ell}$ são seus valores nodais e o somatório é realizado sobre os nós do elemento finito analisado.

Da Equação (B.1) nota-se uma propriedade importante das funções de forma. Elas possuem valor unitário no respectivo nó onde são definidas e valor nulo nos demais nós do elemento. Essa propriedade será utilizada para a determinação das funções de forma dos elementos triangulares e quadrilaterais, conforme será apresentada nas próximas seções.

\section{Funções de forma do elemento finito triangular}

Dada a variedade de formas que o elemento finito pode estar configurado na malha, define-se um elemento padronizado em um espaço auxiliar, conforme o exemplo da Figura 48, por meio do qual será realizado o mapeamento dos elementos no espaço físico nas configurações 
inicial e atual. Nesse espaço, o elemento triangular padrão possui vértices de coordenadas $(0,0)$, $(1,0)$ e $(0,1)$. As funções de forma serão então definidas nesse espaço.

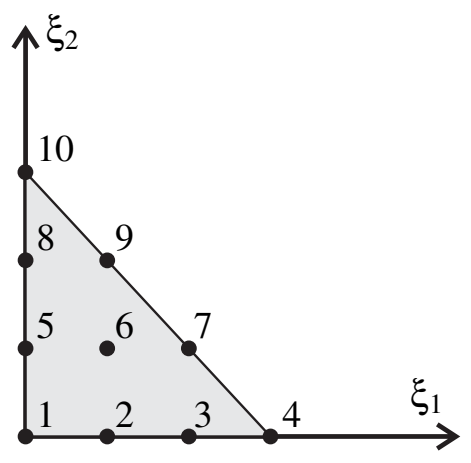

Figura 48 - Espaço auxiliar com elemento finito triangular cúbico padrão

As funções de forma do elemento finito no espaço auxiliar, assim como suas derivadas, podem ser obtidas por meio do algoritmo apresentado no algoritmo 4 , na qual $n$ é o número de nós do elemento finito, grau é o grau de aproximação polinomial e coef é uma matriz que fornece os coeficientes da função e é obtida a partir da propriedade de que cada uma das funções de forma deve possuir valor unitário no seu respectivo nó e valor nulo nos demais.

A matriz coef pode ser determinada a partir do algoritmo 5, na qual $\operatorname{coord}(i, j)$ fornece a coordenada $j$ do nó $i$ e inv $(\cdot)$ denota a operação de matriz inversa.

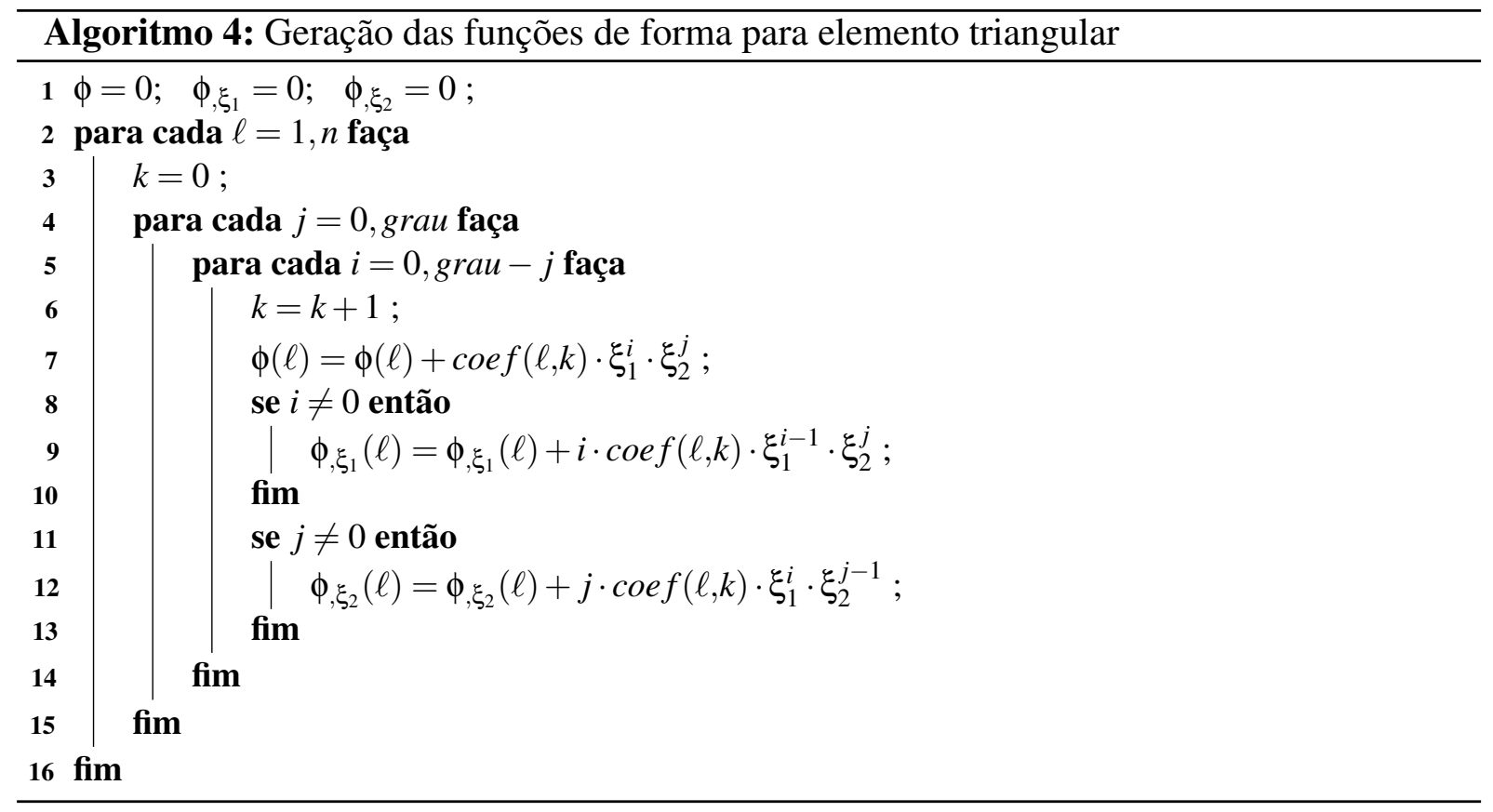




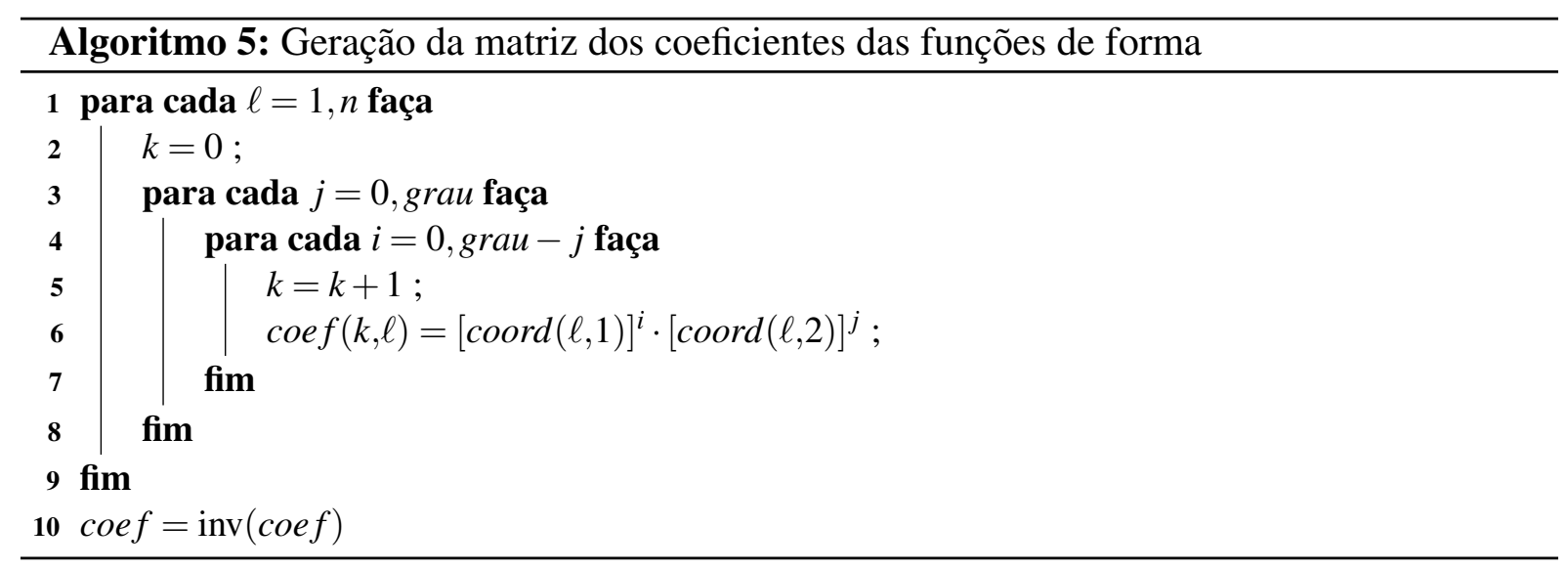

\section{Funções de forma do elemento finito quadrilateral}

Um dos métodos de obtenção das funções de forma do elemento finito quadrilateral parte dos polinômios de Lagrange. Esses polinômios coincidem com as funções de forma unidimensionais $\varphi$ e são dados por:

$$
\varphi_{i}(\xi)=\prod_{\substack{k=1 \\ k \neq i}}^{n} \frac{\xi-\eta_{k}}{\eta_{i}-\eta_{k}}
$$

no qual $\eta_{k}$ e $\eta_{i}$ fornecem a posição dos $n$ nós no espaço unidimensional e $\xi$ é a coordenada unidimensional que assume valores no intervalo $[-1,+1]$. As funções de forma do elemento finito quadrilateral são obtidas por meio de combinação dos polinômios de Lagrange para as duas direções do espaço auxiliar. Essas funções ficam dadas por:

$$
\phi_{\ell}\left(\xi_{1}, \xi_{2}\right)=\varphi_{i}\left(\xi_{1}\right) \varphi_{j}\left(\xi_{2}\right)
$$

sendo $\ell=n(j-1)+i$, com $i$ e $j$ variando de 1 a $n$.

É de interesse também o conhecimento das derivadas das funções de forma. Para isso, determina-se inicialmente a derivada dos polinômios de Lagrange em relação à coordenada $\xi$ do espaço unidimensional. Essa derivada pode ser realizada com o artifício da diferenciação logarítmica, que resulta em:

$$
\frac{d \varphi_{i}(\xi)}{d \xi}=\sum_{\substack{k=1 \\ k \neq i}}^{n}\left(\frac{1}{\eta_{i}-\eta_{k}} \prod_{\substack{m=1 \\ m \neq i \\ m \neq k}}^{n} \frac{\xi-\eta_{m}}{\eta_{i}-\eta_{m}}\right)
$$

Derivando-se a expressão (B.3), portanto, obtém-se:

$$
\begin{aligned}
& \phi_{\ell, 1}\left(\xi_{1}, \xi_{2}\right)=\frac{\partial \phi_{\ell}\left(\xi_{1}, \xi_{2}\right)}{\partial \xi_{1}}=\frac{d \varphi_{i}\left(\xi_{1}\right)}{d \xi_{1}} \varphi_{j}\left(\xi_{2}\right) \\
& \phi_{\ell, 2}\left(\xi_{1}, \xi_{2}\right)=\frac{\partial \phi_{\ell}\left(\xi_{1}, \xi_{2}\right)}{\partial \xi_{2}}=\varphi_{i}\left(\xi_{1}\right) \frac{d \varphi_{j}\left(\xi_{2}\right)}{d \xi_{2}}
\end{aligned}
$$

